\title{
PERFILES BÁSICOS DEL BANDOLERISMO MORISCO VALENCIANO: DEL DESARME A LA EXPULSIÓN (1563-1609)
}

\author{
JORGE ANTONIO CATALÁ SANZ \\ Universitat de València \\ SERGIO URZAINQUI SÁNCHEZ \\ Archivo del Reino de Valencia
}

Fecha de recepción: diciembre 2008

Fecha de aceptación: marzo 2009

\section{VISIÓN TRADICIONAL DEL PROBLEMA}

Pese a lo mucho que, desde ángulos diversos, se ha escrito en las últimas décadas acerca de los moriscos valencianos, la imagen que de la cuestión específica del bandolerismo morisco prevalece todavía en nuestra historiografía procede, en sus rasgos fundamentales y en no pocos de sus pormenores, de la que en 1972 compuso Sebastián García Martínez bajo el título de «Bandolerismo, piratería y control de moriscos en Valencia durante el reinado de Felipe II», reeditada como libro un lustro después y más conocida por su versión catalana de 1980: Bandolers, corsaris $i$ moriscos ${ }^{1}$. Lo que no deja de presentar dificultades, ya que el autor no se propuso llevar a cabo una investigación detallada de la violencia morisca, sino ofrecer una aproximación general al fenómeno del bandidaje en Valencia durante los siglos XVI y XVII, del que aquella

1. GARCÍA MARTíNEZ, S.: «Bandolerismo, piratería y control de moriscos en Valencia durante el reinado de Felipe II», en Estudis, Valencia, 1, 1972, pp. 85-167. Junto con otros suyos, este trabajo se ha reeditado bajo un nuevo título: El País Valencià modern: societat, política i cultura a l'època dels Àustria, Catarroja, 2006. No obstante, para la confección de este artículo hemos empleado como referencia la publicación de su tesis doctoral patrocinada por el Ayuntamiento de Villena (Valencia bajo Carlos II. Bandolerismo, reivindicaciones agrarias y servicios a la monarquía, Valencia, 1991), que incluye un capítulo introductorio sobre el bandolerismo como fenómeno social y otro específico sobre el ocaso del mismo en el siglo XVII. 
sólo habría sido un componente esencial hasta 1609. Su propia definición del asunto lo pone de manifiesto. El bandolerismo morisco adoptó dos caras: una vinculada al aristocrático, de raigambre medieval, de cuyas rivalidades señoriales y venganzas familiares fue fuerza de choque y brazo armado; la otra ligada al popular, protagonizado por cristianos viejos, con el que, a su entender, compartió «motivaciones, tácticas y módulos», si bien con una exasperación creciente «a medida que se quemaban las etapas precedentes a la expulsión» ${ }^{2}$. Basándose en los estudios clásicos de Braudel y Reglà, García Martínez parte, pues, de la premisa de que el bandolerismo no fue un problema privativo del reino, sino característico de los países de la cuenca mediterránea, con una etiología similar, por más que la existencia de la comunidad morisca, su frustrada asimilación, su expulsión y las dificultades de repoblación le imprimieran un sello peculiar en suelo valenciano. Dicho problema se habría difundido en la segunda mitad del Quinientos, cuando la explosión demográfica y el declive simultáneo de las fuerzas económicas trajeron consigo la agravación de la miseria y el empeoramiento del orden público, y no dejó ya de crecer hasta alcanzar su fase más violenta entre los años 1652 y 1668 . Si nos ceñimos a la vertiente propiamente morisca del asunto, el apogeo se habría producido entre 1563 y 1609, período en que la población de nuevos convertidos aumentó a un ritmo mucho mayor que la de cristianos viejos, mientras lo hacían también los controles y medidas de restricción que pesaban sobre los primeros hasta su definitivo extrañamiento.

Junto con la desconexión entre población y producción, otros factores actuaron como causas concomitantes del bandolerismo (sin distinción de credos), las mismas que Reglà adujera en relación con Cataluña: ${ }^{3}$ la connivencia de los estamentos privilegiados, y en especial de la nobleza señorial, con los forajidos, de cuyos servicios se valieron en ocasiones; la falta de medios de la justicia regia, acentuada por la escasa colaboración, cuando no abierta pasividad, de los justicias locales; las limitaciones que imponía el sistema procesal foral, que, a ojos de los virreyes, se tornaban en formidables escudos para los bandidos; y el armamento generalizado del país, sobre todo las armas de fuego cortas -los pedrenyals-, que facilitaban los golpes de los salteadores, para quienes las reiteradas prohibiciones de llevarlas y las cada vez mayores sanciones previstas por su uso eran papel mojado ${ }^{4}$. Esto último también puede hacerse extensivo a los bandoleros moriscos, dada la probada ineficacia del desarme de 1563, de la que pragmáticas como la de 7 de junio de 1586, puesta en ejecución por Aytona, son -y fueron- testimonio conspicuo.

Respecto a los focos de origen y las zonas de mayor actividad del bandolerismo morisco, García Martínez afirma que la estructura geopolítica del reino -caracterizada por la abundancia de macizos montañosos donde cobijarse, colindantes con ricas vegas que depredar; su condición de triple territorio fronterizo (con Cataluña, Aragón y

\footnotetext{
2. Ibidem: pp. 24-25.

3. REGLÀ, J.: El bandolerisme català del Barroc, Barcelona, 1966, pp. 25-28.

4. García MartíneZ, S.: Op. cit., pp. 32-38.
} 
Castilla); y la distinta distribución étnica de la población: morisco el interior, cristiano el litoral-, contribuyó a hacer de éste un vivero de bandidos y un escenario idóneo para sus correrías, para, a continuación, enumerar, de sur a norte, los siguientes núcleos de peligrosidad. En primer lugar, «la Marina y las montañas», sobre todo, la Marina Alta (Pego, Benidoleig, El Verger, Xaló) y el Comtat (Benilloba, Cocentaina, Muro de Alcoy), área compacta y abrupta, densamente habitada por nuevos convertidos, desde la que podía accederse con facilidad a la frontera castellana a fin de escapar de la justicia. Este reducto primordial de forajidos moriscos se extendía hacia la llanura litoral de la Huerta de Gandia (Almoines, Palmera, Benieto), otro enclave de delincuencia morisca, aunque de menor intensidad que el anterior. En la franja central del país, donde convergían de forma ejemplar los factores propiciadores del desarrollo del bandidaje, destaca seis comarcas: la Ribera Alta (Cotes, Càrcer, Sumacàrcer) y la Baja (Corbera); la Canal de Navarrés (Anna, Bolbaite); el Valle de Ayora-Cofrentes (Teresa, Zarra); la Hoya de Buñol (Buñol, Cheste); y el Camp de Túria (Benisanó y, en menor medida, Benaguasil, Olocau, Riba-roja y Vilamarxant). De manera más ligera se habría visto azotado por esta lacra, en su opinión, el Camp de Morvedre (Algar de Palancia, Alfara de Algimia). Por último, en el norte del reino, cuyas tierras altas estaban poco pobladas por nuevos convertidos, García Martínez sólo califica de relevante la zona del Alto Palancia (Segorbe, Navajas, Castellnovo) y, muy por detrás de ésta, el Alto Mijares (Ayódar) ${ }^{5}$.

El panorama del bandolerismo morisco que se obtiene de la descripción general de García Martínez suscita diversas dudas. Podemos empezar por el final: la geografía del fenómeno sugerida. La enumeración de lugares conexos con el bandidaje - dice el autor-, resulta del orden de importancia determinado por el número de veces que cada localidad -y, por extensión, cada comarca- aparece en las fuentes y bibliografía manejadas ${ }^{6}$. No obstante, comoquiera que García Martínez no hace explícita ninguna escala cuantitativa de referencias, sino sólo consideraciones cualitativas en función de la mayor o menor actividad delictiva documentada en cada sitio, hemos de colegir que los núcleos fundamentales del bandolerismo morisco fueron, a su modo de ver, siete: cuatro principales (la Marina Alta, el Comtat, la Canal de Navarrés y el Valle de Cofrentes) y tres secundarios (la Safor, la Hoya de Buñol y el Camp de Túria), siendo las dos primeras comarcas meridionales los territorios que más duramente sufrieron los efectos de aquel mal. En principio, esta relación de enclaves no plantea mayores problemas, por cuanto, amén de estar densamente habitados por cristianos nuevos, reunían los rasgos ideales, tanto en términos geomorfológicos como geopolíticos, para transformarse en escenarios preferentes de las tropelías de los bandidos. Sin embargo, pueden señalarse algunas objeciones. En primer lugar, de la lectura de las pragmáticas y crides estudiadas por García Martínez y, en concreto, de las publicadas por el conde de Aytona en 23 de junio de 1586 y el marqués de Caracena en 1 de diciembre de

\footnotetext{
5. Ibidem: pp. 27-31.
}

6. Ibídem: p. 27. 
1608, que traen anexas sendas listas de facinerosos buscados por la justicia con mención de sus lugares de origen respectivos, se desprende, por un lado, que la Hoya de Buñol era la mayor cuna de salteadores moriscos del reino ${ }^{7}, y$, por otro, que muchos de ellos eran oriundos de zonas no especialmente tenidas en cuenta por el autor, como la Ribera Alta o el Camp de Morvedre, (aunque sí reconocidas como nidos importantes de bandidaje popular y bandositats). A esto se añade que núcleos ni siquiera citados por éste antes de 1609, como ocurre con la Valldigna, sí aparecen en cambio referidos en estos documentos como patria chica de cuadrillas y teatro de sus fechorías ${ }^{8}$, extremo que ha confirmado Eugenio Císcar ${ }^{9}$. Tales discrepancias son indicios suficientes de la conveniencia de revisar la geografía del bandolerismo morisco propuesta por García Martínez, para comprobar si, a partir del examen de fuentes complementarias, cabe o no confeccionar un cuadro distinto de localización del fenómeno.

Pero hay más. En la exposición de este autor parece aceptarse a veces, al menos de forma implícita, la coincidencia entre los focos de procedencia de los malhechores y las áreas donde éstos desplegaron su actividad delictiva (por ejemplo: el Comtat). Otras, por el contrario, da la impresión de que los primeros eran refugios que los bandidos sólo abandonaban para perpetrar sus crímenes en otros sitios, por lo común las vegas habitadas por cristianos viejos, como es el caso de Ayora. El asunto es de la mayor trascendencia, por cuanto afecta a nuestra comprensión de la naturaleza y motivación de sus acciones. Conviene traer a colación, a este respecto, la definición que en su trabajo sobre el bandolerismo morisco en Andalucía da Bernard Vincent del término monfi, que allí se aplicaba a los salteadores. Aunque las autoridades adoptaron la palabra para calificar a los criminales moriscos, desde la perspectiva de los nuevos convertidos, el monfí era, en cambio, un «héroe de la libertad», incluso un «hombre santo», por cuanto -y he aquí el quid de la cuestión-, los monfíes, salvo excepciones, «tan sólo atacaban a los cristianos». Eran, en consecuencia, «vengadores de una minoría oprimida» ${ }^{10}$, punto de vista compartido, según Raphaël Carrasco, por los musulmanes valencianos, para quienes los correligionarios fuera de la ley eran «guerreros de la fe». Con todo, ello no obsta para que Carrasco advierta de que tal imagen dista de la realidad, pues los moriscos integrados en grupos armados colaboraron a menudo con cristianos viejos,

7. Casi un tercio de los 61 moriscos con origen conocido nombrados en la crida de 23 de junio de 1586 eran de esta comarca. Véase facsímil en CANET, J. LL., y ROMERO, D.: Crides, pragmàtiques, edictes, cartes $i$ ordres per a l'administració i govern de la ciutat i Regne de València en el segle XVI, Valencia, 2002, p. 519.

8. De junio de 1585 a junio de 1586 Aytona ordenó capturar a tres bandoleros de aquel valle: Blanquet, Portugalet y Penelet. (Además de la crida anterior, ARV, Real Cancillería, Curiae Lugartenentiae, 1.341, sin foliar, 26 de junio de 1585).

9. CísCAR PAllarés, E.: La Valldigna, siglos XVI y XVII. Cambio y continuidad en el campo valenciano, Valencia, 1997, pp. 230-232.

10. VINCENT, B.: «El bandolerismo morisco en Andalucía (siglo XVI)», en Minorías y marginados en la España del siglo XVI, Granada, 1987, pp. 175-176 y 197. 
sirviendo a propósitos de muy diversa índole ${ }^{11}$. En este sentido, Ben Ehlers ha señalado que los procesos criminales contra nuevos convertidos desafían la caracterización de la violencia en la zona morisca como una guerra santa entre Cristiandad e Islam: «Even cases involving marauding morisco bandits, viewed in detail, defy the conception of a brewing war between two distinct nations» ${ }^{12}$. A la luz de este dilema, se entiende mejor la relevancia de dilucidar si hubo o no coincidencia entre los focos de origen y las zonas de actuación de los salteadores moriscos, esto es, si cometieron sus crímenes en el ámbito de sus propias aljamas o fuera de éstas, pues el sentido de la respuesta nos ayudará a desentrañar si, en efecto, éstos se comportaron en esencia como vengadores de una minoría oprimida o, por el contrario, la motivación de sus actos era más compleja.

Por último, es necesario prestar atención a la cronología del fenómeno. A pesar de que, como se ha dicho, en la introducción de su obra García Martínez afirma que el auge del bandolerismo morisco se produjo entre 1563 y 1609, es obvio que en casi medio siglo hubo momentos en que creció la frecuencia y virulencia de sus ataques y otros en que la tensión remitió. De hecho, el propio autor distingue varias coyunturas críticas. Primero, la que se inició con la sublevación granadina en diciembre de 1568 , que puso en jaque a las autoridades para prevenir el contagio y que, como en su día constató Emilia Salvador, dio lugar a una avalancha de órdenes de arresto contra moriscos que deambulaban, acuadrillados o sueltos, por diversas partes del reino ${ }^{13}$. La impunidad con que se infiltraron en Valencia los granadinos deportados, consumidos por el resentimiento, prolongó - a juicio de García Martínez- los efectos perturbadores de la guerra más allá de $1570^{14}$. Precisamente, el activismo de los infiltrados fue, junto con la eclosión del bandolerismo nobiliario, que arrastró consigo a los moriscos de lugares de señorío, la causa de una nueva fase de pujanza criminal desde 1577 hasta el final de la década, sin parangón, no obstante, con la que estaba por venir. En efecto, el «rictus de ferocidad y exasperación» que cobró el bandolerismo morisco a partir de 1584, y que llevó al virrey Aytona, que empezaba su segundo trienio, a tomar medidas excepcionales para aplastarlo, coincidió con el recrudecimiento de las incursiones piráticas y de la agitación de los nuevos convertidos, alimentada por la difusión de las armas de fuego y, según creía el propio Felipe II, por los granadinos refugiados. En cualquier caso, la drástica política represiva puesta en ejecución permitió pacificar el país antes de que el rey prorrogase el gobierno de Aytona, en julio de 1587, como recompensa por su eficaz lucha contra el $\operatorname{crimen}^{15}$. Por fin, la delincuencia morisca

11. CARRASCO, R.: «Les morisques levantins à la croisée des pouvoirs», en La monarchie catholique et les Morisques (1520-1620). Études franco-espagnols, Montpellier, 2005, p. 152.

12. EHLERS, B.: Between Christians and Moriscos. Juan de Ribera and Religious Reform in Valencia, 15681614. Baltimore, 2006, p. 139.

13. SAlvador ESTEBAn, E.: Felipe II y los moriscos valencianos. Las repercusiones de las revuelta granadina (1568-1570), Valladolid, 1987, p. 35.

14. García MartíneZ, S.: Op. cit., p. 73.

15. Ibidem: pp. 91-100. 
volvió a proliferar en vísperas de la expulsión, desde 1605 en adelante, hecho del cual son buen reflejo las pragmáticas y pregones de Villamizar y, sobre todo, de Caracena, encaminadas a lograr a cualquier precio, al margen incluso del ordenamiento foral, la captura de forajidos y el castigo de sus favorecedores ${ }^{16}$.

En líneas generales, la curva de evolución del bandidaje morisco que bosquejan estos cuatro períodos críticos y sus correspondientes intermedios de relativa calma concuerda con la de la aplicación de la pena capital, que revela, por un lado, que el promedio de ejecuciones de nuevos convertidos alcanzó su techo durante los primeros trienios de Aytona y, por otro, que en los años inmediatamente anteriores a la expulsión rebrotó la agitación morisca ${ }^{17}$. Sin embargo, no encaja bien con la de la persecución inquisitorial, que muestra que durante el lustro 1591-1595 se produjo un extraordinario incremento de los procesamientos de moriscos valencianos, hasta el punto que ése fue, de manera muy destacada, el momento culminante del siglo XVI ${ }^{18}$. En consecuencia, la divergencia de criterios represivos hace necesario revisar de nuevo un aspecto sustancial del fenómeno del bandidaje morisco: su cronología, a la luz de fuentes alternativas.

\section{NUEVA PERSPECTIVA}

Para nuestros fines, además de consultar la documentación al uso (pragmáticas, pregones y edictos, correspondencia virreinal, crónicas y dietarios, etc...) y estudiar con detalle unos cuantos procesos criminales, hemos examinado de modo sistemático dos fondos principales, ambos pertenecientes al Archivo del Reino de Valencia: los libros de cuentas de la Tesorería General del Maestre Racional comprendidos entre los años 1563 y 1609 (registros 8.874 a 8.917) y los volúmenes de Conclusiones Criminales de la Audiencia, desde el inicio de la serie conservada, que corresponde a 1571, hasta la expulsión de los moriscos (registros 1.791-1.820). En los expedientes de tesorería hemos buscado y recopilado todas las órdenes de pago libradas a favor de jueces de corte, alguaciles, notarios, verguetas, comisarios y demás oficiales reales por el tiempo y medios empleados en tomar declaración de testigos sobre los asaltos, robos, asesinatos, agresiones y cualesquiera otros actos violentos atribuidos a cristianos nuevos, así como en reconocer parajes, formar diligencias, perseguir, apresar y trasladar a forajidos moriscos. Por añadidura, hemos recogido las noticias, muy escasas, que en relación con dichos delitos se filtran a través de los asientos de ingresos ${ }^{19}$. Pese a las lagunas de

16. Ibídem: pp. 120-130.

17. PÉrez García, P., y CatalÁ SanZ, J. A.: «La pena capital en la Valencia del XVII», en Estudis, 24, 1998, pp. 203-246; y «La pena capital en la Valencia del Quinientos», en Conflictos y represiones en el Antiguo Régimen, Valencia, 2000, pp. 21-112, en especial p. 27.

18. Cfr. CARrasco, R.: «Historia de una represión. Los moriscos y la inquisición en Valencia, 1566-1620», en La monarchie catholique..., pp. 70-71; y BENÍTEZ SÁnCHEZ-BlAnCO, R.: Heroicas decisiones. La monarquía católica y los moriscos valencianos, Valencia, 2001, p. 355.

19. Por ejemplo, cuando se conmuta la condena a un reo por el pago de una pena pecuniaria. A veces, al abonarse la suma, se consigna el crimen que cometió y algunos pormenores del mismo. 
que adolece la fuente ${ }^{20}$ y lo sumario de la información anotada, hemos podido reunir datos sobre un elevado número de crímenes e identificar a centenares de moriscos a los que las autoridades creyeron, en alguna fase de la investigación, autores o partícipes en los mismos.

No tan versátil como la anterior ${ }^{21}$, pero más fiable -por cuanto se basa en averiguaciones ya llevadas a cabo- es la serie de conclusiones criminales de la Real Audiencia, donde se consignan las resoluciones de los jueces al término de cada proceso y antes de dictar sentencia definitiva. Aunque en ocasiones la naturaleza exacta del delito del que se acusa a los reos queda oculta en una vaga y genérica referencia a lo contenido en el escrito de denuncia, (lo que, en cualquier caso, afecta a menos del 7\% de las conclusiones vistas), estos registros dan cuenta de las fechorías de más de 400 delincuentes moriscos, detenidos o en rebeldía, de muchos de los cuales no teníamos la menor noticia previa. Desde el punto de vista documental e historiográfico, ésta es precisamente una de las constataciones más interesantes, pues, además de corroborar la complementariedad de los fondos consultados, induce a pensar que la Audiencia, al menos desde su remodelación y potenciamiento entre 1572 y $1585^{22}$, dispuso de medios de indagación mucho más eficaces de lo que algunas fuentes dejan ver, no en vano numerosos integrantes de bandas armadas no identificados en los libros de tesorería aparecen en cambio correctamente reconocidos y localizados en los registros del alto tribunal. Cosa bien distinta es que todos ellos cumplieran condena.

En conjunto, y descontados de antemano los acusados de salirse del reino o pretender hacerlo -asunto que excede del objeto de esta investigación y del que hay cuantiosos testimonios en nuestra documentación-, hemos reunido información sobre más de 800 moriscos perseguidos, imputados o sentenciados por cometer delitos contra las personas o contra la propiedad entre 1563 y 1609. Por supuesto, no todos ellos eran bandoleros ni se echaron al monte, razón por la cual hemos excluido del análisis a aquellos individuos que, si bien quebrantaron gravemente la ley, no puede decirse, a tenor de lo que manifiestan las fuentes, que se dedicaran al crimen como forma de vida (lo que deja fuera a una veintena de homicidas, a otros tantos alteradores del orden y a unos cuantos fugados de los que ignoramos la causa de su ingreso en prisión). También a quienes, a la inversa, siendo delincuentes habituales, no hicieron de la emboscada y el saqueo su sustento, lo que nos ha llevado a descartar a ladrones y cuatreros, siempre y cuando no perpetraran sus robos con violencia, y a los contrabandistas de grano y de

20. Para una descripción de las carencias de esta fuente nos remitimos a los trabajos sobre la pena capital ya mencionados: PÉrez García, P., y CATAlÁ SANZ, J. A.: «La pena capital en la Valencia del XVII», pp. 203-204, y «La pena capital en la Valencia del Quinientos», pp. 21-23.

21. Si bien el abanico de temas y problemas sobre los que ofrece información es más limitado que en los libros de cuentas del Maestre Racional, no deja, con todo, de ser una ventana muy amplia a través de la cual asomarse al pasado. Como ejemplo de aplicación de esta fuente para el estudio específico de los moriscos véase PARdo Molero, J. F.: «La emigración de los moriscos valencianos», Saitabi, Valencia, 2003, 53, pp. 95-116.

22. CANET APARISI, T.: La Audiencia valenciana en la época foral moderna, Valencia, 1986. pp. 65-72. 
caballos, por más que, probablemente, unos y otros tuvieran lazos con los salteadores. Asimismo, quedan al margen de nuestro registro el medio centenar de receptadores castigados por la Audiencia por dar cobijo a bandidos, ya que hemos querido distinguir claramente a éstos de aquellos. Por último, no hemos incluido a los numerosísimos culpados de llevar, poseer o esconder armas prohibidas, a no ser que además de ello cometieran otro delito, por cuanto de la simple tenencia de armas no puede, ni debe, inferirse la condición de facinerosos o malhechores de los imputados, estando tan difundida en aquellos días la posesión de las mismas aun a riesgo de sufrir las durísimas penas previstas por contravenir la ley. En resumen, el número de moriscos de los que se puede hacer concepto de su calidad de bandoleros se reduce a 558, bien porque se les califique así en las declaraciones de los testigos, en las denuncias de los fiscales o en las resoluciones de los jueces, bien porque, luego de consumar un crimen grave (como los de homicidio, agresión o resistencia a la autoridad, robo u otros), se convirtieran en fugitivos reclamados por la justicia y llamados en los bandos y pregones virreinales. De hecho, en decenas de casos no tenemos otra base que la mención de los mismos en las listas de bandolers y malfatans publicadas por los virreyes. Estos 558 malhechores son los que integran la tabla que se adjunta al final, en la que se compendian sus datos personales, la cronología de sus actividades delictivas y, cuando se explicitan en las fuentes, sus respectivos lugares de origen, los escenarios de sus crímenes, la naturaleza de los mismos y las condenas que se les impusieron. No hay, por el contrario, especificaciones sobre su ocupación laboral porque muy pocas veces queda escrita en la documentación.

Lo que esta tabla encierra refleja una realidad social dramática, brutal, constante, inextinguible y ampliamente propagada. Sin embargo, no representa más que una parte del problema, habida cuenta de que no se contienen aquí los casos, que debieron de ser abundantes, de bandidos capturados y sentenciados por la justicia señorial y municipal. Sin ir más lejos, el propio análisis de la geografía del fenómeno ofrece, como se verá, pistas sobre este vacío. Para empezar, se ha de destacar que, de los 558 forajidos, al menos 456 eran naturales del reino o, como mínimo, residentes afincados en localidades valencianas el tiempo suficiente para ser tenidos por vecinos de éstas, lo que supone el $81,72 \%$ del total. De otros 81 no conocemos su procedencia ni domicilio, lo que, a falta de mayores concreciones, reduce a un exiguo 3,76\% - esto es, 21 individuos- la proporción de salteadores foráneos: 13 granadinos, tres turcos, dos argelinos, un moro de Fez, un catalán y un aragonés. Por llamativa que resulte esta distribución, no hay que precipitarse a la hora de elevar conclusiones. Por un lado, es probable que muchos de los criminales de origen desconocido fueran forasteros. Por otro, el empleo de los gentilicios «tagarí» o «alarb» para apellidar a una decena de individuos y el uso de nombres no cristianos por otros sin señas hace sospechar su condición de extranjeros. A mayor abundamiento, se ha de reparar en el hecho de que la mayoría de los granadinos o los así apellidados estuvieron activos entre 1574 y 1587 , lo que da firmeza a las alertas de las autoridades acerca de la participación de infiltrados y refugiados en la fase de mayor pujanza del bandidaje morisco. Pese a ello, es evidente que la responsabilidad fundamental del vigor y beligerancia que 
el crimen organizado llegó a adquirir entre los nuevos convertidos del reino se ha de buscar dentro de sus propias aljamas.

¿Cuáles de ellas fueron cunas de bandoleros? En la documentación se distinguen como lugar de origen o residencia habitual 133 localidades, cifra que equivale a la mitad de los municipios moriscos y de población mixta de la lista confeccionada por Lapeyre (de hecho, la inmensa mayoría de éstas eran núcleos principales), o, si se incluyen también las aldeas, despoblados y sitios no identificados por el hispanista, el $28 \%$ del total ${ }^{23}$. En cualquier caso, el número acredita la enormidad del asunto. De estos lugares, 58 fueron patria de un solo forajido, 23 de un par de ellos, 15 de tres, 10 de cuatro y sólo 27 de cinco o más bandidos. Estas 27 poblaciones, que representan la quinta parte del conjunto, concentraban el $53,7 \%$ de los fuera de la ley nativos ${ }^{24}$, lo que da pie para calificarlas de nidos primordiales del bandidaje converso. Muy por encima de las demás sobresalen -véase cuadro 1- Yátova y Chiva, que, por sí solas, agrupaban casi a la octava parte de los bandoleros autóctonos. Si se les suman Buñol y su baronía, queda claro, como se ha dicho, que la Hoya de Buñol fue el mayor semillero del reino y no resulta difícil entender las razones que llevaron a dictar, en diciembre de $1583^{25}$, el secuestro de la jurisdicción del estado para tratar de garantizar la paz en la comarca. Si nos atenemos a las cifras estrictas, cabe destacar también como cunas relevantes a Muro de Alcoy, Corbera, Benisanó, Chelva, Turís, Benilloba, Algar de Palancia, Segorbe y Senija, seguidas de otras localidades. Sin embargo, conviene advertir que, a diferencia de los pueblos de la Hoya de Buñol, que fueron focos de delincuencia persistentes, algunos de estos reductos se nos presentan más bien como viveros ocasionales. Es el caso de Corbera, la totalidad de cuyos 13 bandidos se reparten entre dos sucesos criminales: el asalto, con trágico desenlace, de dos pastores en Llaurí en $1589^{26}$, y la formación de una banda armada en $1602^{27}$. También lo es de Chelva, 8 de cuyos 11 malhechores se echaron al monte después de acribillar al vizconde en octubre de 1584, asesinato que contribuyó de forma decisiva al endurecimiento de la política represiva de Aytona $^{28}$. Y algo semejante puede afirmarse de Senija, donde 5 de los 8 salteadores vecinos de la localidad estuvieron implicados en el secuestro y posterior muerte de Joan Bernabeu, rico cristiano de Benisa, en $1570^{29}$.

23. LAPEYRe, H.: Geografia de la España morisca, Valencia, 1986, pp. 46-62.

24. Para completar la cifra de 456 bandidos nacidos en el reino hay que contar también a los individuos de los que se dice ser de una comarca o área determinada (vgr. la Hoya de Buñol o la Vall de Segó), pero no la localidad exacta donde habitan.

25. ARV: Real Audiencia, Conclusiones Criminales, 1.795, 30 r-v.

26. ARV: Real Audiencia, Conclusiones Criminales, 1.801, $20 \mathrm{r}-\mathrm{v}$.

27. ARV: Real Audiencia, Conclusiones Criminales, 1.814, 33 r-v.

28. ARV: Real Audiencia, Libro de denuncias criminales, 2.118, 190 r; Conclusiones Criminales, 1.797, 3 r; y Maestre Racional, 8.895, 67 v. y 123 r-v. Véase también Herrero Morell, J. A.: Política pacificadora y fortalecimiento regio en el reino de Valencia (1581-1585), Tesis de Licenciatura inédita, Valencia, 1994, p. 170.

29. ARV: Real Audiencia, Conclusiones Criminales, $1.791,39$ r. y 51 v-52 v. 


\begin{tabular}{|c|c|}
\hline \multicolumn{2}{|c|}{ Cuadro 1. Principales cunas de bandidos moriscos } \\
\hline & $\mathrm{N}^{0}$ de individuos \\
\hline Yátova & 32 \\
\hline Chiva & 24 \\
\hline Muro de Alcoy & 14 \\
\hline Corbera & 13 \\
\hline Benisanó & 12 \\
\hline Buñol & 11 \\
\hline Chelva & 11 \\
\hline Turís & 10 \\
\hline Benilloba & 10 \\
\hline Algar de Palancia & 9 \\
\hline Segorbe & 8 \\
\hline Senija & 8 \\
\hline Carlet & 7 \\
\hline Jarafuel & 7 \\
\hline Alberic & 6 \\
\hline Bétera & 6 \\
\hline Cirat & 6 \\
\hline Vall d’Uixó & 6 \\
\hline Alcàntera de Xúquer & 5 \\
\hline Benaguasil & 5 \\
\hline Benidoleig & 5 \\
\hline Bolbaite & 5 \\
\hline Masalavés & 5 \\
\hline Monòver/Monóvar & 5 \\
\hline Quart de les Valls & 5 \\
\hline Riba-Roja de Túria & 5 \\
\hline Vilamarxant & 5 \\
\hline
\end{tabular}

De inmediato se comprueba que muchos de los nidos primordiales del bandidaje morisco, además de estar densamente habitados por nuevos convertidos, compartían los rasgos señalados por García Martínez como elementos propiciadores de la delincuencia: ubicación en los estribos de macizos montañosos, acceso natural a las fronteras de Castilla o Aragón, cercanía de poblaciones cristianas con las que existía una permanente tensión social, cultural y religiosa. En otros sitios resultó crucial su emplazamiento junto a redes viarias principales donde perpetrar los asaltos. Esto se hace 
patente en las poblaciones de la Ribera Alta próximas al camino real entre Valencia y Xàtiva: Carlet, Masalavés y Alberic (además de Càrcer o Genovés, que no aparecen en el cuadro 1); y en las del Camp de Morvedre y el Alto Palancia situadas en torno al eje Sagunto-Segorbe-Teruel: Algar de Palancia, la propia Segorbe, Quart de les Valls (así como Estivella, Petrés, Algimia de Alfara, Sot de Ferrer o Geldo, que tampoco figuran en el cuadro). La distribución por comarcas no hace sino confirmar estos aspectos, pues a la cabeza de la clasificación de los refugios de bandidos se sitúan aquellas que aunaban tales «factores de riesgo»: la Hoya de Buñol, la Ribera Alta, el Camp de Morvedre, el Camp de Túria, el Comtat, la Marina Alta y el Alto Palancia.

\begin{tabular}{|l|c|c|}
\hline \multicolumn{2}{|c|}{ Cuadro 2. Distribución de los bandidos moriscos por comarcas (de norte a sur) } \\
\hline & $\mathbf{N}^{\mathbf{0}}$ de individuos & \% \\
\hline El Alto Mijares & 14 & 3,07 \\
\hline El Alto Palancia & 26 & 5,70 \\
\hline La Plana Baixa & 16 & 3,51 \\
\hline El Camp de Morvedre & 38 & 8,33 \\
\hline Los Serranos & 15 & 3,29 \\
\hline El Camp de Túria & 38 & 8,33 \\
\hline L'Horta (Nord, Sud, Oest) & 9 & 1,97 \\
\hline La Hoya de Buñol & 80 & 17,54 \\
\hline El Valle de Ayora-Cofrentes & 13 & 2,85 \\
\hline La Ribera Alta & 73 & 16,01 \\
\hline La Ribera Baixa & 15 & 3,29 \\
\hline La Canal de Navarrés & 12 & 2,63 \\
\hline La Costera & 9 & 1,97 \\
\hline La Vall d'Albaida & 6 & 1,32 \\
\hline La Safor & 21 & 4,61 \\
\hline El Comtat & 29 & 6,36 \\
\hline La Marina Alta & 27 & 5,92 \\
\hline La Marina Baixa & 6 & 1,32 \\
\hline El Vinalopó Mitjà & 5 & 1,10 \\
\hline El Baix Vinalopó & 45,88 \\
\hline Total & & $100 \%$ \\
\hline
\end{tabular}

Dicha clasificación, no obstante, difiere de la sugerida por García Martínez tanto en sus componentes como en el orden de los mismos. En primer lugar, y como venimos insistiendo, la Hoya de Buñol se encarama a la cima de los núcleos del bandolerismo morisco, a gran distancia de las demás zonas, con la excepción de la Ribera Alta. Basta 
fijarse en que el número de delincuentes que allí habitaban (que excede de la sexta parte del total), supera al de los que residían en la tercera y cuarta comarcas juntas: el Camp de Morvedre y el Camp de Túria. He aquí precisamente el segundo hallazgo reseñable. Ni estos dos territorios, ni la Ribera Alta, ni tampoco el Alto Palancia merecen para García Martínez la consideración de enclaves fundamentales. Sin embargo, de acuerdo con nuestras fuentes, estas cuatro áreas congregaban el 38,3\% de los bandidos moriscos y, junto con la Hoya de Buñol, el 55,9\% de la suma general. A la inversa, la relevancia que este autor otorga a la Canal de Navarrés, el Valle de Ayora-Cofrentes y la Safor se contradice con el bajo volumen que aquí alcanzan, pues ninguna de estas tres comarcas llega al umbral del 5\%. Tal vez la indistinción entre los lugares de origen de los proscritos y los escenarios de sus correrías alimente la idea de que tales reductos eran núcleos de peligrosidad mayores de lo que en realidad fueron, por lo que conviene examinar los teatros criminales por separado. Para ello cabe tener en cuenta no sólo los lugares donde consumaron sus fechorías los forajidos que integran la tabla, sino también aquellos otros en que hay constancia de que se perpetraron delitos o se llevaron a cabo acciones relacionadas con el bandidaje morisco (asaltos, robos, saqueos, homicidios, receptación de forajidos, concurrencia de cuadrillas), pero no se especifica la identidad de los culpables. Son, en suma, 134 escenarios, localizados con precisión variable en los registros consultados («prop del riu de Belcaire», «camí de Gaibiel a Viver», «en la Vall d'Alfàndech i la Marina», «en Otanell», etc.), pero que, a pesar de las inexactitudes de que adolecen, permiten extraer interesantes conclusiones.

\begin{tabular}{|l|c|}
\hline \multicolumn{2}{|c|}{ Cuadro 3. Escenarios de los crímenes. Comarcas principales } \\
\hline & $\mathbf{\%}$ \\
\hline La Hoya de Buñol & 15,67 \\
\hline La Ribera Alta & 13,43 \\
\hline El Camp de Morvedre & 8,96 \\
\hline El Camp de Túria & 8,21 \\
\hline El Comtat & 7,46 \\
\hline La Plana Baixa & 5,97 \\
\hline El Valle de Ayora-Cofrentes & 5,22 \\
\hline La Safor & 4,48 \\
\hline L'Horta (Nord, Sud, Oest) & 4,48 \\
\hline El Alto Palancia & 3,73 \\
\hline
\end{tabular}

La primera y más relevante es que, lejos de modificar sustancialmente el panorama descrito, la agrupación por comarcas de tales lugares corrobora la valoración anterior. Como puede verse en el cuadro 3, en el cual se disponen en orden descendente las diez comarcas donde se cometieron más crímenes, las cinco primeras coinciden con los refugios de salteadores más importantes: la Hoya de Buñol de nuevo al frente, seguida 
de la Ribera Alta, el Camp de Morvedre, el Camp de Túria y el Comtat. En conjunto, estas cinco comarcas fueron escenario de más de la mitad de los delitos de los bandidos moriscos (el 53,7\%). Por el contrario, continúa fuera de las zonas de mayor peligrosidad la Canal de Navarrés, aunque sí aparecen el Valle de Ayora-Cofrentes y la Safor, a la zaga, en cualquier caso, de las mencionadas y sin guardar proporción con la concentración de nuevos convertidos en aquellos lares ni con la agitación que, con cierta frecuencia, turbó a sus habitantes y provocó la alarma de las autoridades ${ }^{30}$, lo que indica que debemos mantener la cautela, si no respecto a la fiabilidad, sí al menos en cuanto a la representatividad de nuestras fuentes. Finalmente, se ha de subrayar la inclusión de la Huerta de Valencia (Paterna, Manises, Burjassot, Torrent, Alaquàs, Picassent) entre los teatros de operaciones más significativos, ya que, pese a estar escasamente poblada por moriscos, era un nudo de comunicaciones que se avenía a las depredaciones de los bandoleros. Esta comprobación pone de manifiesto la necesidad de esclarecer cuánto se alejaban de sus aljamas los salteadores moriscos a la hora de ejecutar sus acciones, o, dicho en otros términos, si sus estrategias delatan una deliberada voluntad de saquear territorios ajenos y, en especial, de atentar contra cristianos viejos. A la espera de que el estudio de los procesos que se les fulminaron dé sus frutos, por el momento sólo podemos enfocar la cuestión cotejando la índole de los escenarios criminales con los focos de procedencia. El resultado se resume en el cuadro 4, en que se distinguen seis categorías: teatros coincidentes con las cunas de bandidos (lo que no implica que se correspondieran siempre con los propios puntos de origen de los malhechores); lugares habitados por moriscos pero que, según nuestras fuentes, no eran refugios acreditados; localidades cristianas; poblaciones mixtas; áreas con fuerte presencia morisca (pues la descripción dada en la documentación no permite concretar más: el barranco de Juncar, la sierra de Martés, la Marina, la Vall de Segó, la Vall de Perpunxent, etc...); y caminos reales y vías públicas. Por último, se registran dos agresiones fuera del reino, una en Requena y otra en Castilla ${ }^{31}$.

A tenor de tales datos, se observa una marcada propensión a hostigar sus propias tierras que no se conforma bien con la tesis de que los bandoleros moriscos eran esencialmente vengadores de una minoría oprimida, salvo que se limitaran a atacar a los cristianos viejos que se adentraran en ellas, extremo que está por verificar. En más de la mitad de las ocasiones, los crímenes se efectuaron en enclaves caracterizados por ser cunas de bandidos, y de éstas, al menos en una veintena se sabe con certeza que

30. Escolano se hace eco de que en 1568 algunos bandoleros moriscos de Cortes «escucharon de muy buena gana» a los emisarios granadinos llegados para levantar en armas al reino. Asimismo, refiere que, luego de la guerra de Granada, los moriscos de Teresa de Cofrentes se conjuraron para atacar Ayora. Escolano, G.: Segunda parte de la Década primera de la insigne y coronada Ciudad y Reino de Valencia, Valencia, 1611, cols. 1.774 y 1.777. Véase también SALVADOR, E.: Op. cit, p. 36; y GARCÍA MARTínEZ, S.: Op. cit, p. 80.

31. Esta última se atribuye a los hermanos Miquel y Rodrigo Amillo, de la Vall de Segó, culpados de varios crímenes graves, entre ellos un robo en Castilla en 1590. (ARV: Real Audiencia, Conclusiones Criminales, 1.803, 122-123). 
los autores no salieron de su propia aljama y en otras quince que no traspasaron las lindes de su comarca. Si a estos casos se suman las fechorías perpetradas en localidades moriscas distintas de los nidos de salteadores y en zonas de tradicional asentamiento converso se advierte que al menos tres de cada cuatro delitos se consumaron en suelo o áreas de influencia morisca. Podrá objetarse que eso no basta para refutar el carácter selectivo de la beligerancia morisca. Es cierto. El ensañamiento con que algunos forajidos liquidaron a sacerdotes, oficiales de justicia, correos, mercaderes o simples ganaderos cristianos revela que sus actos no estaban exentos de odio religioso y ánimo vindicativo. También puede alegarse que las cuadrillas más temerarias deambularon por el reino sin dificultad -y nuestra tabla asi lo avala: al menos 40 bandidos vagaron por diferentes regiones antes de poner fin a sus correrías o ser atrapados-, cometiendo toda clase de atropellos a diestro y siniestro. Aquí únicamente podemos traer a colación algunos ejemplos de violencia intraétnica que testimonian la compleja naturaleza del bandolerismo morisco. Así, Jeroni Raboset, alias Alí Campillo Raboset, fue hallado culpable de asesinar a Casdonis Portilli, nuevo convertido de Benillup, en abril de 1565, y a Azmet Borhou, morisco de La Roca, en la Vall d'Alcalà, siete años después, para robarles ${ }^{32}$. En 1573, Joan Crespí Aliret, alias Carcaxer, cristiano nuevo de Rafalsineu, fue condenado a muerte y ejecutado por el asesinato premeditado de Miquel Perpel, morisco de Piles ${ }^{33}$. Por su parte, Miquel Sabadet, morisco del Raval de Gandia, fue perseguido en 1589 por haber dado muerte a dos correligionarios: Baltasar Xerp y Francesc Suqueyl ${ }^{34}$. Menos sangriento, pero igualmente ilustrativo de la variedad de motivos que inspiraban las acciones de los bandidos moriscos, es el robo de 500 cabezas de ganado de que fue objeto Gaspar Pardo, morisco de Olocau, a manos de un par de ladrones de la Hoya de Buñol y un tercero de Ayacor, aldea morisca de Canals ${ }^{35}$.

\begin{tabular}{|l|c|c|}
\hline \multicolumn{3}{|c|}{ Cuadro 4. Índole de los escenarios criminales } \\
\hline & Número de casos & $\%$ \\
\hline Cunas de bandidos & 70 & 52,24 \\
\hline Aljamas moriscas, pero no cunas & 16 & 11,94 \\
\hline Localidades cristianas & 10 & 7,46 \\
\hline Poblaciones mixtas & 5 & 3,73 \\
\hline Áreas con fuerte presencia morisca & 17 & 12,69 \\
\hline Caminos y vías públicas & 14 & 10,45 \\
\hline Fuera del reino & 2 & 1,49 \\
\hline Total & 134 & $100 \%$ \\
\hline
\end{tabular}

32. ARV: Real Audiencia, Conclusiones Criminales, 1.793, $4 \mathrm{r}$.

33. ARV: Real Audiencia, Conclusiones Criminales, 1.792, 36 v-37 r; y Maestre Racional, 8.884, 59 r.

34. ARV: Real Cancillería, Curiae Lugartenentiae, 1.345, 109 r.

35. ARV: Real Audiencia, Conclusiones Criminales, 1.806, 4 r. 
Asimismo, aunque escasas, no faltan pruebas del entendimiento, eventual o firme, entre bandoleros conversos y cristianos viejos, que arrojan luz sobre una vertiente del fenómeno mal conocida. Herrero Morell menciona la actuación de una cuadrilla mixta, compuesta por moriscos y cristianos catalanes, en los alrededores de Alzira, que provocó el envío de una comisión en septiembre de $1585^{36}$. Medida similar se había adoptado en marzo de 1583 para el logro de la captura de otra banda de cristianos viejos y nuevos que merodeaba por la Hoya de Buñol y el Camp de Túria ${ }^{37}$. Sabemos también de los colaboradores cristianos de malhechores como Pere Monní o Miquel Abraix Nono. El primero, nuevo convertido de Betxí, fue condenado a pena capital por asaltar junto con Joan Asensi, cristiano viejo, a un guarda del General en el camino de Cabanes a Onda $^{38}$. El segundo, famoso salteador morisco de Chiva, contó entre los miembros de su grupo a Alfonso Cañada y Juan Monterde, cristianos de Siete Aguas y Sinarcas respectivamente, con los que dio algunos de sus golpes ${ }^{39}$. Sea como fuere, estos casos confirman la dificultad de caracterizar el problema y ponen de manifiesto la necesidad de investigar más de cerca el modus operandi de las bandas armadas moriscas para comprender mejor el sentido y propósito de sus actos.

Antes de dar por concluida la revisión de la geografía del bandolerismo morisco hemos de llamar la atención sobre la siguiente paradoja: si los mayores semilleros de bandidos y los teatros criminales primordiales reunían las características idóneas para serlo, ¿por qué algunas de las mayores aljamas del reino sitas junto a zonas montañosas y vías de comunicación principales y en constante conflicto con poblaciones cristianas vecinas no se mencionan, o sólo de forma anecdótica, en los registros de tesorería y en las resoluciones judiciales consultadas? ¿Cómo se explica, por ejemplo, que Cortes de Pallás, Teresa de Cofrentes o Gestalgar, notorios centros de agitación morisca, no aparezcan entre los focos de procedencia más destacados? ¿Cómo cabe interpretar que Fanzara o Navajas, dos de las más grandes aljamas septentrionales, no sean citadas una sola vez como nidos de forajidos ni escenarios de violencia? ¿Cómo se entiende que las importantes morerías de Aspe, Elda y Novelda no se señalen como núcleos de bandidaje cuando desde la propia cancillería regia se expidieron cartas acerca de la infiltración de granadinos y el acaecimiento de desacatos en ellas durante la guerra de las Alpujarras? $?^{40}$ Por ahora sólo podemos formular un par de conjeturas, complementarias entre sí. La primera se funda en una evidencia cuantitativa: dado que aproximadamente el $70 \%$ de los bandoleros perseguidos o imputados y el $68 \%$ de los teatros criminales identificados se concentran en el imaginario hexágono comprendido entre Vall d'Uixó, Segorbe, Buñol, Xàtiva, Gandia y Valencia, cabe colegir que la actividad represiva de la justicia real descendía notablemente, salvo excepciones, en cuanto se entraba en la

36. Herrero Morell, J. A.: Op. cit., p. 167.

37. ARV: Maestre Racional, 8.894, $84 \mathrm{r}$.

38. ARV: Real Audiencia, Conclusiones Criminales, 1.811, $101 \mathrm{r}$.

39. ARV: Real Audiencia, Conclusiones Criminales, 1.818, $162 \mathrm{r}$.

40. SAlvador Esteban, E.: Op. cit., pp. 29 y 49. 
gobernación de Castellón, al norte, se salía de la de Xàtiva, al sur, o se traspasaba la línea dibujada por la Sierra de Martés y el río Júcar, al oeste. La segunda yace en la sospecha de que, bien por propia iniciativa, bien por instigación de los virreyes, algunas administraciones señoriales se enfrentaron solas al problema del bandidaje con un alto grado de eficacia, sin dejar por ello rastro documental en los archivos vistos. Sólo investigaciones futuras podrán validar o desmentir tales hipótesis.

Es momento de abordar el análisis de la evolución del fenómeno. Por mor de la síntesis, en la tabla hemos consignado tan sólo los años en que estuvieron activos los forajidos, sin precisar más. A tenor de los datos que poseemos, la trayectoria delictiva no excedió de un año en el 72,4\% del total. Sólo en 154 casos hay certeza de que ese límite se sobrepasara. De éstos, la inmensa mayoría concuerdan con los dos o tres años $^{41}$ de duración media que Hobsbawm indicara en su retrato del «bandido social». Únicamente 17 bandoleros moriscos lograron superar esa barrera, lo que apunta la existencia de una red de apoyos y solidaridades estable e incluso, en ocasiones, como afirma el historiador británico, una considerable protección política ${ }^{42}$. De esto es buen ejemplo la carrera criminal de don Carlos de Abenamir, hijo de don Fernando, miembro de la poderosa familia de los Abenamires de Benaguasil ${ }^{43}$. Imputado por vez primera en 1581 por haber prestado auxilio a Serafín Nadiret, a quien se acusaba de la muerte de un morisco de Manises, don Carlos salió desterrado de su pueblo por un año ${ }^{44}$. De nuevo inculpado en 1585 por deambular por el reino con armas prohibidas, fue a la postre sentenciado a pena capital en $1588^{45}$, condena que, no obstante, le sería conmutada por una elevada suma en metálico. Junto a éste, pueden citarse también como ejemplos de larga vida al margen de la ley al ya referido Jeroni Raboset, buscado de 1565 a 1574; a Joan Poya, de Almedíjar, perseguido desde 1578 hasta 1583; a Blanquet y Pinillet, que saquearon la Valldigna desde finales de 1582 hasta que fueron abatidos en $1586^{46}$; a Miquel Solaya, que comenzó sus correrías en 1583 y fue castigado por Aytona en 1586 valiéndose de procedimientos de dudosa legalidad ${ }^{47}$; a Santoret, de Cirat, activo entre 1579 y 1583; o a Josep Giber, de Benilloba, que participó en el asesinato del procurador de la Vall de Perpunxent en 1603, fue pregonado por Villamizar en 1605 y más tarde por Caracena en diciembre de $1608^{48}$.

De acuerdo con esta información, el gráfico 1 muestra la evolución del volumen de bandidos moriscos perseguidos o procesados por la justicia real entre 1563 y 1609. En lo esencial, la curva resultante no se aleja de la cronología sugerida por García

41. En 108 casos fue de 2 años, en 29 de 3.

42. Hobsbawm, E.: Bandidos, Barcelona, 2001, p. 72.

43. BENÍTEZ SÁNCHEZ-BlanCO, R.: «Las duras negociaciones de la Concordia de 1571 entre los moriscos y la Inquisición», en Conflictos y represiones en el Antiguo Régimen, pp. 113-155.

44. ARV: Real Audiencia, Conclusiones Criminales, 1.794, 179 r-180 r.

45. ARV: Real Audiencia, Conclusiones Criminales, 1.800, 75 r-v.

46. Císcar Pallarés, E.: Op.cit., pp. 230-232.

47. García MartíneZ, S.: Op. cit., pp. 99-100.

48. ARV: Real Audiencia, Conclusiones Criminales, 1.814, 126 r; y BUV, Var. 9, 259-260 y 298-301. 


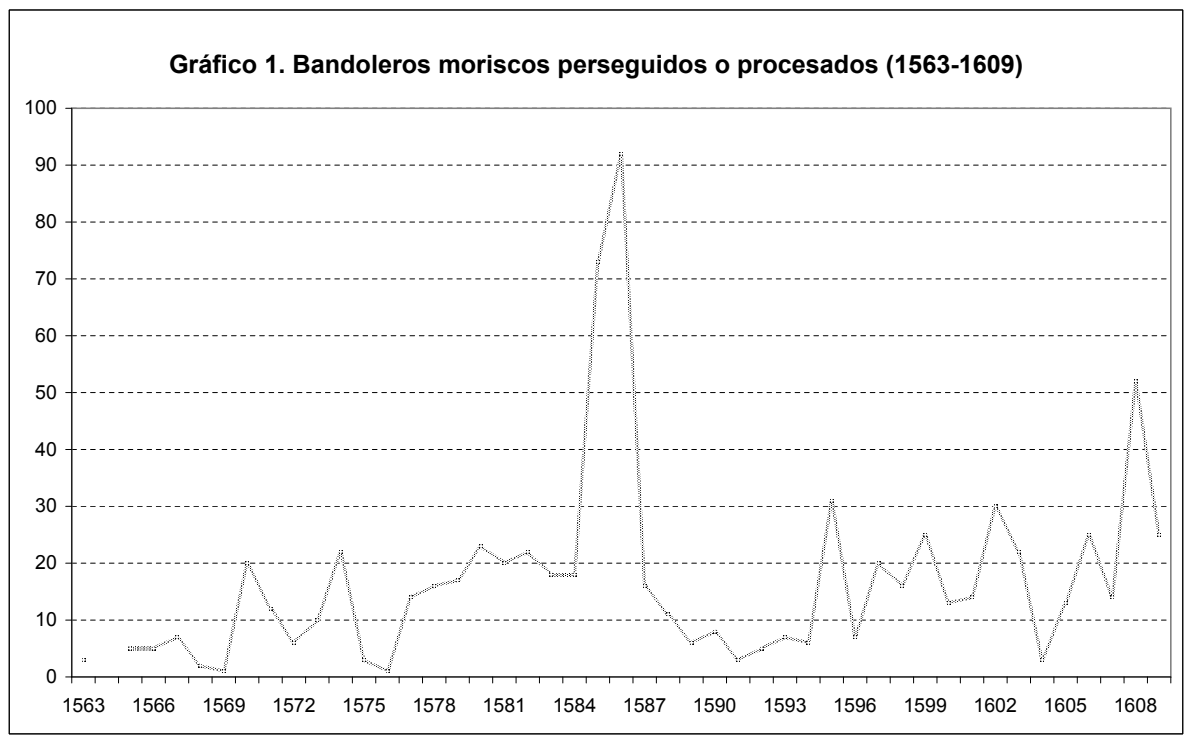

Martínez. En efecto, las cuatro fases que distingue en su obra pueden reconocerse en el gráfico: la primera empieza durante la guerra de Granada y se prolonga hasta 1574; la segunda va de 1577 a 1584; la tercera -y de mayor pujanza del período-, muestra la explosión de energía represora de Aytona en 1585 y 1586; y la cuarta es indicativa de la proliferación de crímenes en el lustro anterior a la expulsión. Sin embargo, el gráfico, además de revelar una inesperada fase de actividad entre los años 1595 y 1602, puede interpretarse de otra manera. Por un lado, si hacemos abstracción de la eclosión de mediados de los años 80, parece evidente que el primer trienio de Aytona (de julio de 1581 a julio de 1584), supuso la continuación de un estado de alerta policial y judicial iniciado a finales del virreinato del conde de Benavente, en 1570, y mantenido por sus sucesores en el cargo. Salvo el hiato de transición entre el gobierno de Mondéjar y el de Gonzaga (1575-1576), la media de facinerosos moriscos en busca y captura osciló en torno a los 17 anuales desde 1570 hasta 1584, con una tendencia al alza a partir de 1577 motivada por diversos factores, entre los que cabe resaltar la presencia de infiltrados granadinos, norteafricanos y turcos; la muerte, a manos de bandidos moriscos, de oficiales de justicia (el guarda Francisco García en 1577 y el comisario Jaume Benedito en 1579) ${ }^{49}$; y las andanzas de la temible cuadrilla de Meliquet por los alrededores de la capital del reino ${ }^{50}$. Por otro lado, luego del apogeo de 1586 y después de unos años de aparente calma (1587-1594), en que la actividad represiva, al menos la encauzada por

49. ARV: Maestre Racional, $8.889,89 \mathrm{v}$.

50. Costa SAnZ, J.: El virreinato de don Pedro Manrique de Lara (1578-1581), Tesis de Licenciatura inédita, Valencia, 1982, p. 118. 
vías acordes a derecho, se redujo prácticamente a la mitad, la lucha contra el crimen volvió a intensificarse en 1595 y, casi sin interrupción -la excepción es la sucesión entre Ribera y Villamizar en 1604-, se mantuvo alta la vigilancia hasta 1609, con niveles superiores incluso a los del período 1570-1584: 20 individuos perseguidos o procesados de media anual, (18 si descontamos la excepcional subida de 1608).

Se echa de ver, por tanto, que la evolución del bandolerismo morisco difiere notablemente de la curva de persecución inquisitorial, cuyo ápice se sitúa en la década 1586-1595, sobre todo en el segundo lustro. A juicio de Carrasco, este incremento tiene su origen en la psicosis colectiva antimorisca que arranca con la conspiración de los nuevos convertidos de Valencia y Aragón para sublevarse en 1583, realimentada por los rumores posteriores sobre posibles levantamientos ${ }^{51}$. No obstante, esta explicación, que tal vez se corresponda con las claves de la lógica represiva del Santo Oficio, no encaja bien con la disminución simultánea de la lucha contra las bandas armadas moriscas por parte de las autoridades del reino. Pese a ello, no se debe descartar que el miedo a eventuales alzamientos coadyuvara a la extraordinaria multiplicación de imputaciones y procesamientos de malhechores moriscos en 1585 y 1586 . En ese clima de sospecha y tensión, dos hechos acaecidos en 1584 pudieron ser quizá los detonantes de la vuelta de tuerca ordenada por Aytona. Primero, en el mes de julio, la fuga masiva a Berbería de los nuevos convertidos de Callosa d'En Sarrià, Algar, Micleta, Polop, Chirles, Bolulla y La Nucía, que vino a acrecentar la sensación de descontrol e indefensión del litoral generada por el saqueo de Chilches un año antes. Y después, en octubre, el asesinato de don Francisco Ladrón de Pallás, vizconde de Chelva, por un grupo de furiosos vasallos moriscos escapados de la cárcel señorial, donde éste los había hecho encerrar. La alarma provocada por este crimen llevó a Felipe II a interesarse personalmente por el asunto, conminando a su virrey a endurecer la política represiva contra los moriscos ${ }^{52}$. Y a fe que lo consiguió.

Un vistazo al gráfico 2, en el cual se presenta el desarrollo del castigo del bandidaje morisco, basta para ratificar el extremado rigor punitivo del conde de Aytona. Conocemos las sentencias dictadas contra 289 de los malhechores incluidos en la tabla (el $51,79 \%$ del conjunto). De ellos, prácticamente tres de cada cinco -172 en totalfueron condenados a pena de muerte, que se ejecutó en un tercio de los casos (60 reos). Otros 102 bandidos fueron sentenciados a galeras (el 35,29\%), que fueron de por vida para 56 de éstos. Tan sólo a 15 forajidos, poco más del 5\%, se les impusieron penas distintas: azotes y destierro, básicamente. Como se observa en el gráfico, en el que se compara el recurso a la pena capital con la condena a galeras, casi el $20 \%$ de las penas de muerte se firmaron en los dos años de máxima intensidad represiva. Añádase a ello que 1585 y 1586 fueron también los de mayor cumplimiento de la pena capital, con 8 y 11 ejecuciones respectivamente, que por sí solas representan el 31,6\% del total. Queda

51. CARrasco, R.: «Historia de una represión...», p. 71.

52. García Martínez, S.: Op. cit., pp. 88-91; Herrero Morell, J. A.: Op. cit., pp. 167-168 y 181. 
claro, en consecuencia, que nunca antes, ni tampoco después, se castigaron con tanta severidad los crímenes de los bandoleros moriscos.

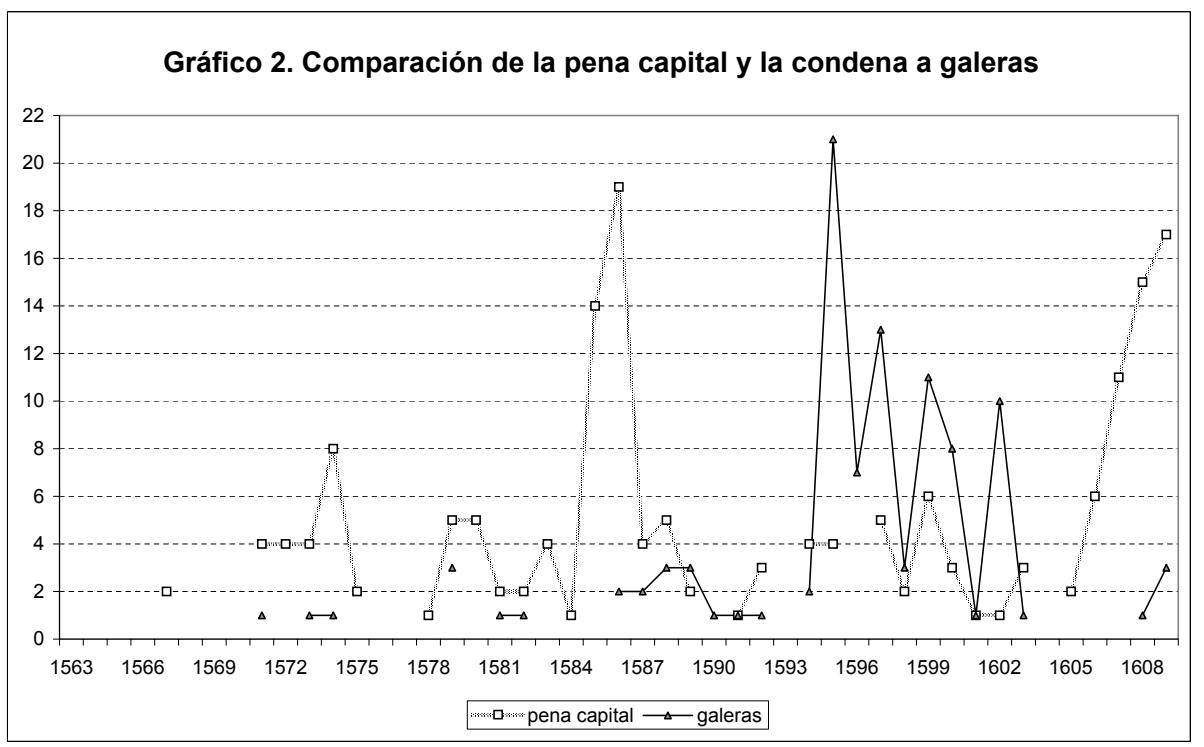

Con todo, de la dureza en la sanción no se infiere necesariamente una mayor eficacia punitiva. Según los registros de conclusiones criminales de la Audiencia, entre 1571 y 1584 fueron sentenciados 57 bandoleros moriscos, lo que da una media de 4 al año. Después de la vorágine sancionadora de 1585-1586, durante el resto del gobierno de Aytona hasta 1594 se firmaron 38 nuevas condenas de forajidos moriscos, a razón de 4,75 anuales. Pero en los tres lustros siguientes, de 1595 a 1604, la suma de sentencias contra éstos se elevó hasta 155, con un promedio de 10,3 por año, más del doble que en las etapas anteriores. No es fácil encontrar una explicación. Es posible que la querencia de Aytona hacia los métodos extrajudiciales tuviera el efecto de descargar de trabajo a los jueces de corte, falseando la verdadera dimensión de la criminalidad morisca en esos años. O tal vez el incremento de resoluciones judiciales a partir de 1595 no fuera sino el reflejo fidedigno de la multiplicación real de delitos. En cualquier caso, lo único que ahora estamos en condiciones de verificar es una marcada propensión, desde ese año hasta 1602, a castigar preferentemente las fechorías de los bandidos moriscos con el envío a galeras en detrimento de la pena de muerte predominante hasta entonces. Por qué fue así durante ese limitado período y por qué la pena capital volvió a imponerse a partir de 1605 hasta la expulsión son cuestiones que quedan abiertas. 


\begin{tabular}{|c|c|c|c|c|c|c|c|c|c|c|c|c|c|c|c|c|c|c|}
\hline نَّ & & & & & & 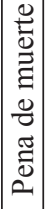 & 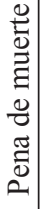 & $\begin{array}{l}0 \\
\frac{0}{0} \\
\vec{\Xi} \\
0 \\
0 \\
0 \\
0 \\
0 \\
0\end{array}$ & & & & 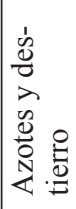 & & & & & & \\
\hline 莬 & 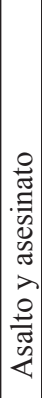 & 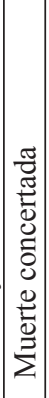 & 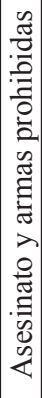 & 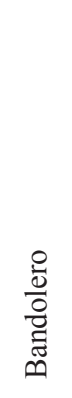 & 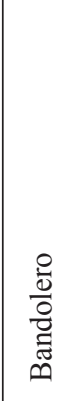 & 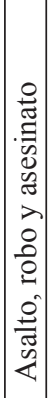 & 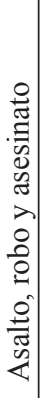 & 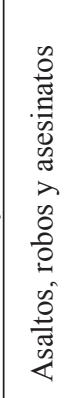 & 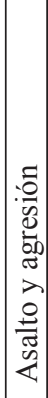 & 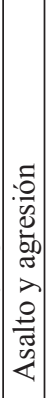 & 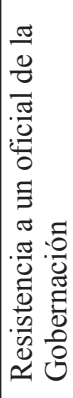 & 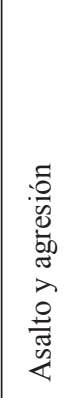 & 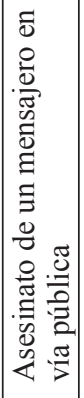 & 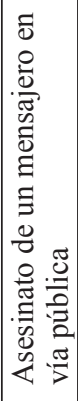 & 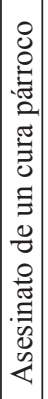 & 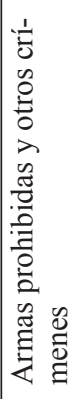 & 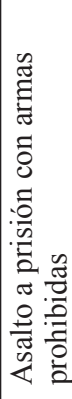 & 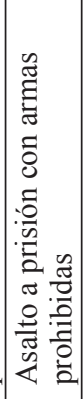 \\
\hline 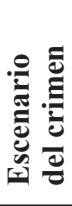 & 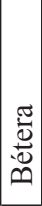 & & & 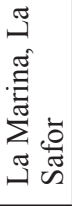 & 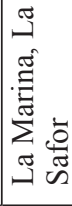 & & & & 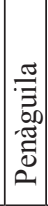 & 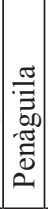 & & & $\frac{\Xi}{\frac{E}{\pi}}$ & 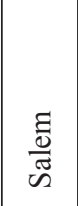 & $\stackrel{n}{\Xi}$ & & 灵 & $\Xi$ \\
\hline 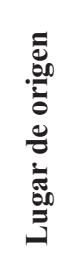 & & 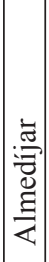 & 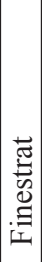 & $\begin{array}{l}: \frac{\pi}{\vec{\Xi}} \\
\stackrel{D}{\mathscr{D}}\end{array}$ & 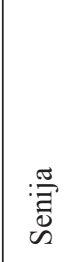 & & & & 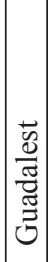 & 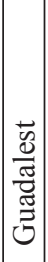 & 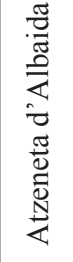 & & 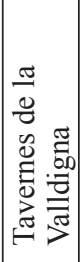 & 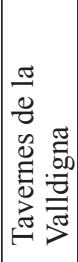 & 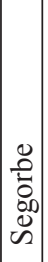 & $\begin{array}{l}\frac{\pi}{\tilde{J}} \\
\tilde{\Xi} \\
0\end{array}$ & 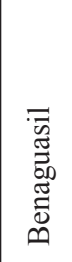 & $\begin{array}{l}\bar{\Xi} \\
\overline{0} \\
\overline{0}\end{array}$ \\
\hline Z & 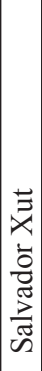 & 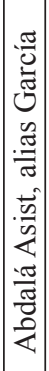 & 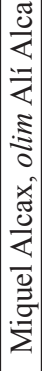 & 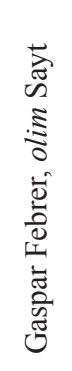 & 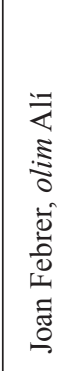 & 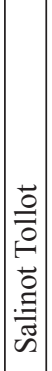 & 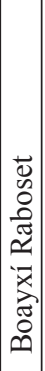 & 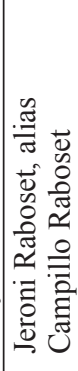 & 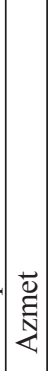 & 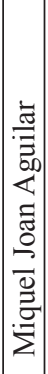 & 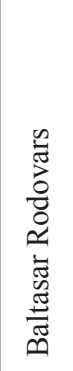 & 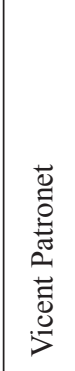 & 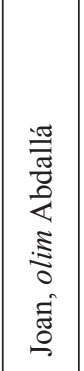 & 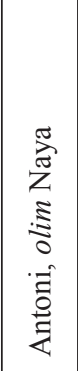 & 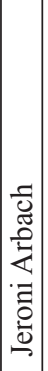 & 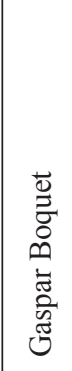 & 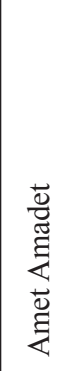 & 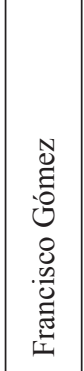 \\
\hline 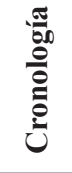 & $\stackrel{0}{2}$ & $\left|\begin{array}{l}0 \\
6 \\
n \\
-2\end{array}\right|$ & \begin{tabular}{l}
0 \\
\hdashline \\
-1
\end{tabular} & $\begin{array}{l}n \\
\curvearrowleft \\
n\end{array}$ & $\begin{array}{l}\stackrel{2}{0} \\
2 \\
\sim\end{array}$ & $\begin{array}{l}\hat{0} \\
n \\
n \\
n \\
0 \\
n \\
n\end{array}$ & $\mid \begin{array}{l}\hat{\sigma} \\
n \\
n \\
n \\
0 \\
n \\
-1\end{array}$ & 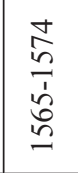 & $\mid \begin{array}{l}2 \\
0 \\
2\end{array}$ & $\mid$\begin{tabular}{l}
$\bullet$ \\
\hdashline \\
2
\end{tabular} & $\begin{array}{l}\hat{0} \\
\curvearrowleft\end{array}$ & $\begin{array}{l}\hat{\sigma} \\
\stackrel{n}{n}\end{array}$ & $\stackrel{\overbrace{}}{\circ}$ & 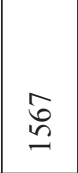 & 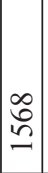 & in & ? & in \\
\hline
\end{tabular}




\begin{tabular}{|c|c|c|c|c|c|c|c|c|c|c|c|c|c|c|c|c|c|c|}
\hline$\frac{\tilde{E}}{\tilde{E}}$ & & & & & & & & & 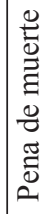 & 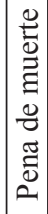 & 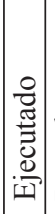 & 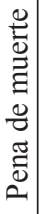 & 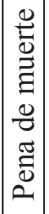 & 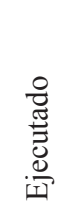 & 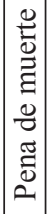 & 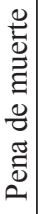 & 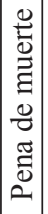 & \\
\hline$\frac{\stackrel{\mathscr{B}}{\bar{D}}}{\stackrel{0}{0}}$ & 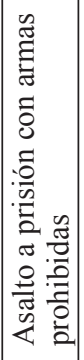 & 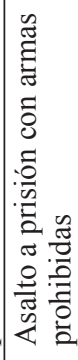 & 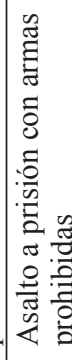 & 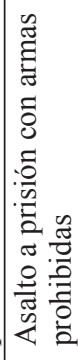 & 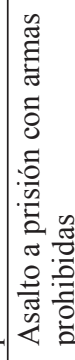 & 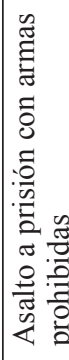 & 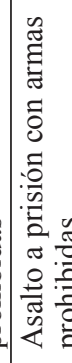 & 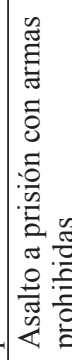 & 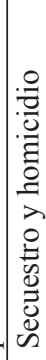 & 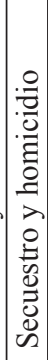 & 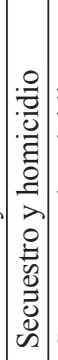 & 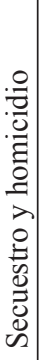 & 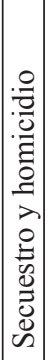 & 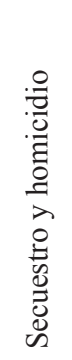 & 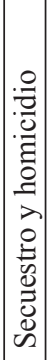 & 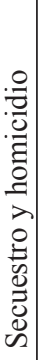 & 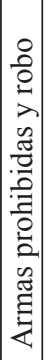 & 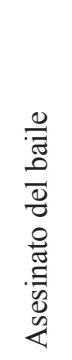 \\
\hline 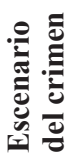 & $\Xi$ & $\Xi$ & 灵 & $\Xi$ & 灵 & 灵 & $\Xi$ & 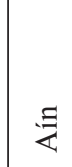 & 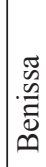 & 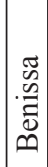 & 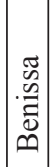 & 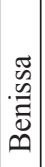 & 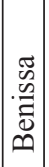 & 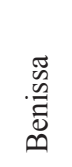 & 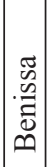 & 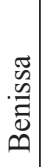 & 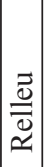 & 旡 \\
\hline 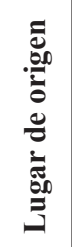 & 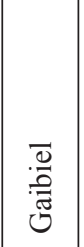 & 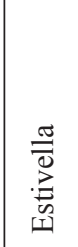 & 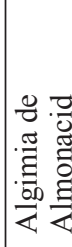 & 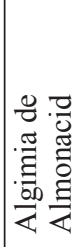 & 茜 & 芜 & 芜 & 苞 & $\begin{array}{l}: \frac{\pi}{7} \\
\stackrel{0}{0} \\
\text { n }\end{array}$ & : $: \frac{\pi}{\overrightarrow{0}}$ & 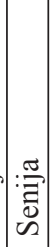 & $\begin{array}{l}: \frac{\pi}{\vec{Z}} \\
\vec{\partial} \\
\tilde{\mathscr{Z}}\end{array}$ & : & $\begin{array}{l}\dot{\bar{\delta}} \\
\stackrel{0}{\vec{\Xi}}\end{array}$ & $\mid \begin{array}{l}\tilde{0} \\
\stackrel{\Xi}{\Xi} \\
0 \\
0\end{array}$ & 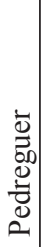 & 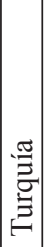 & 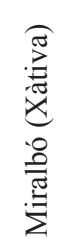 \\
\hline Ż & 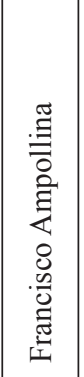 & 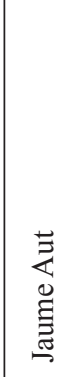 & 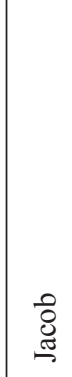 & 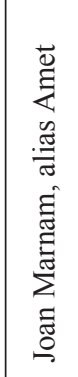 & 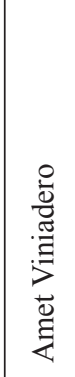 & 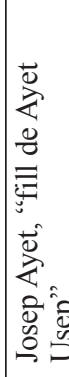 & 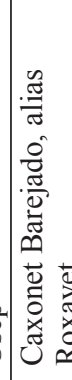 & 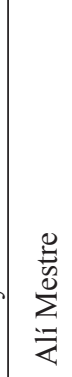 & 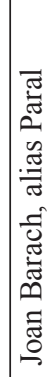 & 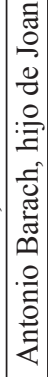 & 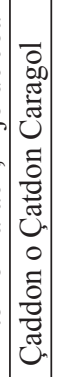 & 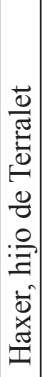 & 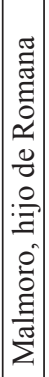 & 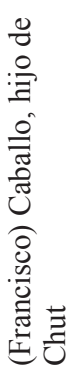 & : & 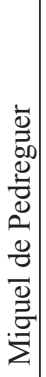 & 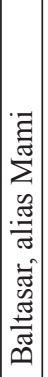 & 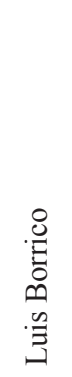 \\
\hline 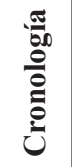 & $\stackrel{?}{i}$ & $\stackrel{?}{n}$ & $\stackrel{?}{i}$ & 召 & $\stackrel{?}{i n}$ & $\stackrel{?}{i}$ & - & $\stackrel{?}{n}$ & $\begin{array}{l}\overline{1} \\
\text { ñ }\end{array}$ & 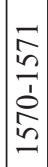 & 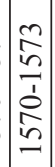 & 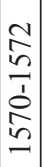 & 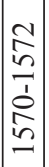 & $\begin{array}{l}\frac{N}{n} \\
\frac{1}{2} \\
\text { in }\end{array}$ & 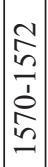 & 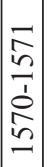 & $\vec{n}$ & in \\
\hline
\end{tabular}




\begin{tabular}{|c|c|c|c|c|c|c|c|c|c|c|c|c|c|c|}
\hline$\overbrace{0}^{\frac{\pi}{0}}$ & 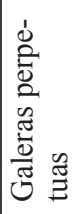 & 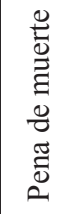 & 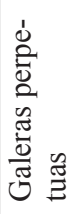 & & & & 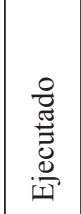 & 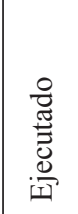 & & 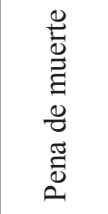 & 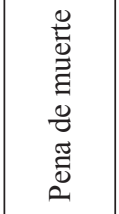 & 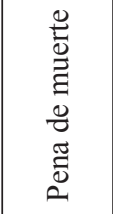 & 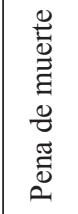 & \\
\hline$\frac{\stackrel{\theta}{\circ}}{\stackrel{0}{0}}$ & 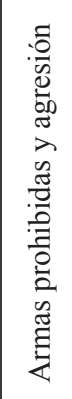 & 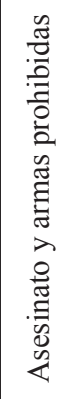 & 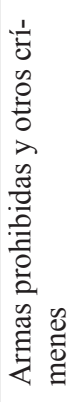 & 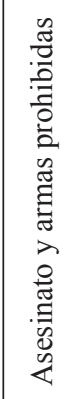 & 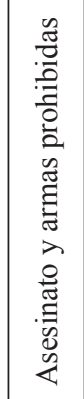 & 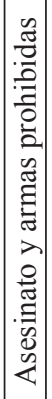 & 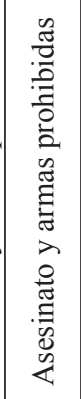 & 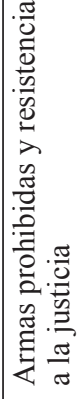 & 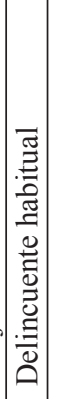 & 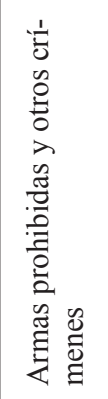 & 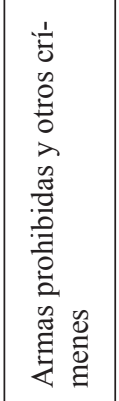 & 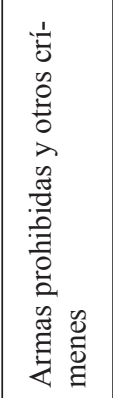 & 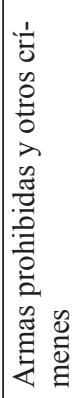 & 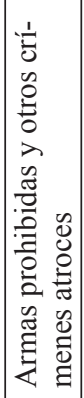 \\
\hline 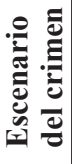 & $\frac{0}{00}$ & 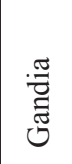 & 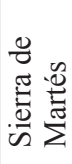 & & & & & 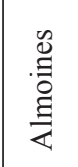 & & 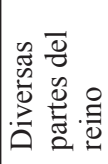 & 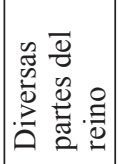 & 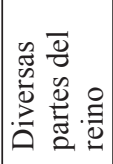 & & \\
\hline 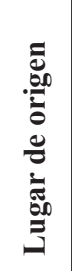 & $\frac{\overrightarrow{0}}{\overrightarrow{0}}$ & 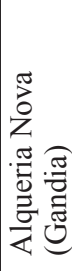 & & $\begin{array}{l}\frac{\pi}{2} \\
\substack{\pi \\
-\pi}\end{array}$ & 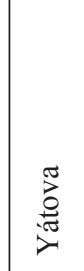 & $\left|\begin{array}{c}\tilde{\pi} \\
\overrightarrow{0} \\
-\pi \\
\nu\end{array}\right|$ & 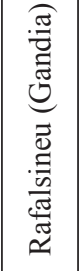 & 咅 & 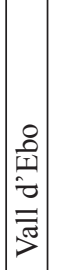 & 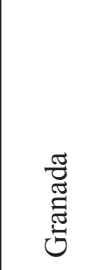 & 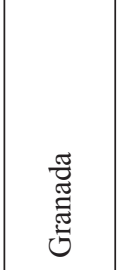 & 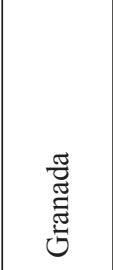 & 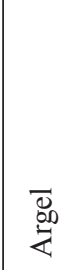 & $\frac{\vec{U}}{\bar{\Xi}}$ \\
\hline है & 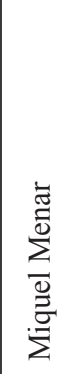 & 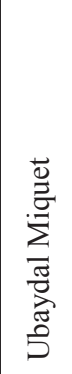 & 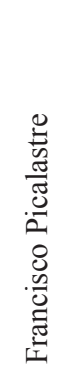 & 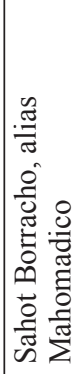 & 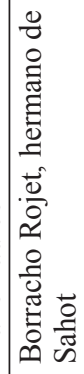 & 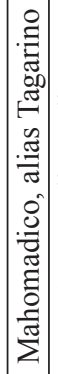 & 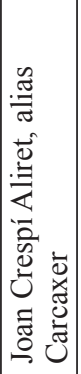 & 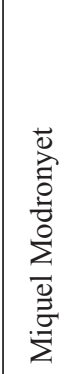 & 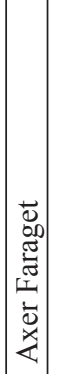 & 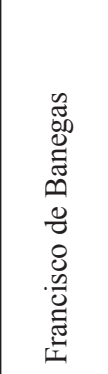 & 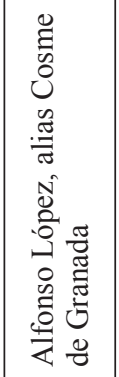 & $\begin{array}{l}\frac{\mathscr{U}}{\pi} \\
\frac{\pi}{0} \\
0 \\
0 \\
0 \\
0 \\
0 \\
\end{array}$ & $\stackrel{\vec{\Xi}}{\mathrm{E}}$ & 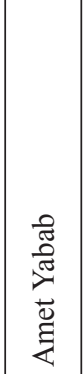 \\
\hline 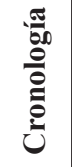 & $\stackrel{\vec{n}}{n}$ & $\stackrel{m}{n}$ & $\stackrel{n}{n}$ & $\stackrel{n}{n}$ & $\stackrel{0}{n}$ & $\tilde{n}$ & $\stackrel{n}{n}$ & $\hat{n}$ & 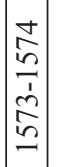 & $\underset{⿱ n}{n}$ & $\underline{n}$ & $\underset{n}{\stackrel{N}{n}}$ & $\stackrel{+}{i n}$ & $\stackrel{v}{n}$ \\
\hline
\end{tabular}




\begin{tabular}{|c|c|c|c|c|c|c|c|c|c|c|c|c|c|c|c|c|c|c|c|c|}
\hline$\frac{\pi}{\tilde{\theta}}$ & 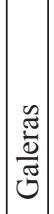 & 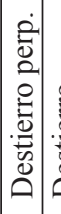 & 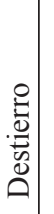 & $\begin{array}{l}0 \\
0 \\
0 \\
0 \\
0 \\
0 \\
0 \\
0 \\
0\end{array}$ & 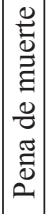 & 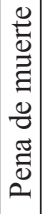 & 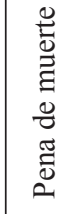 & & & & & & & & & 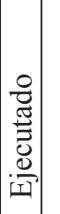 & & & & \\
\hline 总 & 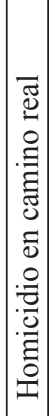 & 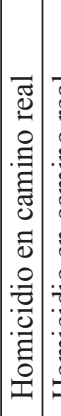 & 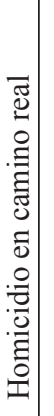 & 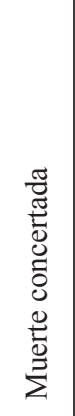 & 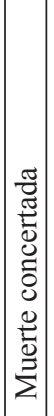 & 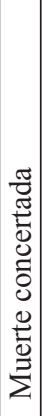 & 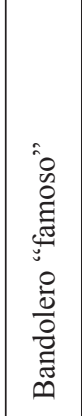 & 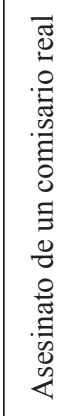 & 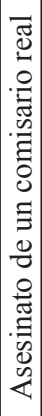 & 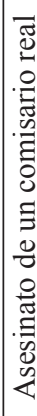 & 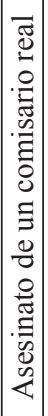 & 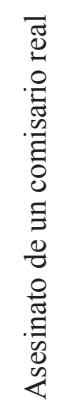 & 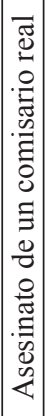 & 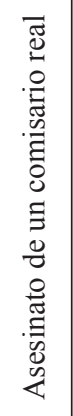 & 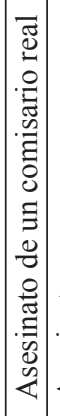 & 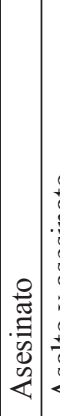 & 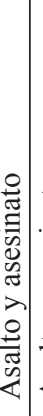 & 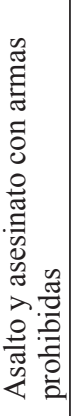 & 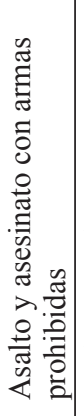 & 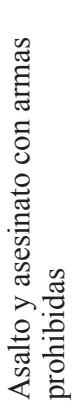 \\
\hline 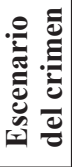 & & & & & & & 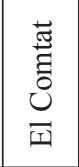 & & 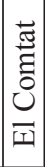 & 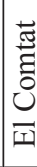 & 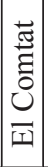 & 劳 & 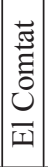 & 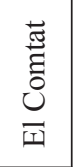 & 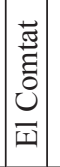 & & & 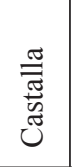 & $\begin{array}{l}\stackrel{\pi}{\pi} \\
\stackrel{\pi}{\pi} \\
\tilde{\pi} \\
\tilde{J}\end{array}$ & 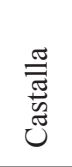 \\
\hline 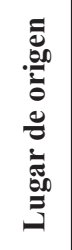 & 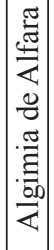 & 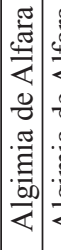 & 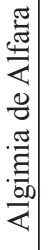 & $\begin{array}{l}\frac{\pi}{0} \\
\frac{0}{0} \\
0\end{array}$ & 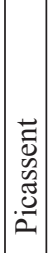 & $\begin{array}{l}\overrightarrow{0} \\
0 \\
0 \\
0 \\
\tilde{\Xi} \\
0 \\
0\end{array}$ & $\begin{array}{l}\hat{0} \\
\frac{0}{Z} \\
0 \\
0 \\
0 \\
\stackrel{0}{\Xi} \\
\sum\end{array}$ & 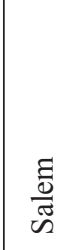 & 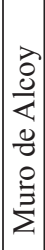 & 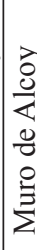 & 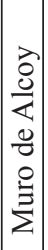 & $\begin{array}{l}\widehat{0} \\
\frac{0}{2} \\
0 \\
0 \\
0 \\
\stackrel{0}{\Xi}\end{array}$ & 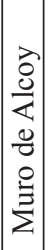 & 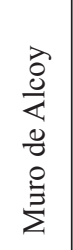 & 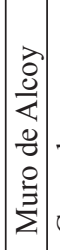 & 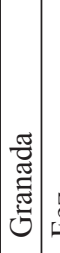 & N & $\begin{array}{l}\stackrel{0}{0} \\
\stackrel{0}{\overrightarrow{0}} \\
\stackrel{0}{0}\end{array}$ & 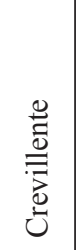 & 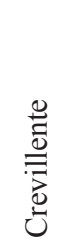 \\
\hline Zे & 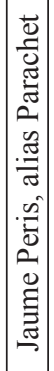 & 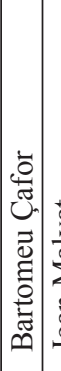 & : & 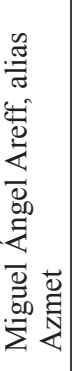 & 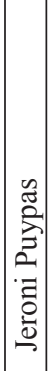 & 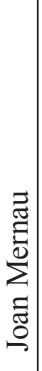 & 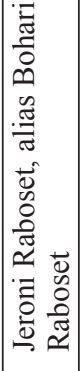 & 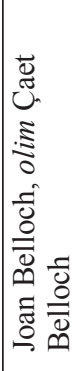 & 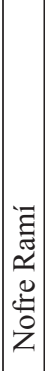 & 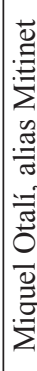 & 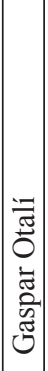 & 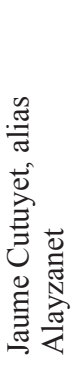 & 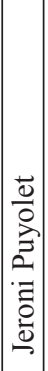 & 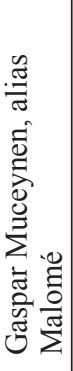 & 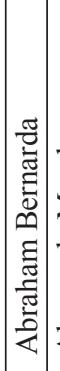 & 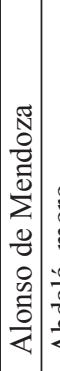 & 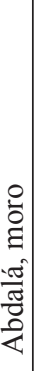 & 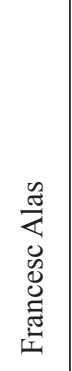 & 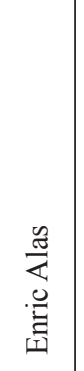 & 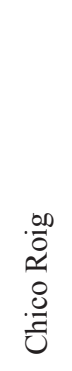 \\
\hline $\begin{array}{l}\stackrel{\frac{\pi}{60}}{0} \\
\frac{0}{0} \\
\stackrel{0}{0} \\
己\end{array}$ & 竞 & 跔 & in & $\frac{\pi}{n}$ & 齐 & $i$ & $\frac{n}{\frac{n}{n}}$ & 咅 & $\tilde{n}$ & in & $i$ & $\underline{n}$ & $i$ & $\stackrel{\mathbb{N}}{n}$ & 站 & $\begin{array}{l}n \\
i \\
n\end{array}$ & 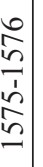 & 会 & $\hat{n}$ & in \\
\hline
\end{tabular}




\begin{tabular}{|c|c|c|c|c|c|c|c|c|c|c|}
\hline$\frac{\tilde{\Xi}}{\tilde{\Xi}}$ & & & 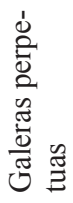 & 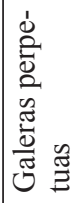 & 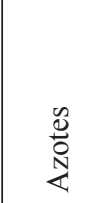 & 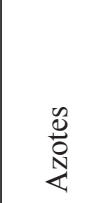 & 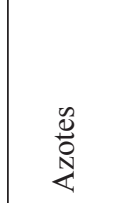 & \begin{tabular}{l}
0 \\
\multirow{0}{0}{} \\
$\dot{0}$
\end{tabular} & & \\
\hline 弟 & 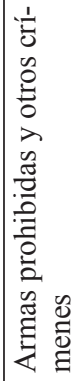 & 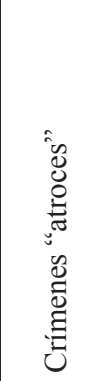 & 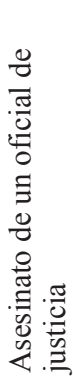 & 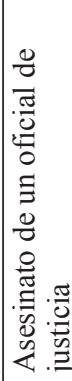 & 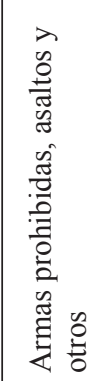 & 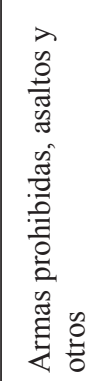 & 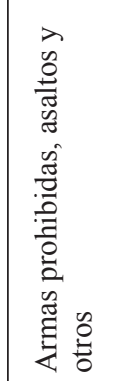 & 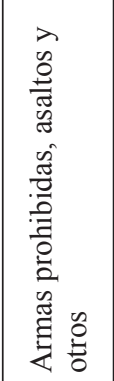 & 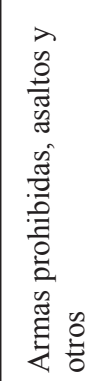 & 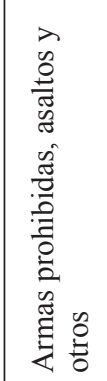 \\
\hline 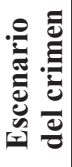 & 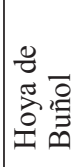 & 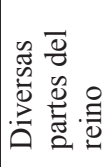 & & & 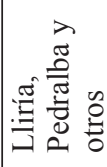 & 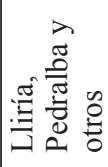 & 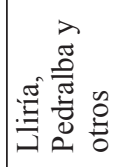 & 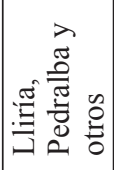 & 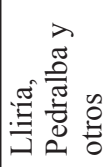 & 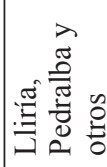 \\
\hline 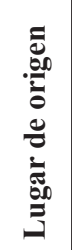 & 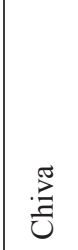 & 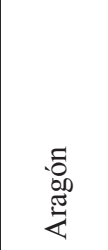 & $\frac{\overrightarrow{0}}{\stackrel{\overrightarrow{0}}{\vec{D}}}$ & $\begin{array}{l}\frac{\overrightarrow{0}}{0} \\
\overline{0} \\
\dot{\omega}\end{array}$ & $\begin{array}{l}\vec{D} \\
\dot{0}\end{array}$ & & 辤 & 辤 & $\frac{\overrightarrow{0}}{0}$ & 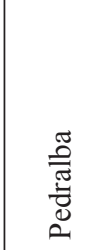 \\
\hline 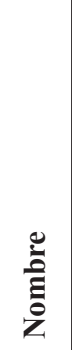 & 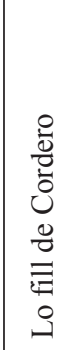 & 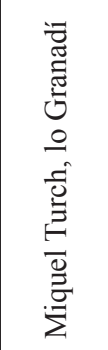 & 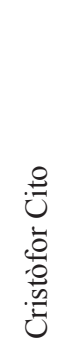 & 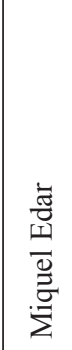 & 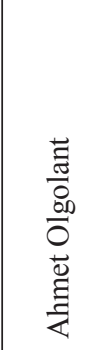 & 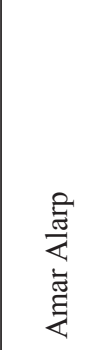 & 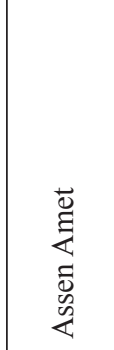 & 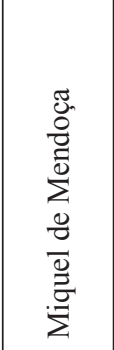 & 䎡 & 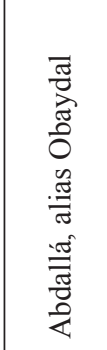 \\
\hline $\begin{array}{l}\frac{\pi}{60} \\
\frac{0}{0} \\
\frac{0}{0} \\
己 \\
0\end{array}$ & 会 & in & $\begin{array}{l}\frac{a}{n} \\
\frac{1}{n} \\
\frac{1}{n}\end{array}$ & $\begin{array}{l}\frac{2}{n} \\
\frac{1}{1} \\
\frac{\hat{n}}{n} \\
n\end{array}$ & $\begin{array}{l}\frac{\infty}{5} \\
\frac{n}{1} \\
\frac{1}{n} \\
n\end{array}$ & $\frac{\infty}{n}$ & $\frac{\substack{n \\
n \\
\frac{1}{n} \\
i n \\
n}}{n}$ & $\frac{\infty}{\frac{\infty}{n}}$ & $\begin{array}{l}\infty \\
\frac{\infty}{n} \\
\frac{1}{2} \\
i n\end{array}$ & $\frac{\infty}{\frac{\infty}{n}}$ \\
\hline
\end{tabular}




\begin{tabular}{|c|c|c|c|c|c|c|c|c|c|c|c|c|c|}
\hline ن̃ & & 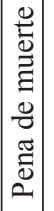 & 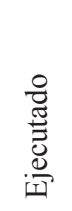 & 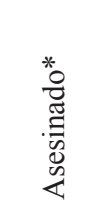 & 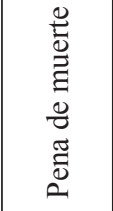 & 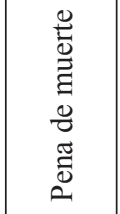 & 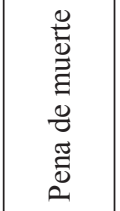 & & 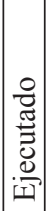 & & 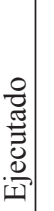 & & \\
\hline 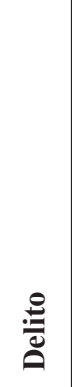 & 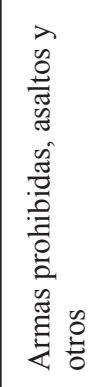 & 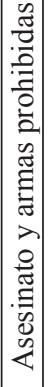 & 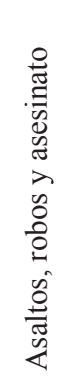 & 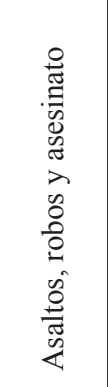 & 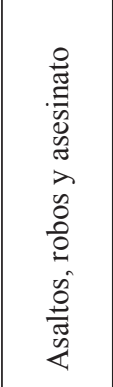 & 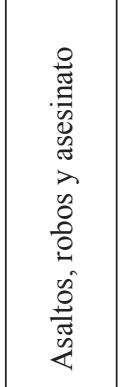 & 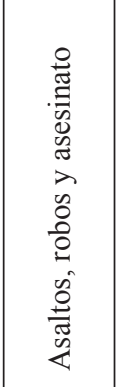 & 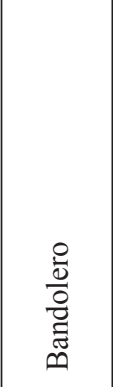 & 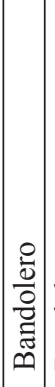 & 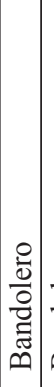 & $\begin{array}{l} \\
\\
0 \\
0 \\
0 \\
0 \\
0 \\
0 \\
0\end{array}$ & 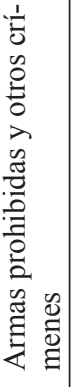 & 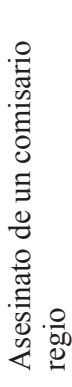 \\
\hline 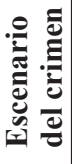 & 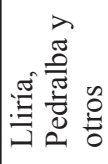 & & & 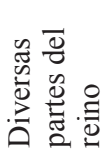 & 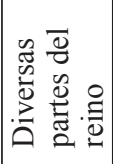 & 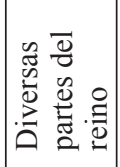 & 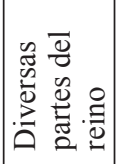 & 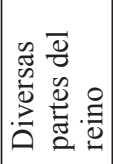 & & & & & $\begin{array}{l}\stackrel{0}{0} \\
\stackrel{0}{0} \\
8 \\
\dot{\infty} \\
\dot{\infty}\end{array}$ \\
\hline 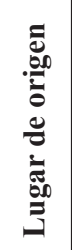 & & 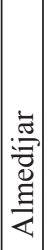 & $\overrightarrow{0}$ & 营 & 苛 & 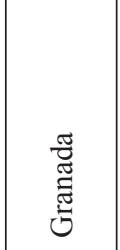 & 䔍 & 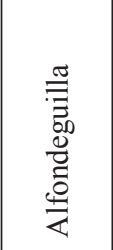 & 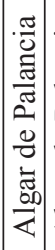 & 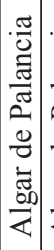 & 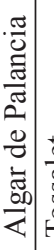 & 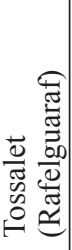 & \\
\hline $\begin{array}{l}\text { ڤ̆ } \\
\text { है } \\
\text { Zे }\end{array}$ & 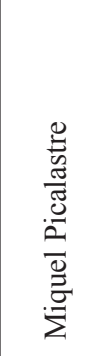 & 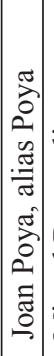 & 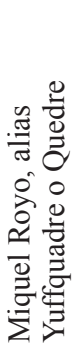 & 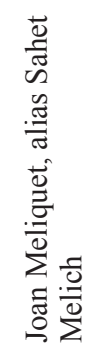 & 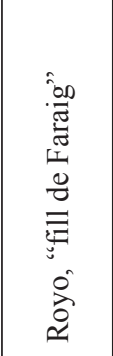 & 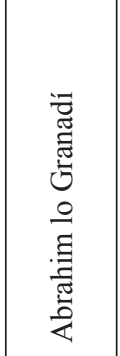 & 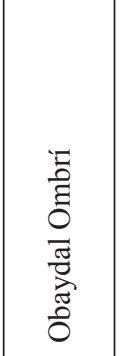 & 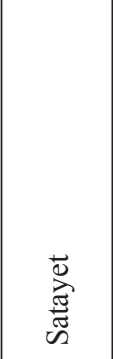 & 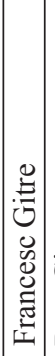 & $\mid \begin{array}{c}0 \\
0 \\
0 \\
0 \\
0 \\
0 \\
0 \\
0 .\end{array}$ & 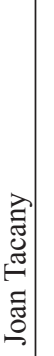 & 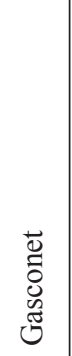 & 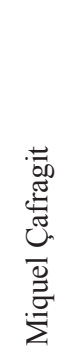 \\
\hline 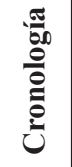 & $\begin{array}{l}\frac{\infty}{5} \\
\frac{n}{1} \\
\frac{1}{n} \\
n\end{array}$ & $\left|\begin{array}{c}n \\
\infty \\
n \\
0 \\
\infty \\
i n \\
-1\end{array}\right|$ & $\stackrel{\infty}{i n}$ & $\begin{array}{l}0 \\
n \\
n \\
\infty \\
\infty \\
n \\
n\end{array}$ & $\begin{array}{l}\frac{a}{\hat{n}} \\
\frac{1}{0} \\
\infty \\
n \\
n\end{array}$ & $\begin{array}{l}\frac{a}{n} \\
\frac{n}{1} \\
\infty \\
n \\
n \\
n\end{array}$ & $\begin{array}{l}\frac{a}{\hat{n}} \\
\frac{1}{1} \\
i \\
n \\
n\end{array}$ & 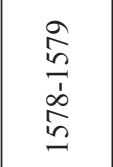 & $\begin{array}{l}2 \\
\hat{n} \\
-1\end{array} \mid$ & $\begin{array}{l}2 \\
\hat{n} \\
2\end{array}$ & مิ & in & 齐 \\
\hline
\end{tabular}




\begin{tabular}{|c|c|c|c|c|c|c|c|c|c|c|c|c|c|c|c|c|c|}
\hline نَّ & & 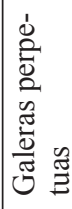 & 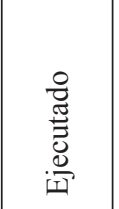 & & 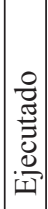 & & 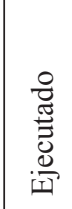 & & 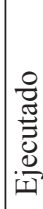 & & & & & & & & 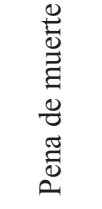 \\
\hline : & 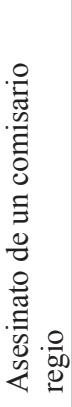 & 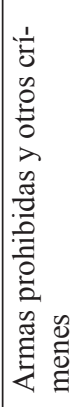 & 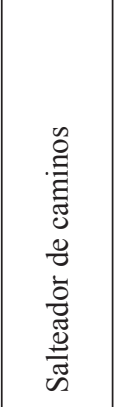 & 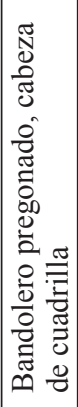 & 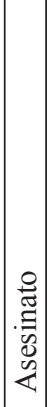 & $\begin{array}{l}0 \\
0 \\
0 \\
2\end{array}$ & 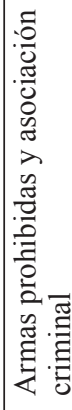 & 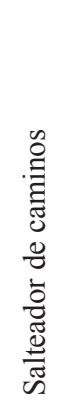 & 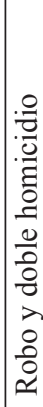 & 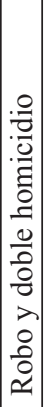 & 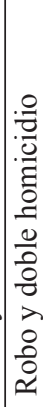 & 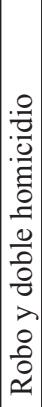 & 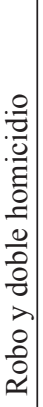 & 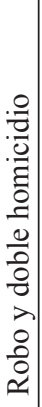 & 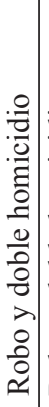 & 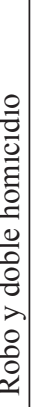 & 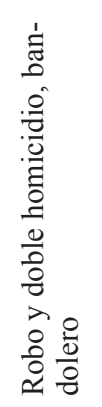 \\
\hline 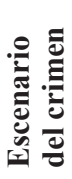 & 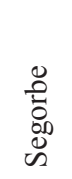 & & 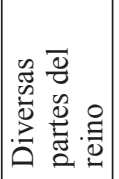 & $\begin{array}{l}\frac{\pi}{0} \\
\frac{\pi}{\pi} \\
\frac{\pi}{\pi} \\
2 \\
0 \\
\frac{0}{2}\end{array}$ & 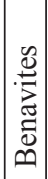 & 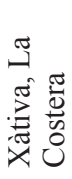 & & 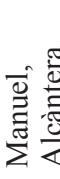 & & & & & & & & & 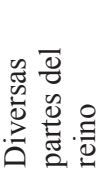 \\
\hline 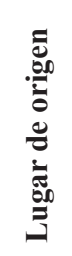 & & 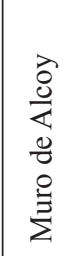 & & تี & & 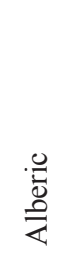 & & & 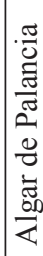 & 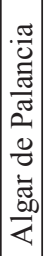 & 苞 & 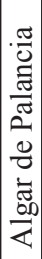 & & & & & $\begin{array}{l}\cdot \frac{\pi}{\sigma} \\
\tilde{\Xi} \\
\text { జ }\end{array}$ \\
\hline है & 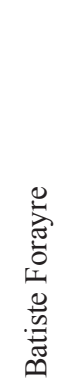 & 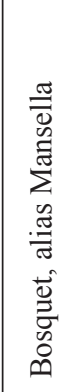 & 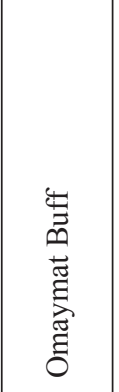 & $\begin{array}{l}\overrightarrow{0} \\
\stackrel{0}{0} \\
\stackrel{\Xi}{\Xi} \\
\mathscr{n}\end{array}$ & 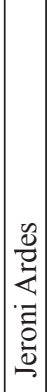 & 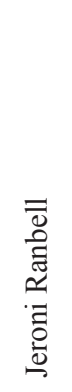 & 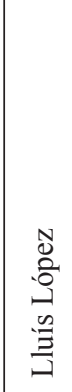 & 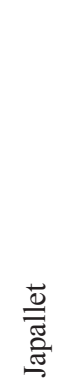 & 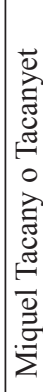 & 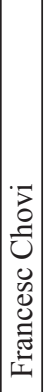 & 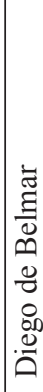 & 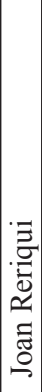 & 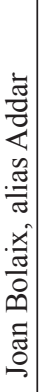 & 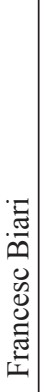 & 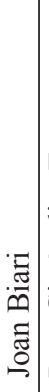 & 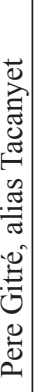 & 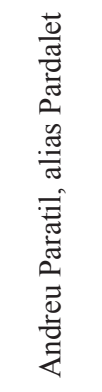 \\
\hline 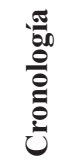 & $\stackrel{2}{n}$ & 命 & 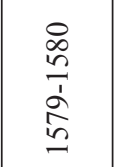 & $\begin{array}{l}0 \\
\infty \\
\frac{1}{1} \\
o \\
\text { in }\end{array}$ & $\begin{array}{l}\infty \\
2 \\
2\end{array}$ & $\begin{array}{l}\infty \\
\stackrel{\infty}{n} \\
\end{array}$ & $\begin{array}{l}\infty \\
\stackrel{0}{n} \\
\end{array}$ & 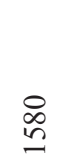 & $\begin{array}{l}\infty \\
n \\
n\end{array}$ & 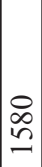 & $\begin{array}{l}\infty \\
n \\
n\end{array}$ & $\begin{array}{l}\infty \\
\infty \\
n \\
\end{array}$ & $\begin{array}{l}\infty \\
\stackrel{2}{-}\end{array}$ & \begin{tabular}{l}
$\infty$ \\
$\stackrel{2}{2}$ \\
\hdashline
\end{tabular} & $\begin{array}{l}\infty \\
\infty \\
\end{array}$ & $\begin{array}{c}\infty \\
\stackrel{\infty}{n} \\
-2\end{array}$ & $\begin{array}{l}\infty \\
\infty \\
n \\
\dot{0} \\
\infty \\
n\end{array}$ \\
\hline
\end{tabular}




\begin{tabular}{|c|c|c|c|c|c|c|c|c|c|c|c|c|c|c|}
\hline ن & & & & & & 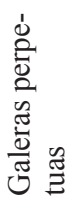 & 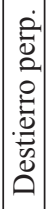 & 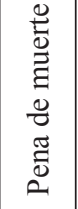 & 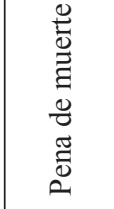 & & & 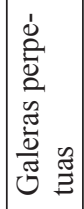 & & \\
\hline$\frac{\stackrel{\mathscr{E}}{\circ}}{\stackrel{0}{0}}$ & 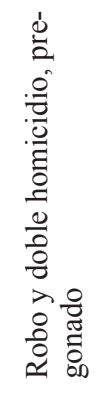 & 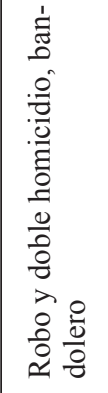 & 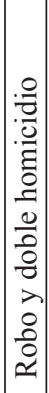 & 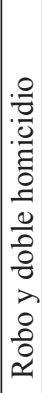 & 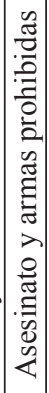 & 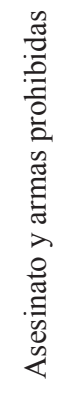 & 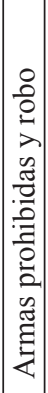 & 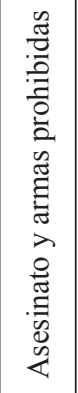 & 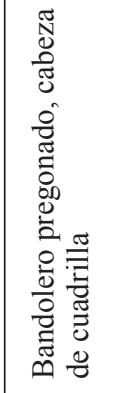 & 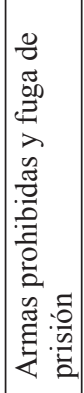 & 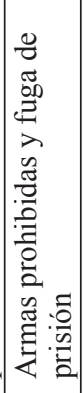 & 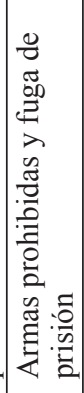 & 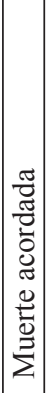 & 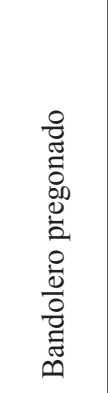 \\
\hline 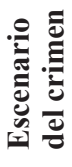 & 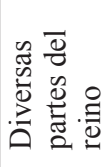 & 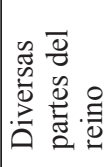 & & & & & & 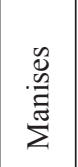 & 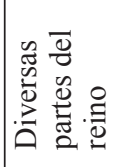 & 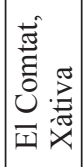 & 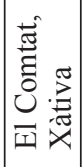 & 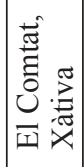 & 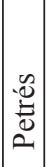 & 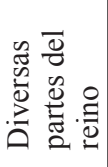 \\
\hline 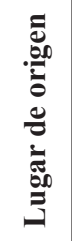 & 䒿 & 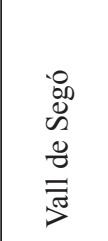 & & 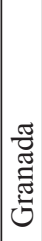 & & 营 & & & 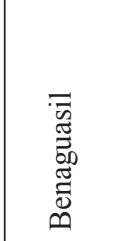 & $\begin{array}{l}\frac{\pi}{0} \\
0 \\
\overline{\bar{D}} \\
\infty \\
0\end{array}$ & 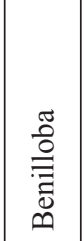 & $\begin{array}{l}\frac{\pi}{0} \\
0 \\
\overline{7} \\
\overline{0} \\
\infty\end{array}$ & & $\begin{array}{l}\frac{\pi}{\vec{d}} \\
\vec{\sigma}\end{array}$ \\
\hline Z & 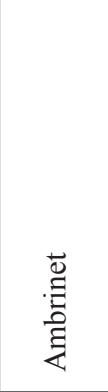 & 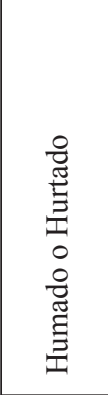 & 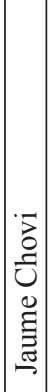 & 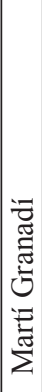 & 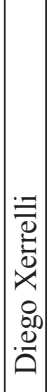 & $\begin{array}{l}\frac{0}{0} \\
\frac{0}{\Sigma} \\
\frac{0}{2} \\
\stackrel{0}{\Sigma}\end{array}$ & 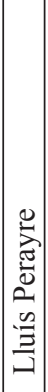 & 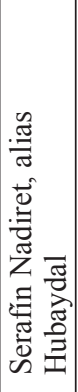 & 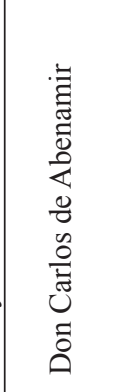 & 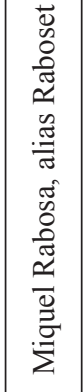 & 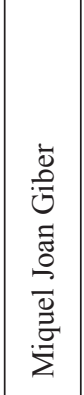 & $\begin{array}{l}\overrightarrow{0} \\
\stackrel{0}{0} \\
. \overline{0} \\
\text { : } \\
\stackrel{0}{0}\end{array}$ & 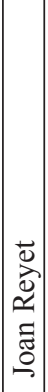 & 选 \\
\hline 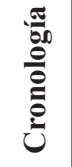 & $\begin{array}{l}0 \\
\infty \\
n \\
\vdots \\
\infty \\
\infty \\
n \\
n\end{array}$ & $\begin{array}{l}\infty \\
\stackrel{\infty}{n} \\
\vdots \\
\infty \\
n \\
n\end{array}$ & $\begin{array}{l}8 \\
\infty \\
2\end{array}$ & $\begin{array}{l}8 \\
\infty \\
2\end{array}$ & \begin{tabular}{l}
8 \\
$\infty$ \\
\hdashline \\
-
\end{tabular} & $\begin{array}{l}\bar{\infty} \\
i n \\
\vdots \\
\infty \\
n \\
n\end{array}$ & $\left|\begin{array}{l}\bar{\infty} \\
\end{array}\right|$ & $\begin{array}{l}\infty \\
n\end{array}$ & $\begin{array}{l}\infty \\
\infty \\
i n \\
\frac{1}{\infty} \\
i n \\
n\end{array}$ & $\begin{array}{l}\infty \\
\infty \\
i \\
\frac{1}{\infty} \\
n \\
n\end{array}$ & $\begin{array}{l}\infty \\
\infty \\
i n \\
\frac{1}{\infty} \\
n \\
n\end{array}$ & $\begin{array}{l}\infty \\
\infty \\
\frac{1}{1} \\
\infty \\
n\end{array}$ & $\left|\begin{array}{l}\bar{\infty} \\
\end{array}\right|$ & $\begin{array}{l}0 \\
\infty \\
n \\
\frac{1}{\infty} \\
\infty \\
n\end{array}$ \\
\hline
\end{tabular}




\begin{tabular}{|c|c|c|c|c|c|c|c|c|c|c|c|}
\hline 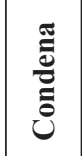 & & & & & 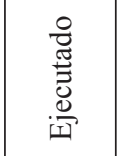 & & 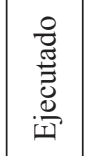 & 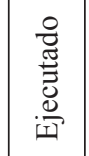 & & & \\
\hline :气̊̆ & 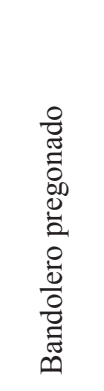 & 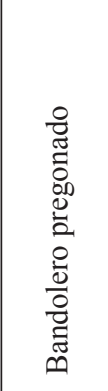 & 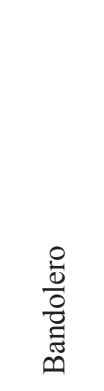 & 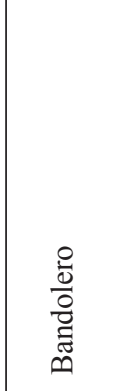 & 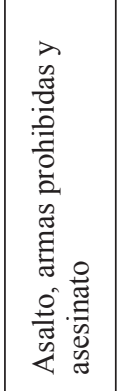 & 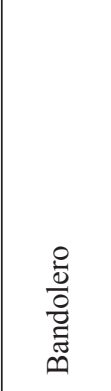 & 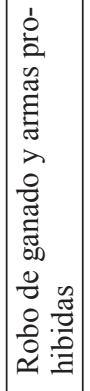 & 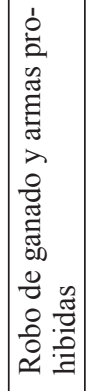 & 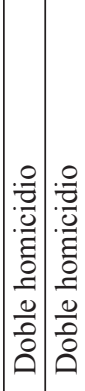 & 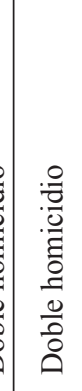 & 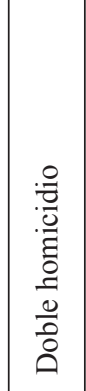 \\
\hline 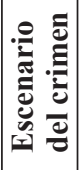 & 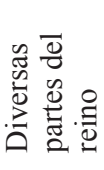 & 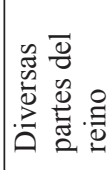 & 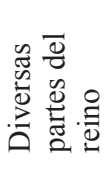 & 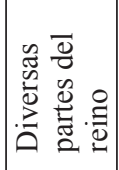 & 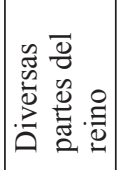 & 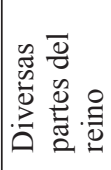 & & & 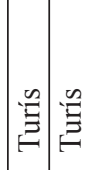 & $\stackrel{\infty}{\Xi}$ & $\stackrel{n}{\Xi}$ \\
\hline 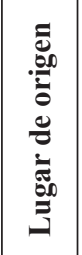 & 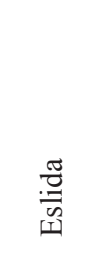 & $\begin{array}{l}\overrightarrow{0} \\
\text { n }\end{array}$ & 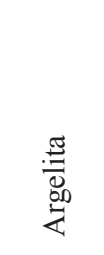 & & 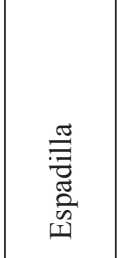 & 兽 & 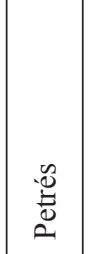 & 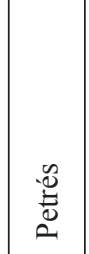 & & & \\
\hline है & 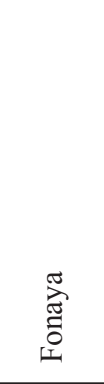 & 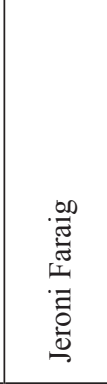 & 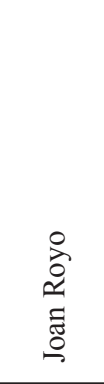 & $\begin{array}{l}\overline{7} \\
\overline{0} \\
\text { లँ }\end{array}$ & 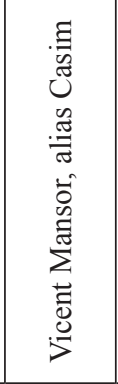 & 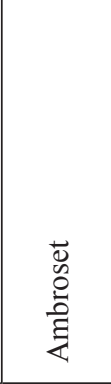 & 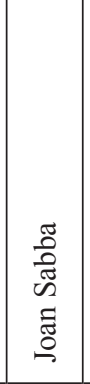 & 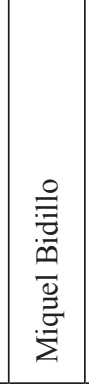 & 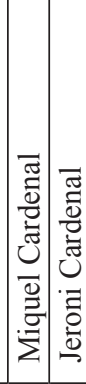 & 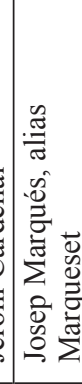 & 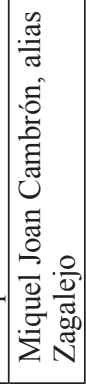 \\
\hline 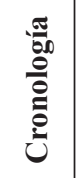 & $\begin{array}{l}n \\
\infty \\
\stackrel{1}{1} \\
\stackrel{\infty}{\infty} \\
\stackrel{n}{n}\end{array}$ & 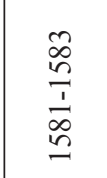 & $\begin{array}{l}\infty \\
\infty \\
n \\
1 \\
\infty \\
n \\
n\end{array}$ & $\begin{array}{l}\vec{\infty} \\
\stackrel{n}{n}\end{array}$ & $\begin{array}{l}\stackrel{n}{\infty} \\
\stackrel{n}{1} \\
\frac{1}{\infty} \\
\stackrel{n}{n}\end{array}$ & $\begin{array}{l}\vec{\infty} \\
\stackrel{n}{n}\end{array}$ & $\begin{array}{l}\tilde{N} \\
\stackrel{2}{n}\end{array}$ & $\begin{array}{l}\stackrel{\infty}{\infty} \\
\stackrel{n}{n}\end{array}$ & 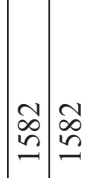 & 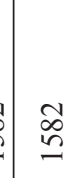 & $\begin{array}{l}\stackrel{0}{\infty} \\
\stackrel{2}{n}\end{array}$ \\
\hline
\end{tabular}




\begin{tabular}{|c|c|c|c|c|c|c|c|c|c|c|c|c|c|c|c|c|c|c|}
\hline 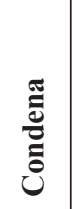 & & & 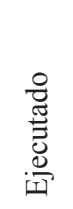 & 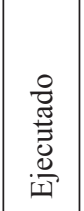 & 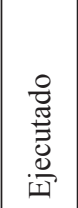 & 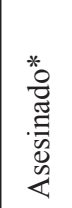 & 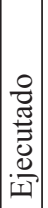 & & 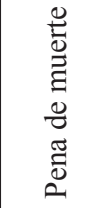 & 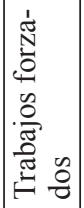 & & 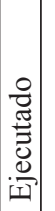 & & 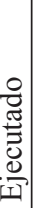 & 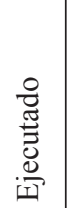 & 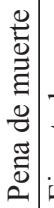 & 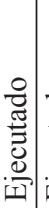 & 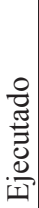 \\
\hline 莺 & $\begin{array}{l}-\frac{1}{0} \\
0 \\
0 \\
0 \\
0 \\
0 \\
2 \\
0 \\
0 \\
0 \\
0 \\
0 \\
0 \\
0 \\
0 \\
0 \\
0 \\
0 \\
0 \\
0 \\
0 \\
0 \\
0 \\
0\end{array}$ & 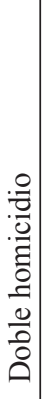 & 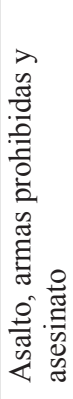 & 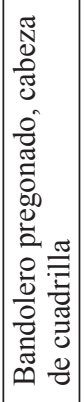 & 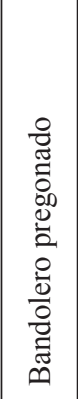 & 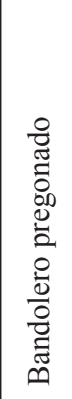 & 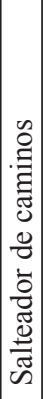 & 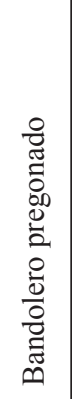 & 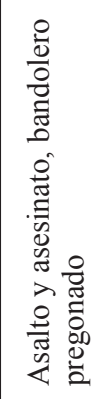 & 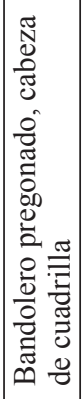 & 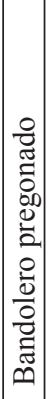 & 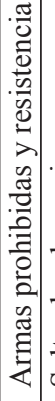 & 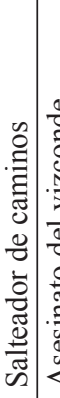 & 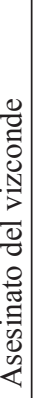 & 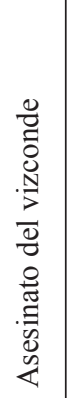 & 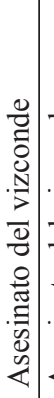 & 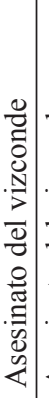 & 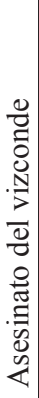 \\
\hline 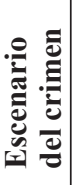 & $\stackrel{气}{\Xi}$ & 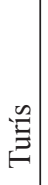 & 岕 & 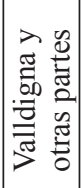 & 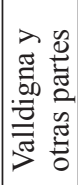 & & & 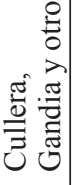 & 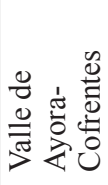 & & & & & 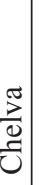 & $\frac{\stackrel{\pi}{2}}{\mathbb{0}}$ & 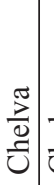 & $\begin{array}{l}\frac{\tilde{z}}{2} \\
\frac{\mathbf{z}}{0} \\
\end{array}$ & 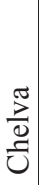 \\
\hline 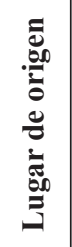 & & & & 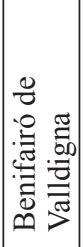 & 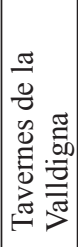 & 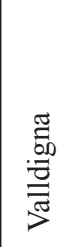 & & 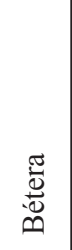 & 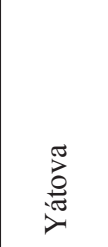 & : & 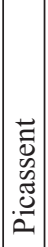 & 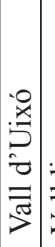 & 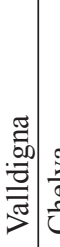 & $\begin{array}{l}\frac{\pi}{2} \\
\frac{2}{0} \\
\end{array}$ & $\begin{array}{l}\frac{\pi}{2} \\
\frac{\pi}{0}\end{array}$ & $\begin{array}{l}\frac{\pi}{2} \\
\frac{2}{0} \\
ت\end{array}$ & $\begin{array}{l}\frac{\pi}{2} \\
0 \\
\\
\end{array}$ & $\begin{array}{l}\frac{\pi}{2} \\
0 \\
\\
\end{array}$ \\
\hline $\begin{array}{l}\text { อ̆ } \\
\text { है } \\
\text { Z }\end{array}$ & 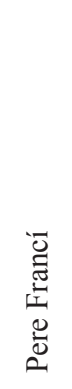 & 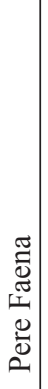 & 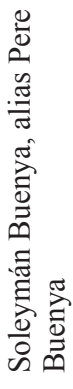 & 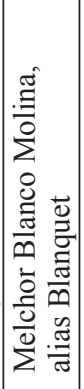 & 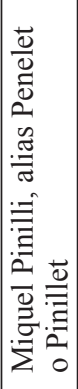 & 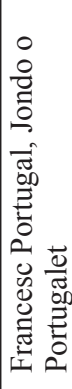 & 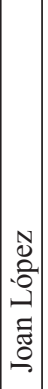 & $\underset{\Xi}{\bar{\Xi}}$ & 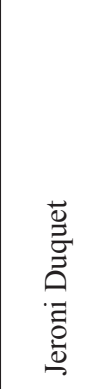 & 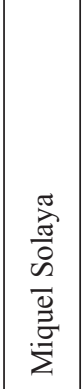 & 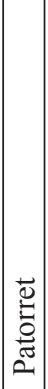 & 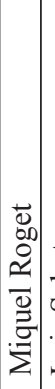 & 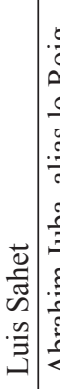 & 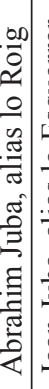 & 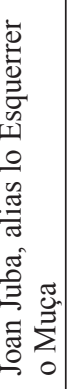 & 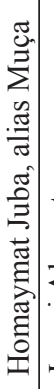 & 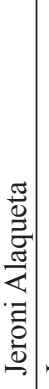 & 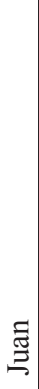 \\
\hline $\begin{array}{l}\frac{\pi}{00} \\
\frac{0}{0} \\
\frac{0}{0} \\
己 \\
0\end{array}$ & $\begin{array}{l}n \\
\infty \\
n \\
\\
\infty \\
n \\
n\end{array}$ & $\begin{array}{l}\text { D } \\
2 \\
\sim\end{array}$ & $\begin{array}{l}m \\
\infty \\
n \\
\tilde{1} \\
\infty \\
n \\
n\end{array}$ & 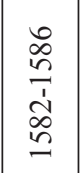 & $\begin{array}{l}\infty \\
\infty \\
n \\
\\
\infty \\
\infty \\
n\end{array}$ & $\begin{array}{l}\infty \\
\infty \\
\stackrel{n}{1} \\
\infty \\
\infty \\
n \\
n\end{array}$ & $\begin{array}{l}\infty \\
n \\
-1\end{array}$ & $\begin{array}{l}\infty \\
\infty \\
n \\
\sim\end{array}$ & $\begin{array}{l}\infty \\
\infty \\
\stackrel{n}{n} \\
\\
\infty \\
\end{array}$ & $\begin{array}{l}0 \\
\infty \\
\\
\\
\infty \\
\infty \\
n \\
n\end{array}$ & $\mid \begin{array}{l}0 \\
\infty \\
n \\
n \\
\tilde{\infty} \\
\infty \\
n \\
-1\end{array}$ & $\mid \begin{array}{l} \pm \\
\infty \\
n \\
-2\end{array}$ & 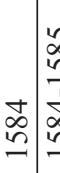 & 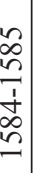 & $\begin{array}{l}n \\
\infty \\
i n \\
\dot{1} \\
\infty \\
n \\
n\end{array}$ & $\begin{array}{lll} & \\
\infty & \\
n & \\
n & \\
\dot{j} & \\
\infty & \\
n & \\
n & & \end{array}$ & $\begin{array}{l}0 \\
\infty \\
n \\
n \\
\dot{j} \\
\infty \\
n \\
n\end{array}$ & $\begin{array}{l}0 \\
\infty \\
n \\
7 \\
\dot{1} \\
\infty \\
n \\
-1\end{array}$ \\
\hline
\end{tabular}




\begin{tabular}{|c|c|c|c|c|c|c|c|c|c|c|c|c|c|c|c|}
\hline 苞 & & 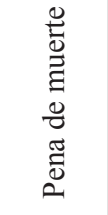 & 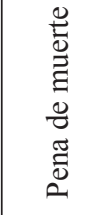 & 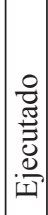 & 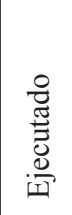 & 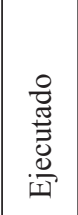 & & & & & 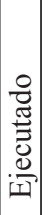 & 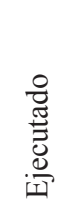 & 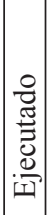 & 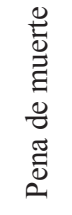 & 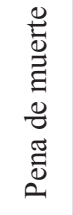 \\
\hline 莬 & 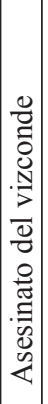 & 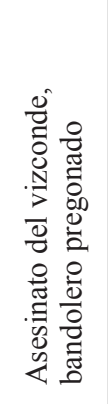 & 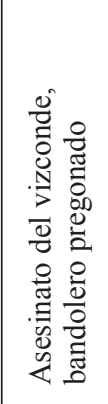 & 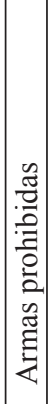 & 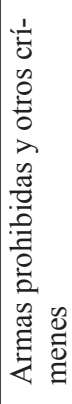 & 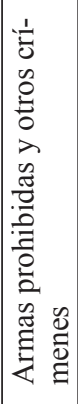 & $\begin{array}{l}0 \\
0 \\
0 \\
0 \\
2 \\
2 \\
0 \\
0 \\
\frac{0}{\pi} \\
\frac{0}{2}\end{array}$ & $\begin{array}{l}0 \\
0 \\
0 \\
0 \\
\lambda \\
0 \\
0 \\
0 \\
\frac{0}{\tilde{U}} \\
\frac{0}{4}\end{array}$ & 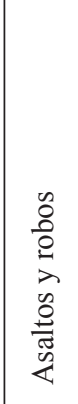 & 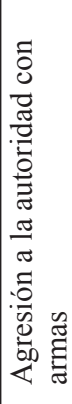 & 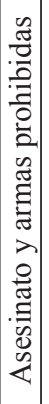 & 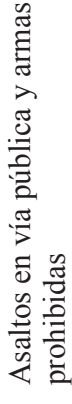 & 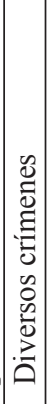 & 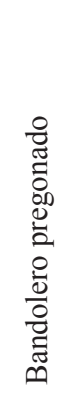 & 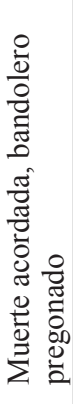 \\
\hline 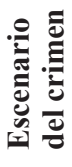 & $\mid \begin{array}{l}\frac{\pi}{2} \\
\frac{2}{0} \\
\\
\end{array}$ & 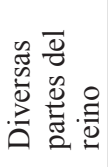 & 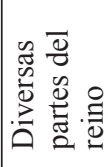 & & & & 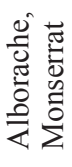 & 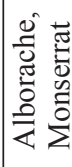 & 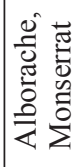 & 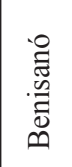 & & & & & 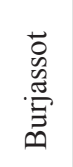 \\
\hline 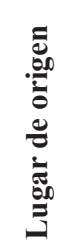 & $\begin{array}{l}\frac{\pi}{3} \\
\frac{3}{0} \\
\end{array}$ & $\frac{\stackrel{\pi}{2}}{\frac{\Xi}{U}}$ & 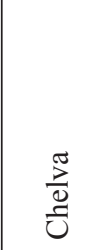 & & 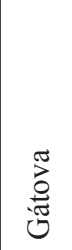 & & : & & & 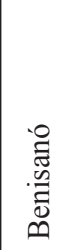 & & 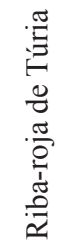 & $\mid \begin{array}{l}\bar{O} \\
\stackrel{\Xi}{\Xi} \\
\bar{D}\end{array}$ & $\frac{\sum_{0}^{\pi}}{0}$ & $\begin{array}{l}\bar{O} \\
\stackrel{\Xi}{\Xi} \\
\emptyset\end{array}$ \\
\hline Z & 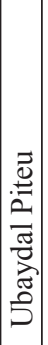 & 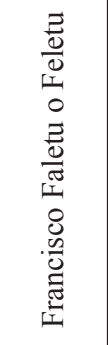 & 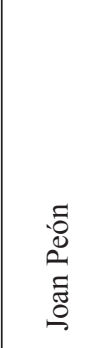 & 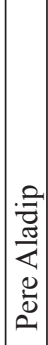 & 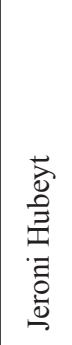 & 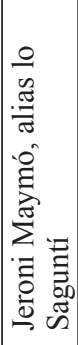 & 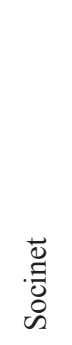 & 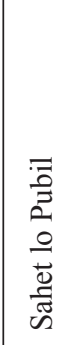 & 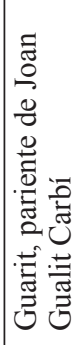 & 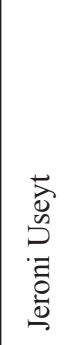 & 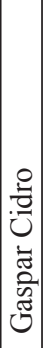 & 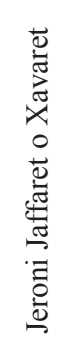 & 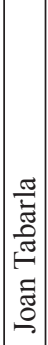 & 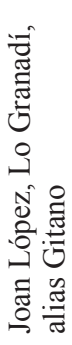 & 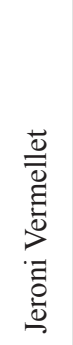 \\
\hline 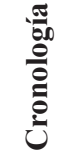 & $\mid \begin{array}{l}5 \\
\infty \\
n \\
-\end{array}$ & $\begin{array}{l}0 \\
\infty \\
i n \\
\dot{1} \\
\infty \\
n \\
n\end{array}$ & $\begin{array}{l}\infty \\
\infty \\
i n \\
\dot{1} \\
\dot{1} \\
n \\
n\end{array}$ & $\begin{array}{l}\infty \\
\infty \\
2\end{array}$ & $\begin{array}{l}2 \\
\stackrel{\infty}{n} \\
n\end{array}$ & $\begin{array}{l}n \\
\infty \\
n \\
n\end{array}$ & $\stackrel{\infty}{n}$ & $\begin{array}{l}n \\
\infty \\
n \\
n\end{array}$ & $\stackrel{\infty}{n}$ & $\begin{array}{l}n \\
\infty \\
n \\
n\end{array}$ & $\mid \begin{array}{l}n \\
\infty \\
n \\
-\end{array}$ & $\begin{array}{l}\infty \\
\infty \\
n\end{array}$ & $\begin{array}{l}n \\
\infty \\
n \\
-\end{array}$ & $\stackrel{\infty}{n}$ & $\begin{array}{l}n \\
\infty \\
n \\
n\end{array}$ \\
\hline
\end{tabular}




\begin{tabular}{|c|c|c|c|c|c|c|c|c|c|c|c|c|c|c|}
\hline 晜 & 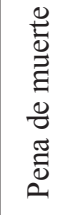 & 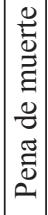 & & & & & & 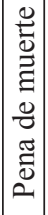 & & 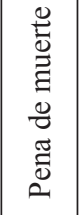 & & & & \\
\hline 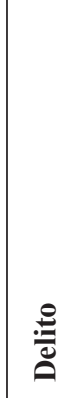 & 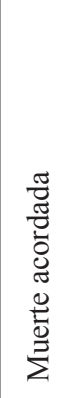 & 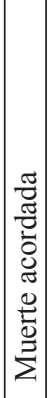 & 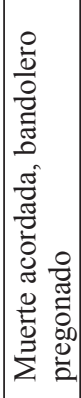 & 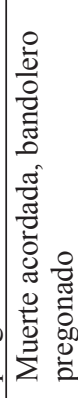 & 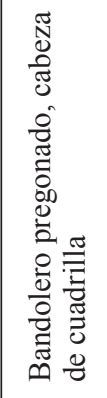 & $\begin{array}{l}\frac{0}{0} \\
\frac{0}{0} \\
\frac{0}{E} \\
\stackrel{0}{\emptyset}\end{array}$ & 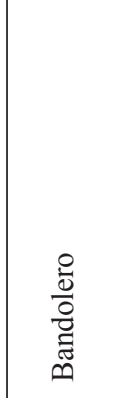 & 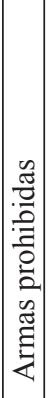 & 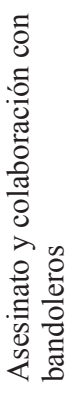 & 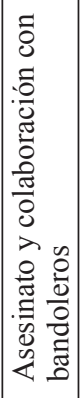 & 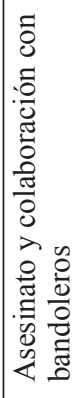 & 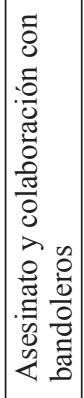 & 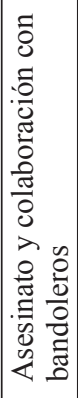 & 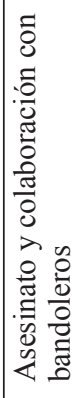 \\
\hline 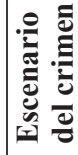 & 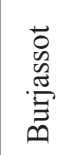 & 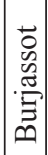 & 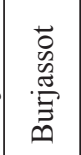 & 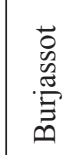 & 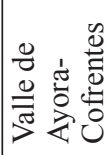 & 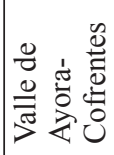 & 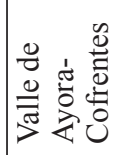 & & 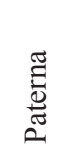 & 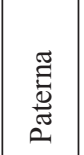 & 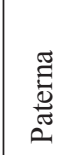 & 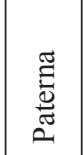 & 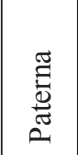 & 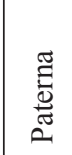 \\
\hline 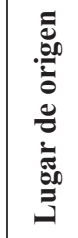 & 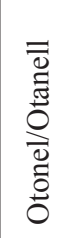 & 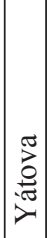 & 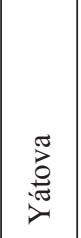 & . & 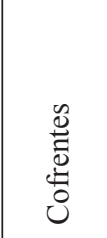 & & & : & 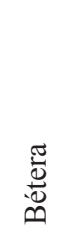 & 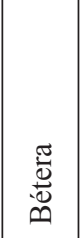 & 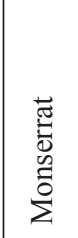 & 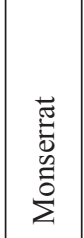 & $\begin{array}{l}\frac{0}{0} \\
\frac{\pi}{0} \\
0 \\
0\end{array}$ & 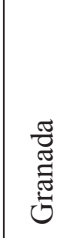 \\
\hline है & 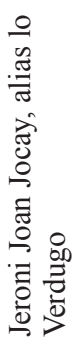 & 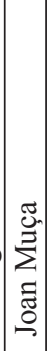 & 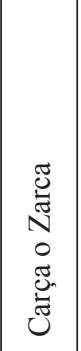 & 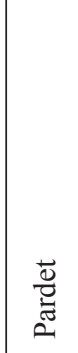 & 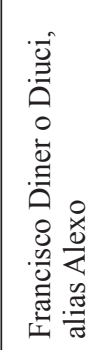 & 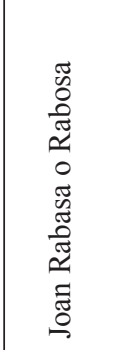 & 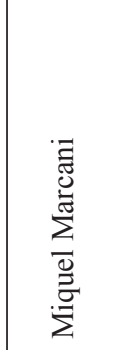 & 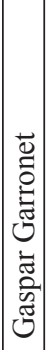 & 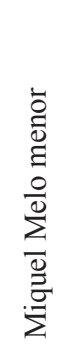 & 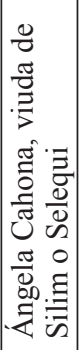 & 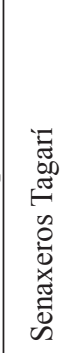 & 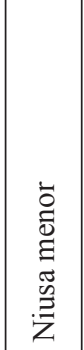 & 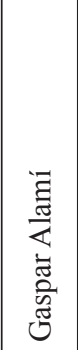 & 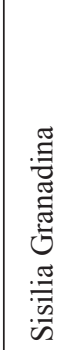 \\
\hline 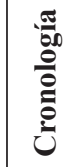 & $\begin{array}{l}n \\
\infty \\
n \\
n\end{array}$ & $\begin{array}{l}n \\
\infty \\
n \\
n\end{array}$ & $\begin{array}{l}n \\
\infty \\
n \\
n\end{array}$ & $\begin{array}{l}n \\
\infty \\
n\end{array}$ & $\begin{array}{l}0 \\
\infty \\
n \\
n \\
\infty \\
\infty \\
n\end{array}$ & $\begin{array}{l}\infty \\
\infty \\
n\end{array}$ & $\begin{array}{l}n \\
\infty \\
n\end{array}$ & $\begin{array}{l}\infty \\
\infty \\
n \\
-1\end{array}$ & $\begin{array}{l}\infty \\
\infty \\
n \\
n\end{array}$ & $\begin{array}{l}n \\
\infty \\
n\end{array}$ & $\begin{array}{l}n \\
\infty \\
n \\
n\end{array}$ & $\begin{array}{l}n \\
\infty \\
n \\
n\end{array}$ & $\begin{array}{l}\infty \\
\infty \\
n \\
n\end{array}$ & $\begin{array}{l}n \\
\infty \\
\sim\end{array}$ \\
\hline
\end{tabular}




\begin{tabular}{|c|c|c|c|c|c|c|c|c|c|c|c|c|c|}
\hline ن & & & & 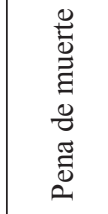 & $\begin{array}{l}\text { Ũ } \\
0 \\
\Xi \\
0 \\
0 \\
0 \\
\tilde{0} \\
0 \\
0\end{array}$ & 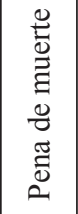 & & & & & & & \\
\hline 总 & 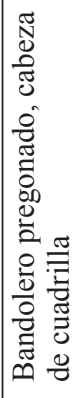 & 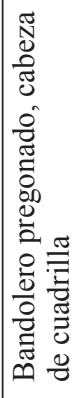 & 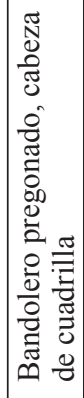 & 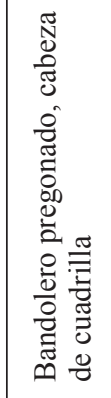 & 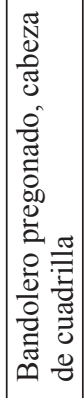 & 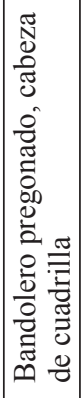 & 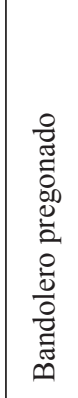 & 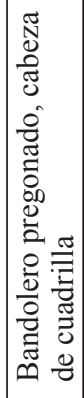 & 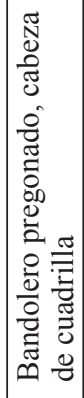 & 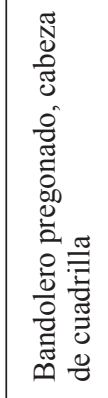 & 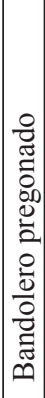 & 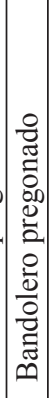 & 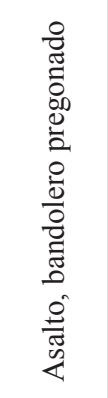 \\
\hline 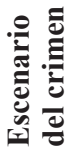 & & & & 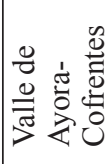 & & & & & $\begin{array}{l}\overline{0} \\
\dot{0} \\
0 \\
\overline{0} \\
\Sigma\end{array}$ & 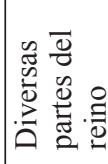 & & & 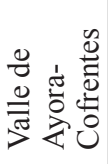 \\
\hline 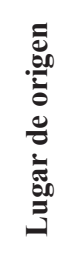 & 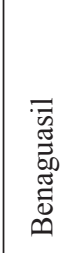 & 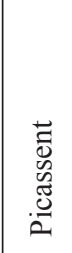 & 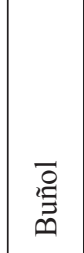 & $\stackrel{n}{\Xi}$ & $\stackrel{\tilde{\Xi}}{\Xi}$ & $\stackrel{n}{\Xi}$ & $\stackrel{\varrho}{\Xi}$ & $\begin{array}{l}\frac{\pi}{2} \\
\stackrel{0}{0} \\
\text { n }\end{array}$ & 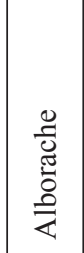 & 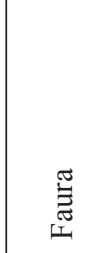 & 导 & 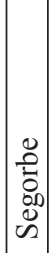 & \\
\hline Zे & 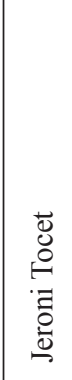 & 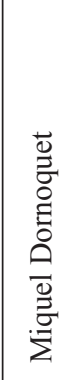 & 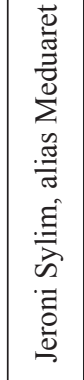 & 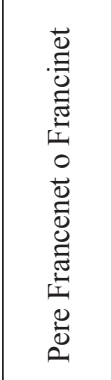 & 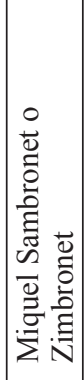 & 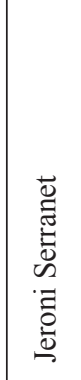 & 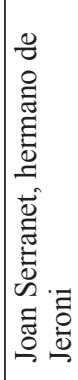 & $\begin{array}{l}3 \\
0 \\
0 \\
0 \\
0 \\
0 \\
0\end{array}$ & 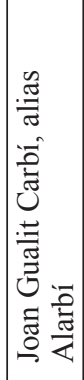 & 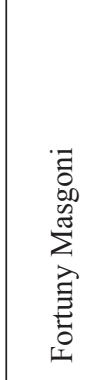 & 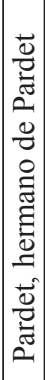 & 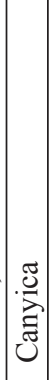 & 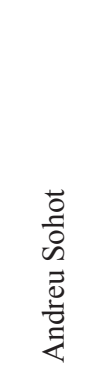 \\
\hline 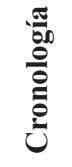 & 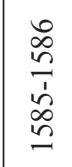 & $\begin{array}{l}\infty \\
\infty \\
n \\
1 \\
1 \\
\infty \\
n \\
n\end{array}$ & $\begin{array}{l}0 \\
\infty \\
i n \\
n \\
\infty \\
\infty \\
n \\
n\end{array}$ & $\begin{array}{l}\infty \\
\infty \\
n \\
n \\
n \\
\infty \\
n \\
n\end{array}$ & $\begin{array}{l}0 \\
\infty \\
n \\
n \\
\infty \\
\infty \\
n\end{array}$ & $\begin{array}{l}\infty \\
\infty \\
\stackrel{n}{n} \\
\dot{1} \\
\infty \\
n \\
n\end{array}$ & $\begin{array}{l}0 \\
\infty \\
n \\
n \\
\infty \\
\infty \\
n\end{array}$ & $\begin{array}{l}0 \\
\infty \\
n \\
n \\
\infty \\
\infty \\
n\end{array}$ & $\begin{array}{l}0 \\
\infty \\
n \\
n \\
\infty \\
n \\
n\end{array}$ & $\begin{array}{l}0 \\
\infty \\
n \\
n \\
\infty \\
\infty \\
n\end{array}$ & $\begin{array}{l}0 \\
\infty \\
n \\
n \\
2 \\
\infty \\
n \\
n \\
-1\end{array}$ & $\mid \begin{array}{l}0 \\
\infty \\
n \\
n \\
2 \\
\infty \\
n \\
n\end{array}$ & $\begin{array}{l}0 \\
\infty \\
n \\
1 \\
\infty \\
\infty \\
n\end{array}$ \\
\hline
\end{tabular}




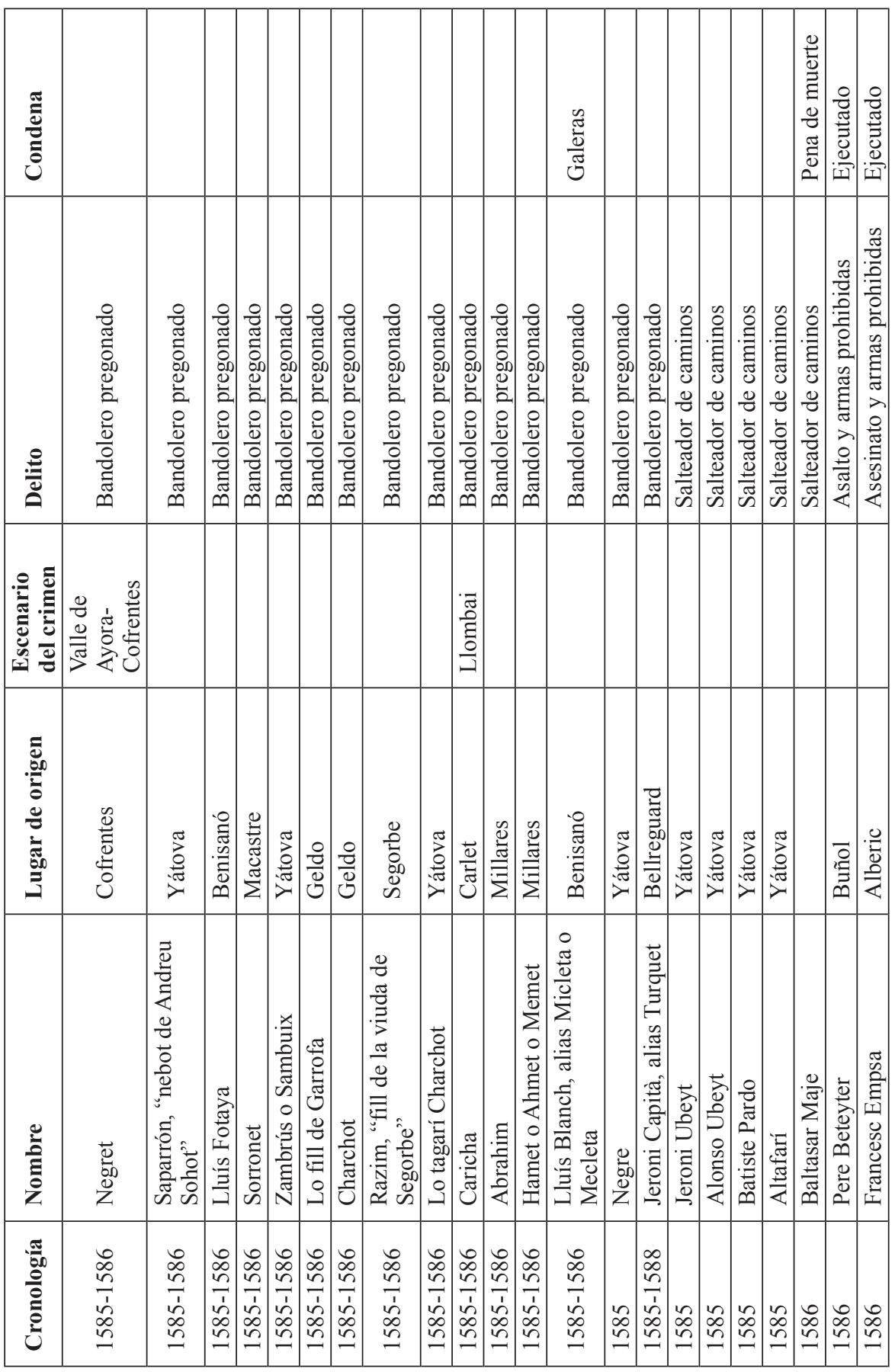




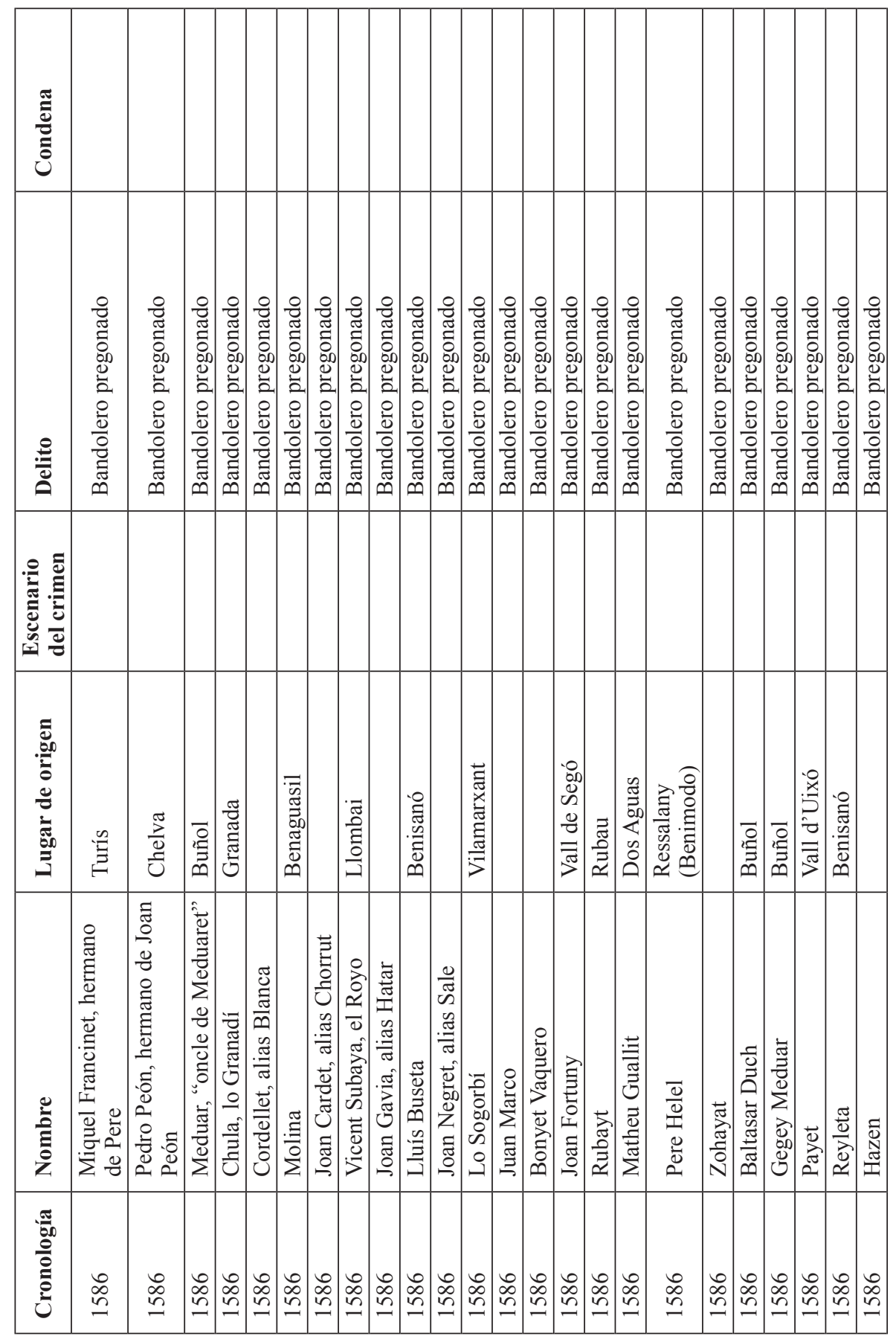




\begin{tabular}{|c|c|c|c|c|c|c|c|c|c|c|c|c|c|c|c|c|c|c|c|c|c|c|}
\hline 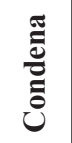 & & & & & & & & 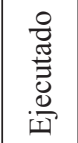 & & & & & & 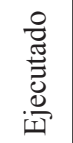 & & & & & 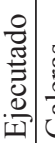 & & 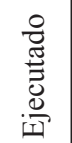 & \\
\hline 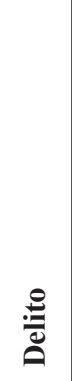 & 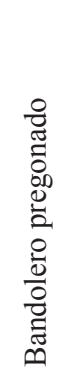 & 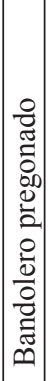 & 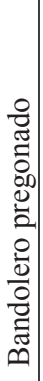 & 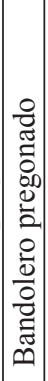 & 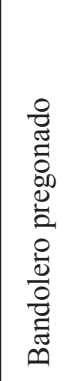 & 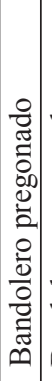 & 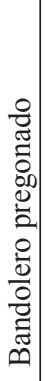 & 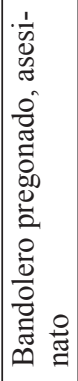 & 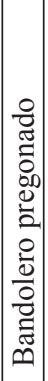 & 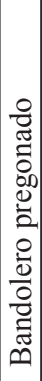 & 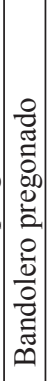 & 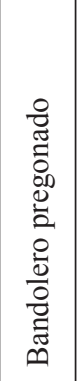 & 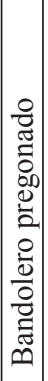 & 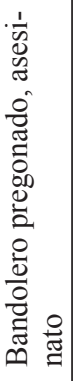 & 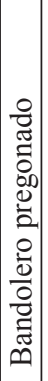 & 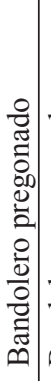 & 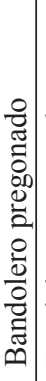 & 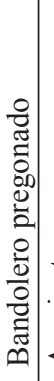 & 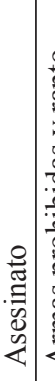 & 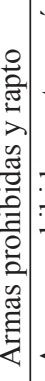 & 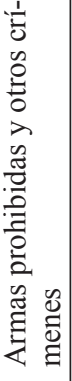 & $\begin{array}{l}0 \\
0 \\
0 \\
0 \\
\vdots \\
0 \\
0 \\
0 \\
0 \\
0 \\
0 \\
0 \\
0\end{array}$ \\
\hline 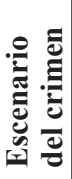 & 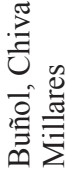 & & & & & & & & & & & & & & & & & & & & & \\
\hline 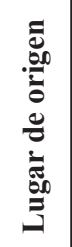 & 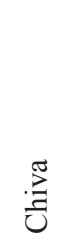 & . & 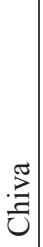 & : & 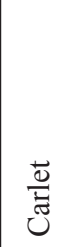 & 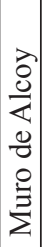 & 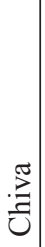 & : & 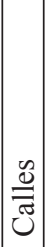 & 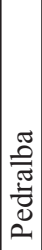 & & & 胥 & 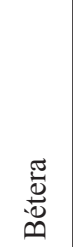 & 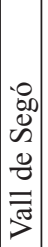 & & & 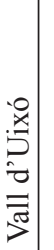 & & 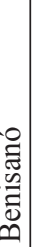 & 胥 & 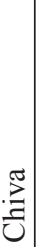 \\
\hline है & 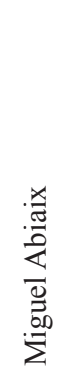 & 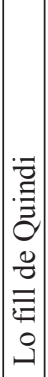 & 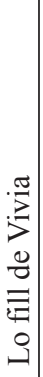 & 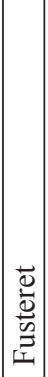 & 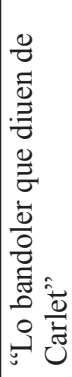 & 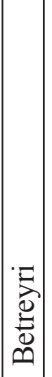 & 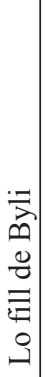 & 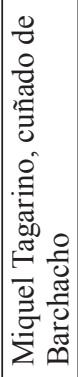 & 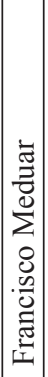 & 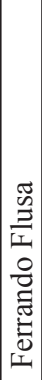 & 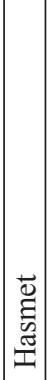 & 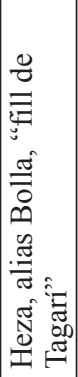 & $\stackrel{\Xi}{z}_{2}$ & 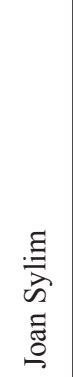 & 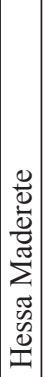 & 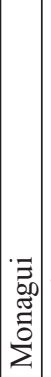 & 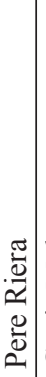 & 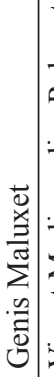 & 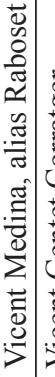 & 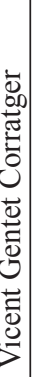 & 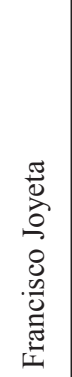 & 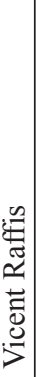 \\
\hline 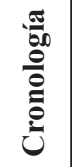 & 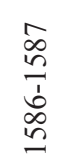 & $\begin{array}{l}0 \\
\infty \\
n \\
n\end{array}$ & 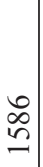 & $\begin{array}{l}0 \\
\infty \\
2 \\
-2\end{array}$ & $\begin{array}{l}\infty \\
\infty \\
\end{array}$ & $\begin{array}{l}\infty \\
\infty \\
\end{array}$ & $\begin{array}{l}\infty \\
\curvearrowleft \\
n\end{array}$ & $\begin{array}{l}\stackrel{0}{\infty} \\
\stackrel{n}{=}\end{array}$ & $\begin{array}{l}0 \\
\infty \\
\\
-\end{array}$ & $\begin{array}{l}0 \\
\infty \\
n \\
-\end{array}$ & \begin{tabular}{l}
0 \\
$\infty$ \\
\hdashline \\
$n$
\end{tabular} & 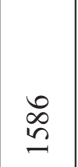 & $\begin{array}{l}\infty \\
\infty \\
n \\
-1\end{array}$ & 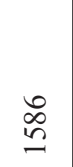 & $\mid \begin{array}{l}0 \\
\infty \\
n \\
n\end{array}$ & $\mid \begin{array}{l}0 \\
\infty \\
2 \\
-\end{array}$ & $\begin{array}{l}\infty \\
\stackrel{\infty}{n}\end{array}$ & 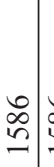 & 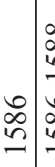 & $\begin{array}{l}\infty \\
\infty \\
n\end{array}$ & $\begin{array}{l}\infty \\
\stackrel{\infty}{n}\end{array}$ & $\begin{array}{l}\infty \\
\infty \\
\end{array}$ \\
\hline
\end{tabular}




\begin{tabular}{|c|c|c|c|c|c|c|c|c|c|c|c|c|c|c|c|c|c|}
\hline نَّ & 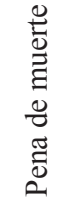 & & 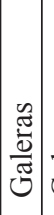 & 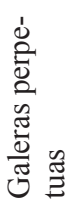 & 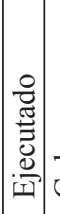 & 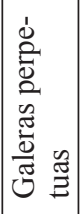 & $\begin{array}{l}\text { 苛 } \\
\stackrel{0}{\Xi} \\
0 \\
0 \\
0 \\
\tilde{0} \\
0 \\
0\end{array}$ & & 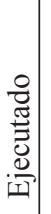 & 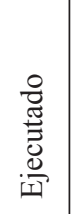 & 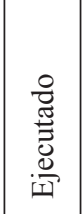 & & 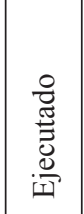 & & 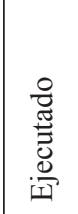 & 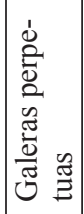 & $\frac{\tilde{J}}{\tilde{d}}$ \\
\hline 竞 & 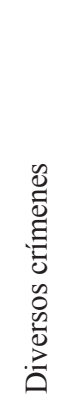 & 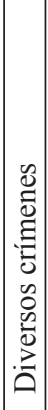 & 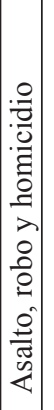 & 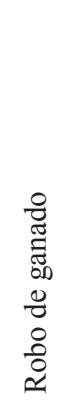 & 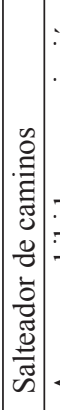 & 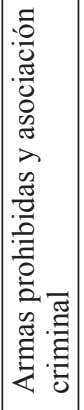 & 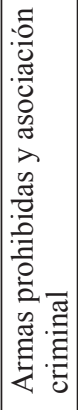 & 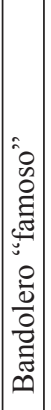 & 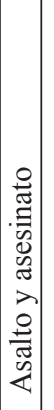 & 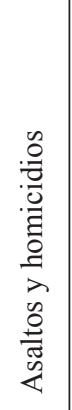 & 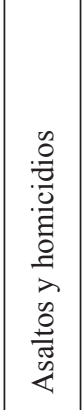 & 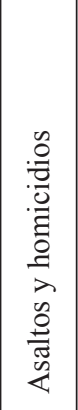 & 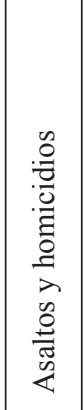 & 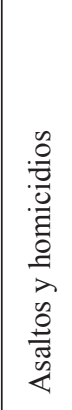 & 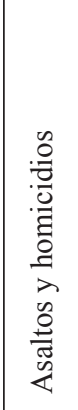 & 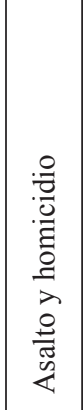 & 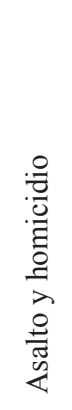 \\
\hline 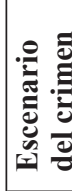 & & & & & & & & & & 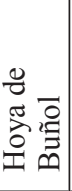 & 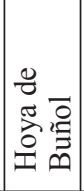 & 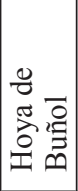 & 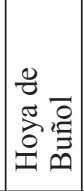 & 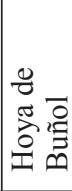 & 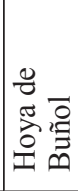 & 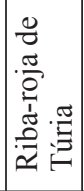 & 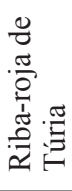 \\
\hline 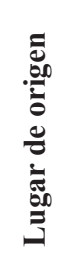 & 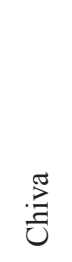 & & & 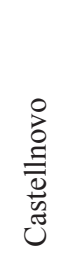 & & 疍 & & 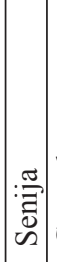 & 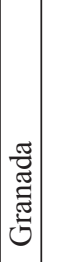 & 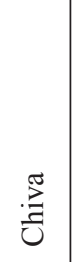 & 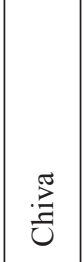 & 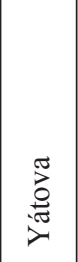 & 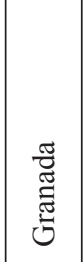 & 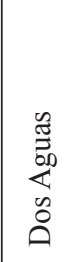 & 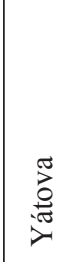 & 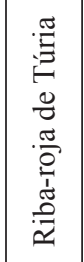 & 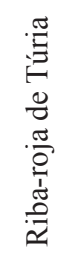 \\
\hline $\begin{array}{l}\text { ปे } \\
\text { है } \\
\text { Zे }\end{array}$ & 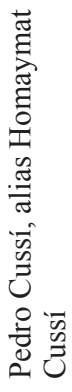 & 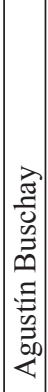 & 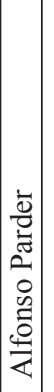 & 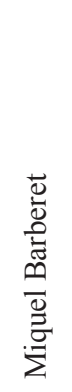 & 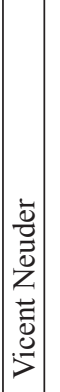 & 导 & 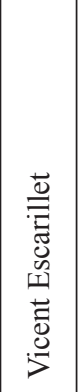 & 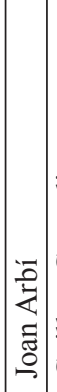 & 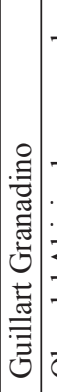 & 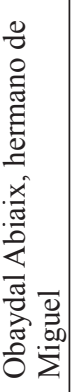 & 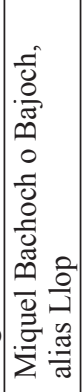 & 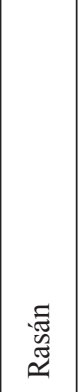 & 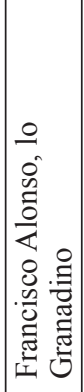 & 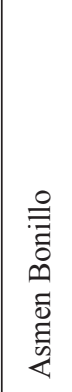 & 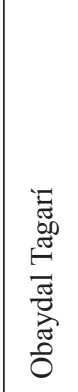 & $\begin{array}{l}\frac{\pi}{0} \\
\sum_{0}^{0} \\
\frac{\pi}{0} \\
0 \\
0 \\
0 \\
0 \\
0 \\
0 \\
0 \\
0\end{array}$ & 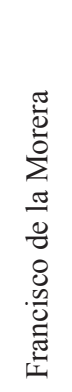 \\
\hline 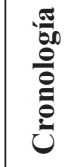 & $\begin{array}{l}\infty \\
\infty \\
n \\
n \\
b \\
\infty \\
\infty \\
n\end{array}$ & 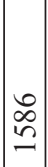 & $\left.\mid \begin{array}{l}\infty \\
\infty \\
i \\
-2\end{array}\right]$ & $\begin{array}{l}\infty \\
i n\end{array}$ & $\begin{array}{l}\infty \\
n \\
n\end{array}$ & $\begin{array}{l}\infty \\
i n\end{array}$ & $\begin{array}{l}\infty \\
\infty \\
n\end{array}$ & $\stackrel{\infty}{n}$ & $\begin{array}{l}\infty \\
n \\
-1\end{array}$ & $\begin{array}{l}\infty \\
\infty \\
i \\
\frac{1}{1} \\
\infty \\
n \\
n\end{array}$ & $\begin{array}{l}\infty \\
\infty \\
n \\
\frac{1}{1} \\
\infty \\
n \\
n\end{array}$ & $\begin{array}{l}\infty \\
\infty \\
n \\
1 \\
1 \\
\infty \\
n \\
n\end{array}$ & $\stackrel{\infty}{\infty}$ & $\begin{array}{l}\infty \\
\infty \\
n \\
1 \\
\infty \\
\infty \\
n \\
n\end{array}$ & $\stackrel{\infty}{\infty}$ & $\begin{array}{l}\infty \\
\infty \\
\stackrel{\infty}{n}\end{array}$ & $\begin{array}{l}\infty \\
\infty \\
\end{array}$ \\
\hline
\end{tabular}




\begin{tabular}{|c|c|c|c|c|c|c|c|c|c|c|c|c|c|c|c|c|c|c|}
\hline 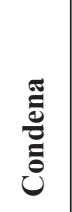 & 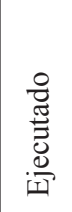 & 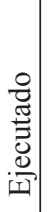 & 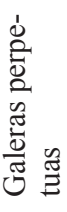 & 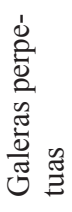 & 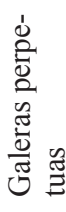 & & 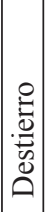 & 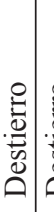 & 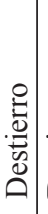 & 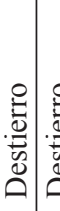 & 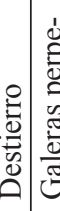 & 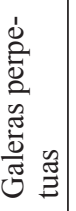 & $\begin{array}{l}\stackrel{\Xi}{0} \\
\stackrel{0}{\Xi} \\
\Xi \\
0 \\
0 \\
\tilde{0} \\
0 \\
0\end{array}$ & & 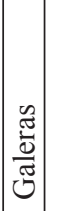 & 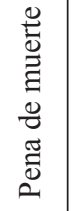 & 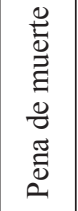 & 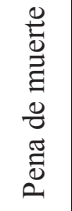 \\
\hline 竞 & 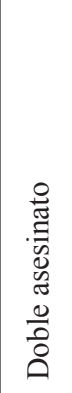 & 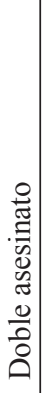 & 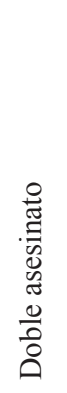 & 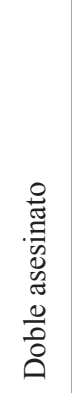 & $\begin{array}{l}0 \\
\stackrel{0}{0} \\
. \\
0 \\
0 \\
0 \\
0 \\
0 \\
0 \\
0\end{array}$ & 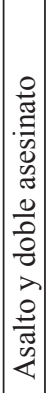 & 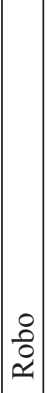 & \begin{tabular}{l}
0 \\
$\vdots$ \\
2 \\
\hdashline
\end{tabular} & 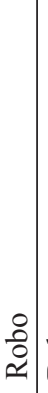 & 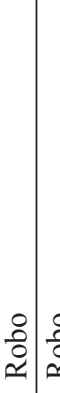 & 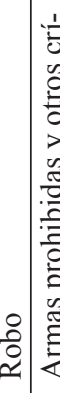 & 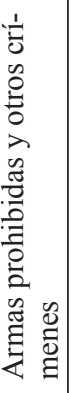 & 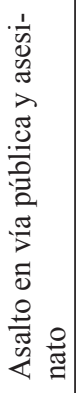 & 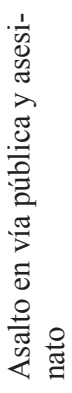 & 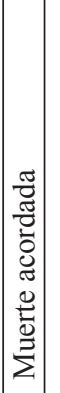 & 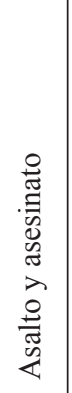 & 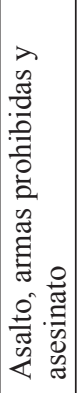 & 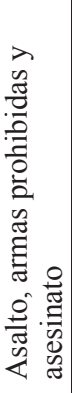 \\
\hline 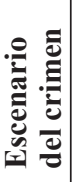 & 壼 & 言 & 壼 & 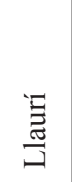 & $\begin{array}{l}\breve{\bar{\Xi}} \\
\stackrel{\Xi}{コ}\end{array}$ & & & & & & & & 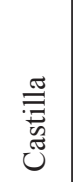 & 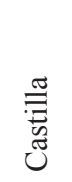 & 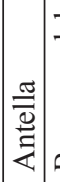 & 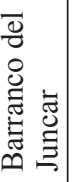 & $\begin{array}{l}\frac{0}{\pi} \\
\ddot{x} \\
0 \\
\frac{0}{\pi} \\
\bar{j}\end{array}$ & 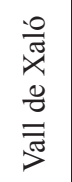 \\
\hline 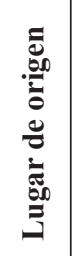 & $\begin{array}{l}\stackrel{\Xi}{\Xi} \\
\stackrel{\Xi}{コ}\end{array}$ & 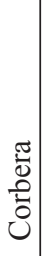 & $\begin{array}{l}\frac{\pi}{0} \\
\stackrel{0}{0} \\
0\end{array}$ & $\begin{array}{l}\frac{\pi}{0} \\
\stackrel{0}{0} \\
ن\end{array}$ & $\begin{array}{l}\frac{\pi}{0} \\
000 \\
\dot{0}\end{array}$ & 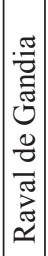 & 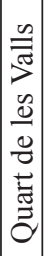 & 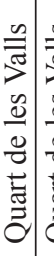 & 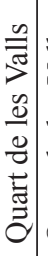 & 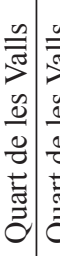 & 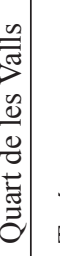 & $\stackrel{n}{\Xi}$ & $\begin{array}{l}0 \\
80 \\
\infty \\
\infty \\
0 \\
0 \\
\overline{0}\end{array}$ & $\begin{array}{l}0 \\
00 \\
0 \\
\omega \\
0 \\
0 \\
\overline{0}\end{array}$ & 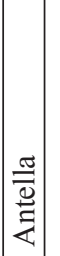 & 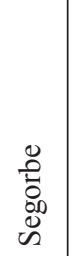 & & \\
\hline $\begin{array}{l}\text { ڤ̆ } \\
\text { है } \\
\text { है }\end{array}$ & 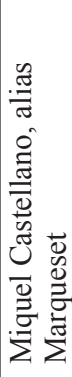 & 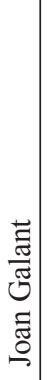 & 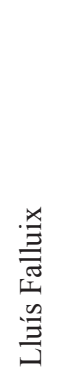 & 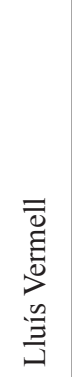 & 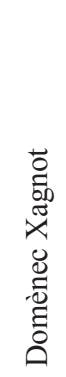 & 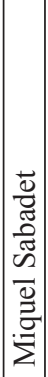 & 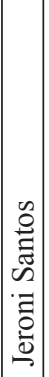 & 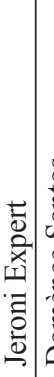 & 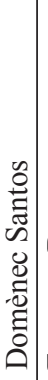 & 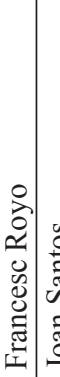 & 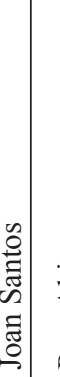 & $\begin{array}{l}: \\
0 \\
0 \\
0 \\
0 \\
0\end{array}$ & 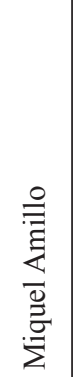 & 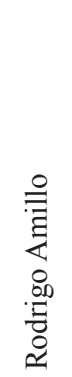 & 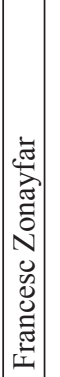 & 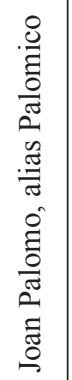 & 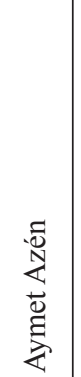 & 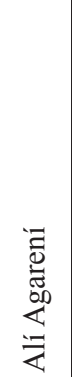 \\
\hline 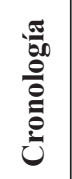 & $\begin{array}{l}\stackrel{\infty}{2} \\
\stackrel{n}{n}\end{array}$ & $\begin{array}{l}2 \\
\infty \\
n\end{array}$ & $\begin{array}{l}20 \\
\stackrel{2}{n}\end{array}$ & $\begin{array}{l}\partial े \\
\stackrel{\infty}{=}\end{array}$ & $\begin{array}{l}\text { के } \\
\text { in }\end{array}$ & $\begin{array}{l}\stackrel{\infty}{\infty} \\
2 \\
=\end{array}$ & $\begin{array}{l}8 \\
2 \\
-2\end{array}$ & 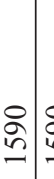 & $\begin{array}{l}\stackrel{8}{2} \\
\stackrel{n}{-1}\end{array}$ & 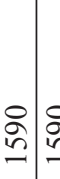 & 离 & 을 & 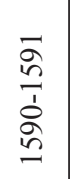 & 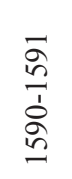 & $\overline{2}$ & ๙̃ & ๙ૂ & ๙̃ \\
\hline
\end{tabular}




\begin{tabular}{|c|c|c|c|c|c|c|c|c|c|c|c|c|c|c|c|}
\hline نَّ & $\left|\begin{array}{l}\frac{z}{\tilde{U}} \\
\frac{\tilde{J}}{\tilde{J}} \\
\tilde{J}\end{array}\right|$ & 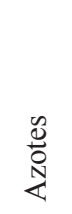 & & & 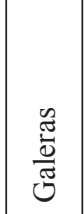 & $\frac{\pi}{\frac{\pi}{\omega}}$ & 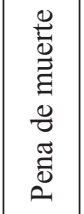 & 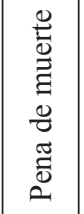 & 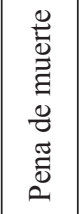 & 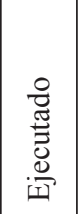 & 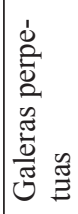 & 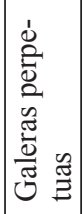 & 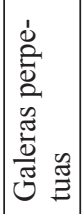 & 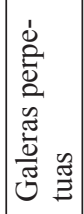 & 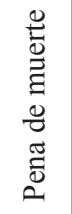 \\
\hline 苞 & 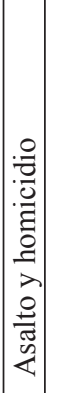 & $\begin{array}{l}8 \\
\stackrel{0}{0} \\
\stackrel{1}{1}\end{array}$ & 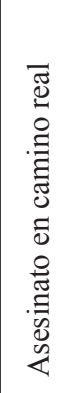 & 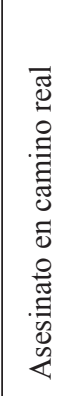 & 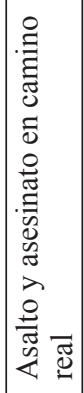 & 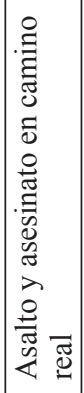 & 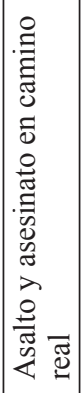 & 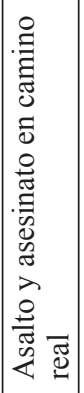 & 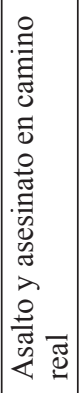 & $\begin{array}{l}8 \\
\stackrel{2}{2} \\
\simeq\end{array}$ & 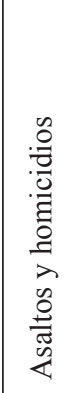 & 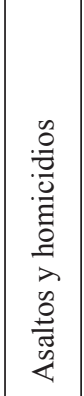 & 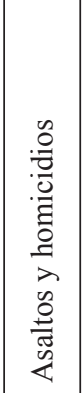 & 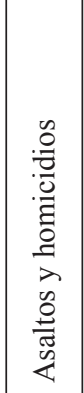 & 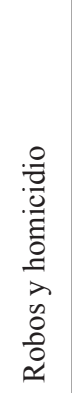 \\
\hline 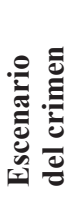 & & 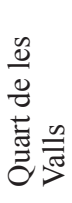 & 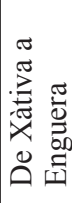 & 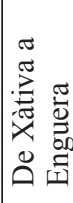 & 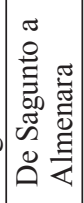 & 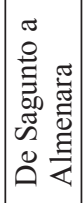 & 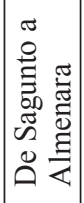 & 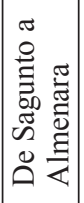 & 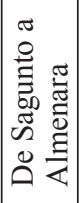 & & 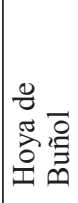 & 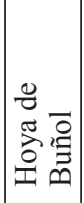 & 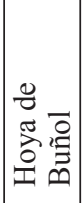 & 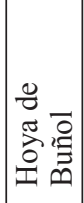 & 光 \\
\hline 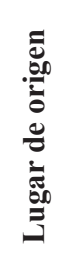 & 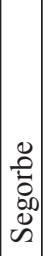 & 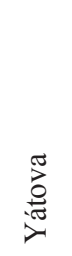 & $\frac{\sqrt[0]{0}}{=}$ & 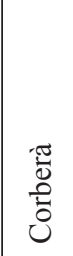 & $\begin{array}{l}0 \\
0 \\
0 \\
\infty \\
0 \\
0 \\
\bar{\Xi} \\
=\end{array}$ & 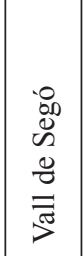 & $\frac{O}{\frac{D}{0}}$ & $\frac{O}{\frac{0}{0}}$ & 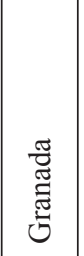 & & . & 胥 & 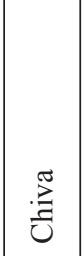 & . & 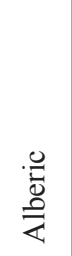 \\
\hline $\begin{array}{l}\text { D. } \\
\text { है } \\
\text { हे }\end{array}$ & 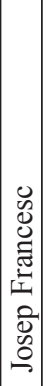 & 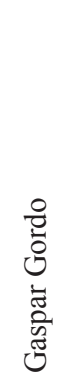 & 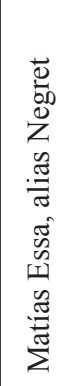 & 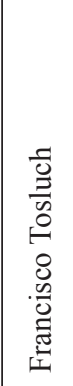 & 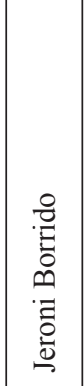 & 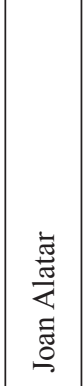 & 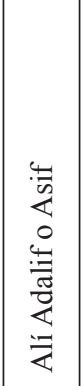 & 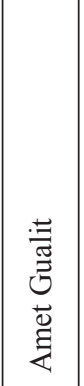 & 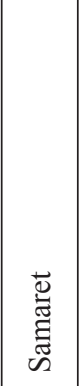 & 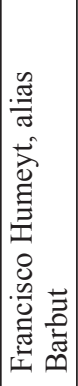 & 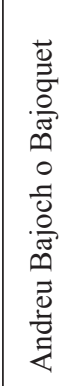 & 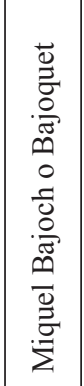 & 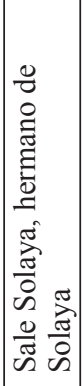 & 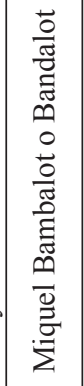 & 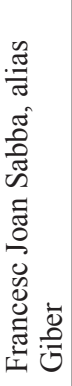 \\
\hline 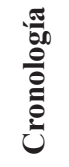 & 命 & ڤू & $\stackrel{n}{n}$ & $\hat{n}$ & $\begin{array}{l}\frac{0}{0} \\
\frac{n}{n} \\
\\
\end{array}$ & 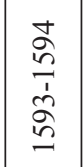 & $\frac{\Delta}{\stackrel{0}{n}}$ & $\begin{array}{l}\frac{0}{0} \\
\frac{n}{n} \\
\stackrel{2}{n}\end{array}$ & $\begin{array}{l}\frac{8}{n} \\
\frac{1}{n} \\
\\
n\end{array}$ & $\begin{array}{l} \pm \\
\stackrel{2}{n}\end{array}$ & हn & ڤn & กิ & مे & $\stackrel{n}{n}$ \\
\hline
\end{tabular}




\begin{tabular}{|c|c|c|c|c|c|c|c|c|c|c|c|c|c|c|c|c|c|c|c|c|c|c|}
\hline 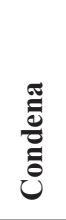 & 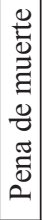 & 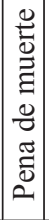 & 离 & 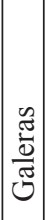 & & & & 离 & 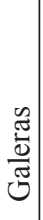 & 离 & 胥 & 离 & 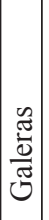 & 胥 & 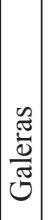 & 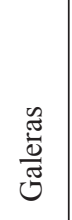 & & $\frac{\mathbb{E}}{\mathbb{U}}$ & & & 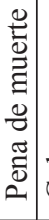 & \\
\hline 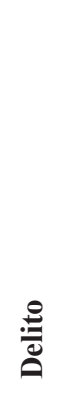 & 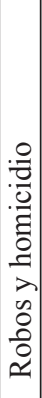 & 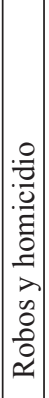 & 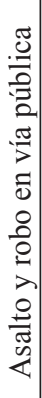 & 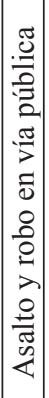 & 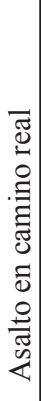 & 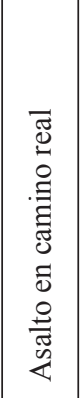 & 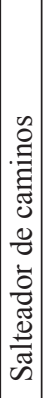 & 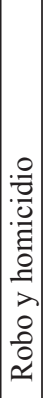 & 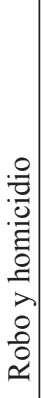 & 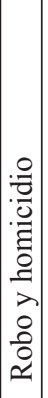 & 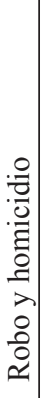 & 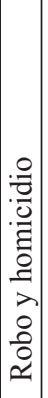 & 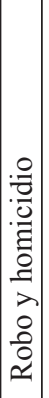 & 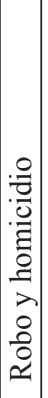 & 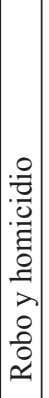 & 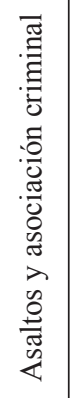 & 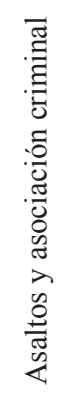 & 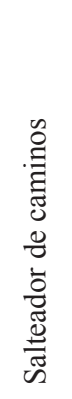 & 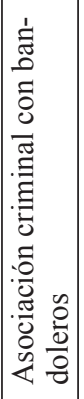 & 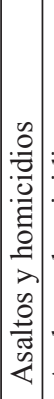 & 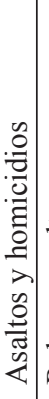 & \\
\hline 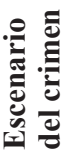 & 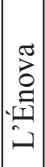 & 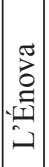 & & & 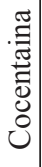 & 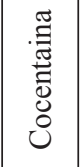 & & & & & & & & & & 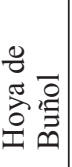 & 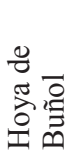 & 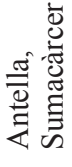 & 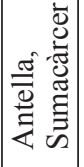 & & & \\
\hline 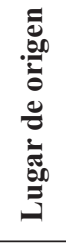 & 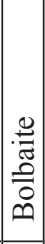 & 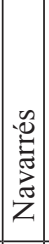 & 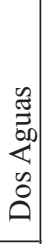 & 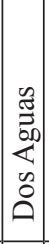 & 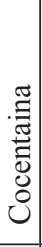 & 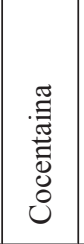 & 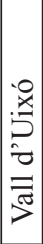 & 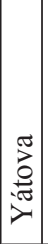 & 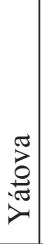 & 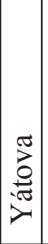 & 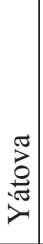 & 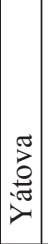 & 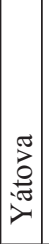 & 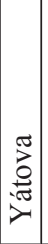 & 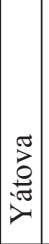 & $\stackrel{\Xi}{\Xi}$ & & 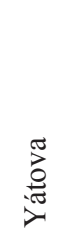 & & & 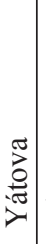 & \\
\hline 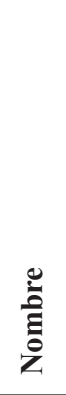 & 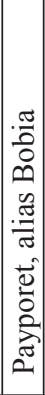 & 岕 & 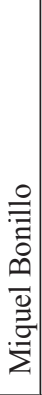 & 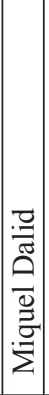 & 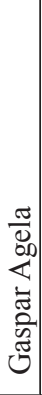 & 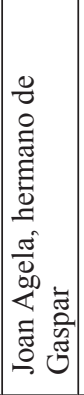 & 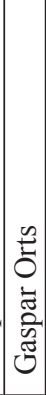 & 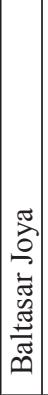 & 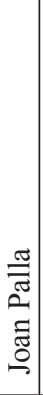 & 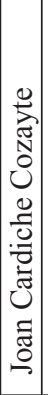 & 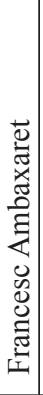 & 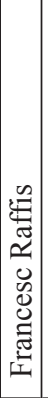 & 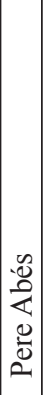 & 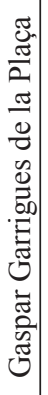 & 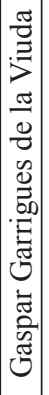 & 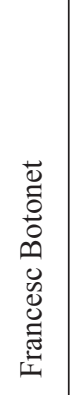 & 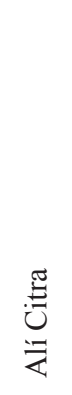 & 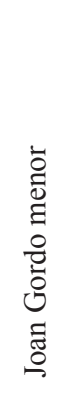 & $\stackrel{\frac{\pi}{Z}}{\Sigma}$ & 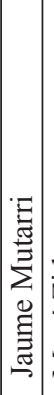 & 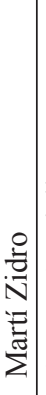 & \\
\hline 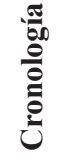 & กิ & $\begin{array}{l}2 \\
2 \\
n \\
-2\end{array}$ & $\begin{array}{l}n \\
2 \\
n \\
-2\end{array}$ & $\begin{array}{l}\dddot{2} \\
\approx \\
-2\end{array}$ & $\stackrel{2}{2}$ & $\stackrel{n}{n}$ & in & $\left|\begin{array}{l}2 \\
2 \\
n \\
-2\end{array}\right|$ & $\begin{array}{l}\check{2} \\
\approx\end{array}$ & $\mid \begin{array}{l}2 \\
\tilde{n} \\
-1\end{array}$ & $\begin{array}{l}2 \\
\approx \\
\approx\end{array}$ & $\mid \begin{array}{l}2 \\
\vdots \\
-2\end{array}$ & $\begin{array}{l}2 \\
\tilde{n} \\
-1\end{array}$ & $\begin{array}{l}2 \\
\vdots \\
-2\end{array}$ & $\mid \begin{array}{l}2 \\
\tilde{n} \\
-1\end{array}$ & $\begin{array}{l}\check{n} \\
\approx\end{array}$ & مิ & $\stackrel{2}{n}$ & $\begin{array}{l}n \\
\end{array}$ & {$\left[\begin{array}{l}2 \\
\approx \\
\approx\end{array}\right.$} & $\triangleq$ & 0 \\
\hline
\end{tabular}




\begin{tabular}{|c|c|c|c|c|c|c|c|c|c|c|c|c|c|c|}
\hline ن̃ & 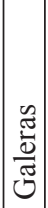 & $\frac{\tilde{\mathscr{U}}}{\mathbb{J}}$ & $\frac{\tilde{\Xi}}{\frac{\pi}{\pi}}$ & 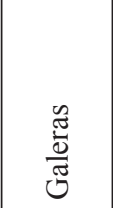 & 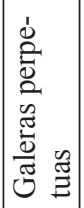 & 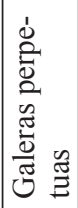 & 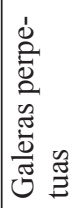 & 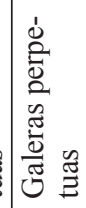 & 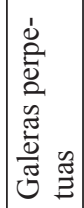 & 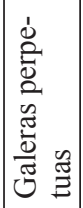 & 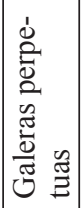 & 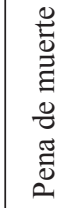 & 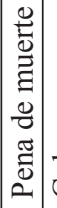 & 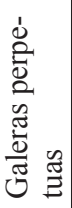 \\
\hline$\stackrel{\stackrel{\Xi}{\bar{\Xi}}}{\stackrel{0}{0}}$ & $\mid \begin{array}{l}n \\
0 \\
0 \\
0 \\
0 \\
0 \\
2 \\
2 \\
0 \\
0 \\
0 \\
0 \\
0 \\
2\end{array}$ & 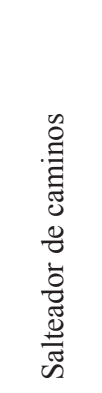 & 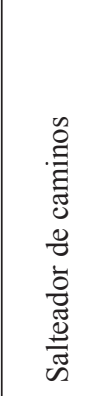 & 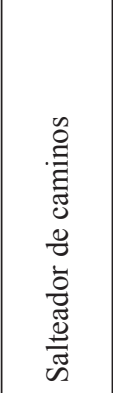 & 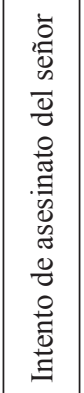 & 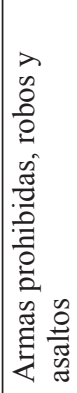 & 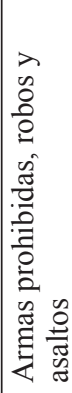 & 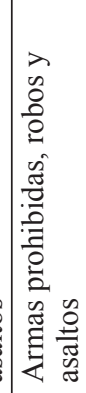 & 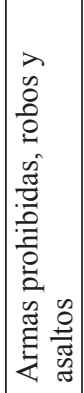 & 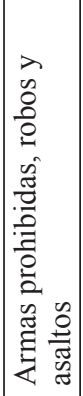 & 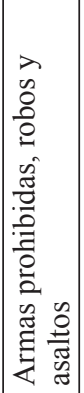 & 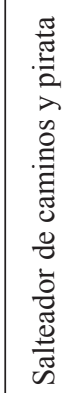 & 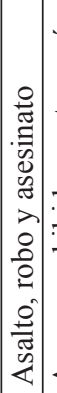 & 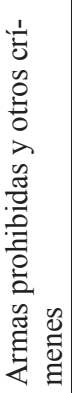 \\
\hline 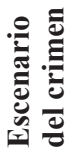 & & 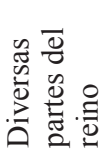 & 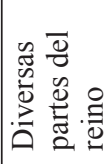 & 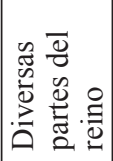 & 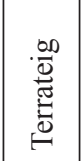 & & & & & & & & & \\
\hline 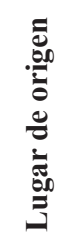 & 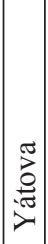 & 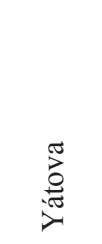 & 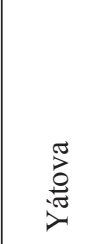 & 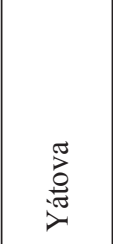 & 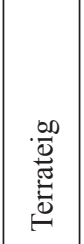 & 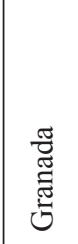 & & 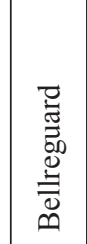 & 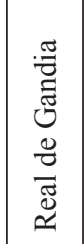 & 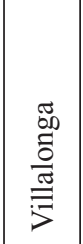 & 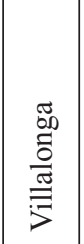 & $\frac{\frac{\theta}{0}}{I I}$ & 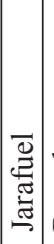 & 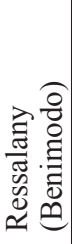 \\
\hline है & 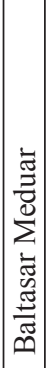 & 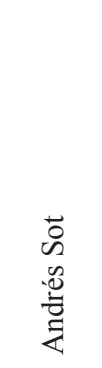 & 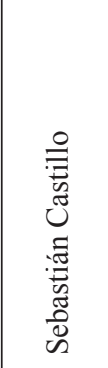 & 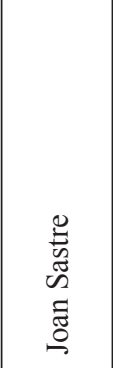 & 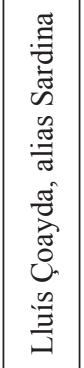 & 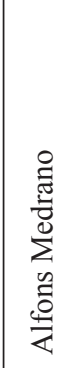 & 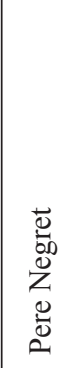 & 离 & $\begin{array}{l}\frac{\overrightarrow{0}}{\vec{E}} \\
\frac{\vec{\Xi}}{n}\end{array}$ & 离 & 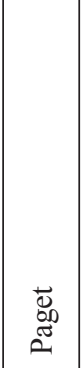 & 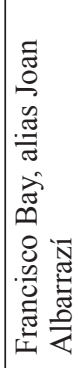 & 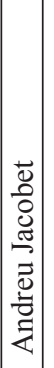 & 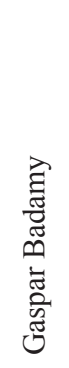 \\
\hline 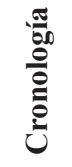 & $\stackrel{2}{\tilde{n}}$ & 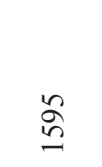 & $\stackrel{2}{n}$ & $\stackrel{n}{n}$ & ஃั & ஃ̊ & $\begin{array}{l}\text { ๙ } \\
\text { nิ }\end{array}$ & $\begin{array}{l}\text { ஃ̊ } \\
\text { in }\end{array}$ & ஃั & 음 & ஃั & $\stackrel{2}{2}$ & 命 & $\hat{a}$ \\
\hline
\end{tabular}




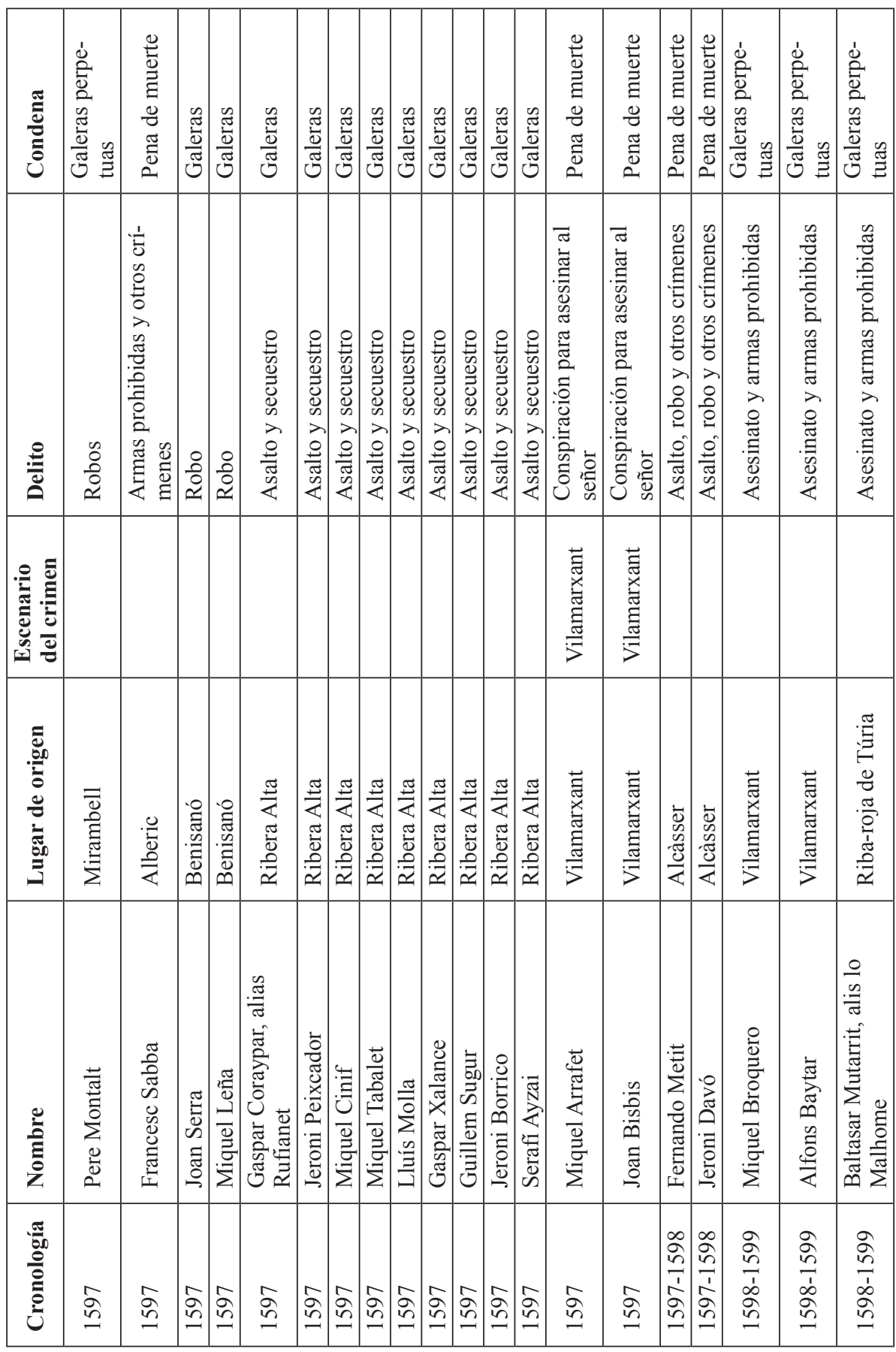




\begin{tabular}{|c|c|c|c|c|c|c|c|c|c|c|c|c|c|c|c|c|c|c|c|}
\hline 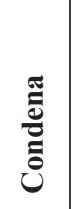 & 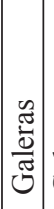 & 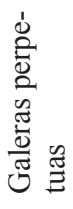 & 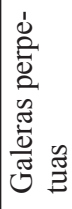 & & $\left|\begin{array}{c}0 \\
\frac{\pi}{0} \\
\frac{\tilde{U}}{\pi} \\
\tilde{J}\end{array}\right|$ & $\left|\begin{array}{c}0 \\
\frac{\pi}{0} \\
\frac{\tilde{d}}{\pi} \\
\tilde{J}\end{array}\right|$ & 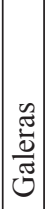 & 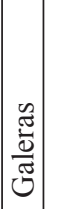 & & & & & 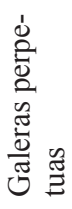 & 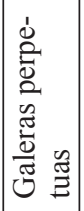 & 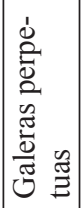 & & 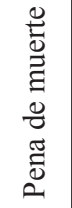 & 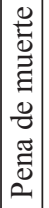 & 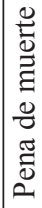 \\
\hline 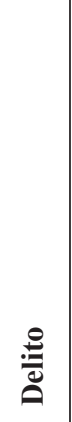 & 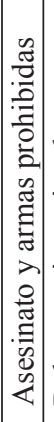 & 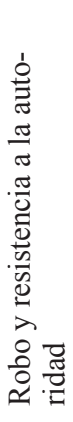 & 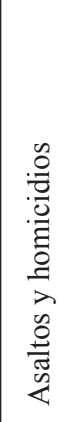 & 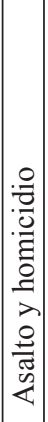 & 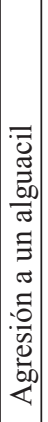 & 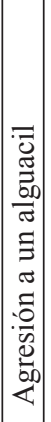 & 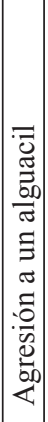 & 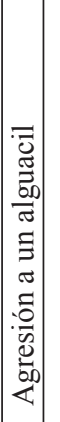 & $\begin{array}{l}\frac{0}{\tilde{Z}} \\
\frac{0}{2}\end{array}$ & 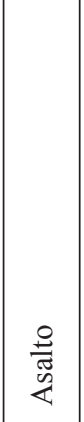 & 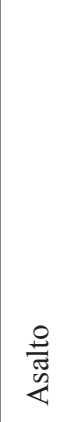 & 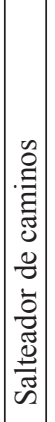 & 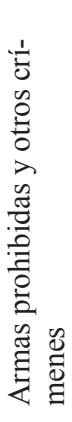 & 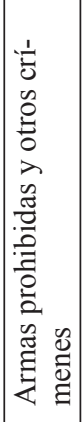 & 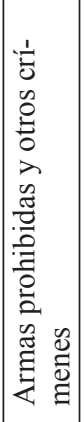 & 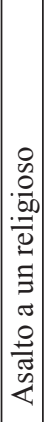 & 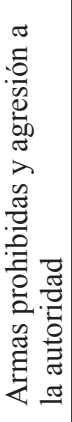 & 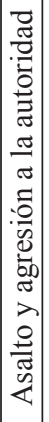 & 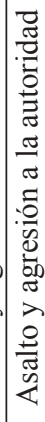 \\
\hline 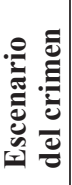 & & 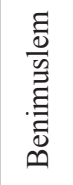 & 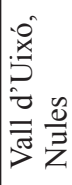 & 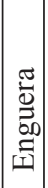 & $\left|\begin{array}{|c|}.00 \\
\frac{0}{0} \\
0 \\
0 \\
.0 \\
0 \\
0 \\
0\end{array}\right|$ & 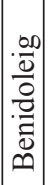 & 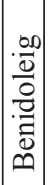 & 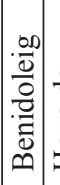 & 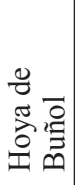 & 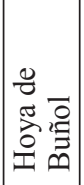 & 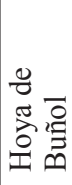 & & & & & 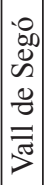 & $\begin{array}{l}\stackrel{0}{\bar{D}} \\
\stackrel{0}{Z}\end{array}$ & 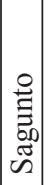 & 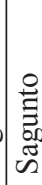 \\
\hline 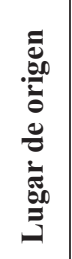 & 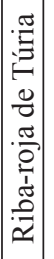 & & 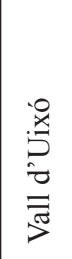 & & $\left|\begin{array}{|c|}.00 \\
\frac{0}{0} \\
0 \\
.0 \\
.0 \\
0 \\
0\end{array}\right|$ & 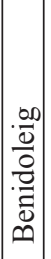 & 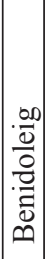 & 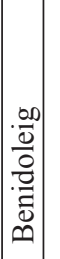 & 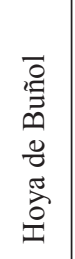 & 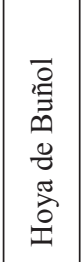 & 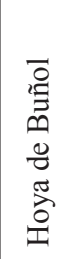 & & $\frac{\overrightarrow{0}}{\tilde{\Xi}}$ & $\frac{\vec{U}}{\bar{\Xi}}$ & $\frac{\vec{U}}{\bar{\Xi}}$ & 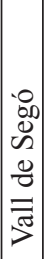 & 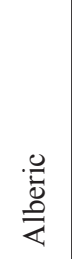 & 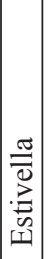 & 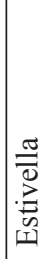 \\
\hline 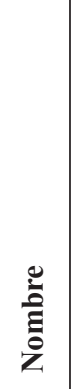 & 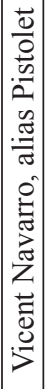 & 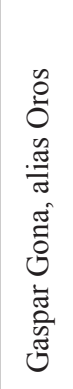 & 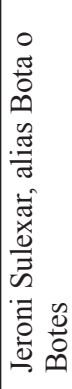 & 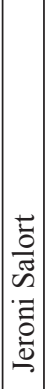 & 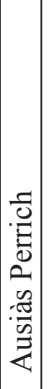 & 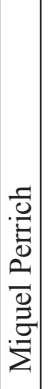 & 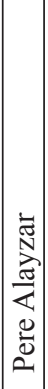 & 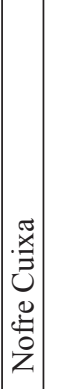 & 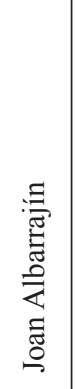 & 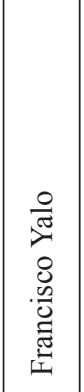 & 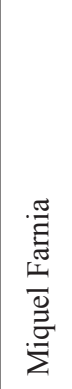 & 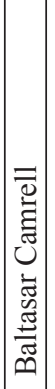 & 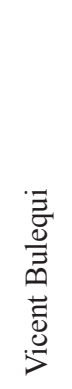 & 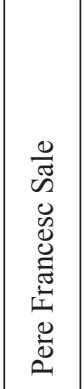 & 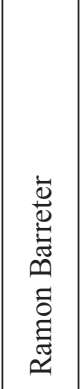 & 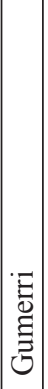 & 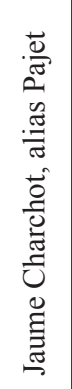 & 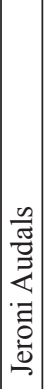 & 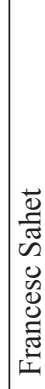 \\
\hline 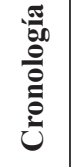 & $\mid$\begin{tabular}{l}
$\infty$ \\
$\vdots$ \\
\hdashline \\
-1
\end{tabular} & $\stackrel{\infty}{2}$ & $\begin{array}{l}\infty \\
\stackrel{2}{n}\end{array}$ & $\begin{array}{l}\infty \\
\tilde{2} \\
-\end{array}$ & 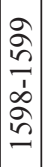 & 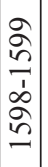 & 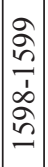 & 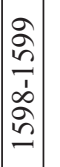 & $\stackrel{\infty}{2}$ & $\begin{array}{l}\infty \\
\stackrel{2}{n}\end{array}$ & $\begin{array}{l}\infty \\
\stackrel{2}{n} \\
=\end{array}$ & ֵֵ & ฉิ & 함 & ฉิ & ฉે & ฉิ & $\begin{array}{l}2 \\
\text { ฉે } \\
-\end{array}$ & ì \\
\hline
\end{tabular}




\begin{tabular}{|c|c|c|c|c|c|c|c|c|c|c|c|c|c|c|c|}
\hline نّ̃ & 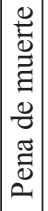 & 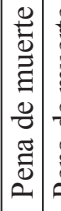 & 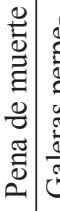 & 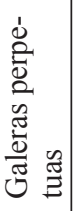 & & & 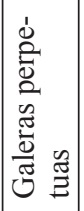 & & & & & 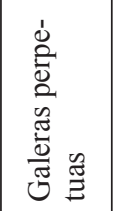 & 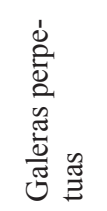 & 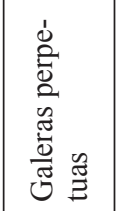 & 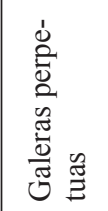 \\
\hline 竞 & 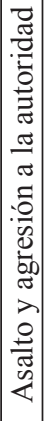 & 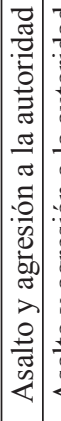 & 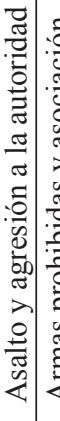 & 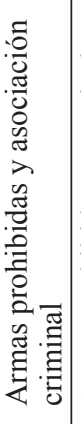 & 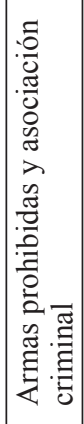 & 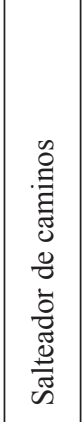 & 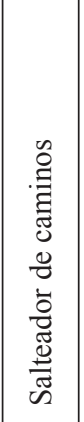 & 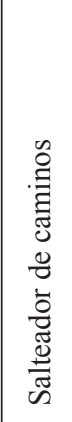 & 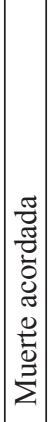 & 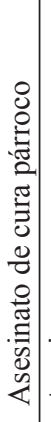 & 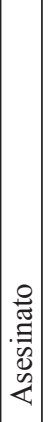 & 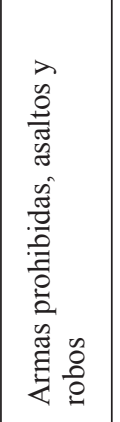 & 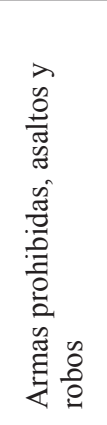 & 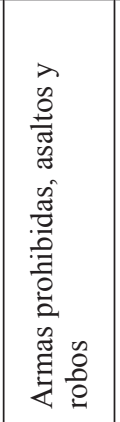 & 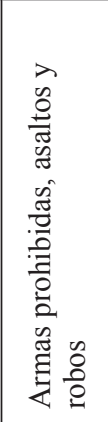 \\
\hline 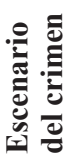 & 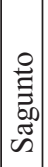 & 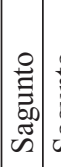 & 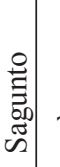 & 苟 & 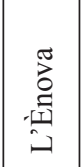 & 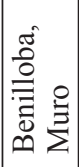 & 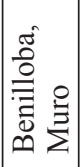 & 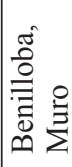 & 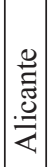 & 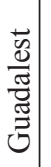 & & 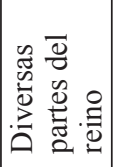 & 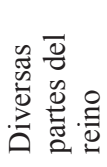 & 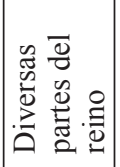 & 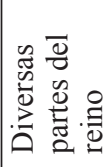 \\
\hline 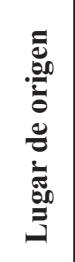 & 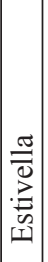 & $\mid$\begin{tabular}{c|c}
0 & 0 \\
$\vdots$ & 0 \\
0 \\
0 \\
2
\end{tabular} & $\begin{array}{l}\frac{\pi}{0} \\
\frac{0}{D} \\
\sim\end{array}$ & 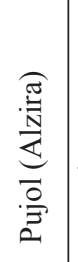 & 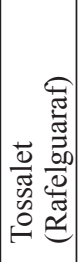 & & $\begin{array}{l}\frac{\pi}{0} \\
0 \\
\overline{\overrightarrow{0}} \\
\infty\end{array}$ & $\begin{array}{l}\stackrel{0}{0} \\
: \overline{0} \\
\stackrel{\overline{0}}{0} \\
\infty\end{array}$ & 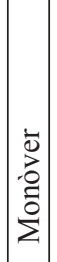 & 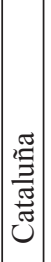 & $\mid \begin{array}{l}a \\
0 \\
0 \\
0 \\
0 \\
\Sigma\end{array}$ & 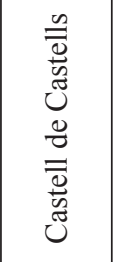 & $\frac{\cdot 0}{\pi}$ & & \\
\hline है & 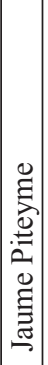 & 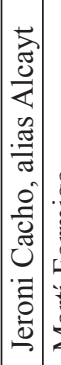 & 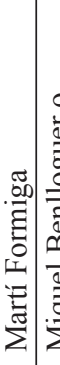 & 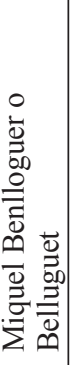 & 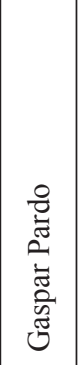 & 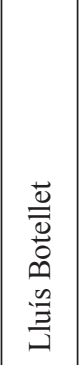 & 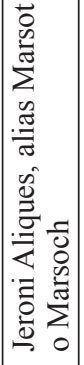 & 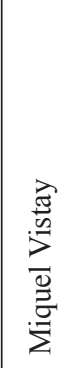 & 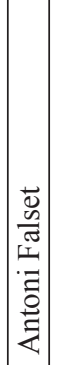 & $\mid \begin{array}{c}\text { चี } \\
0 \\
0 \\
0 \\
0 \\
0 \\
0\end{array}$ & 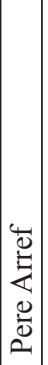 & 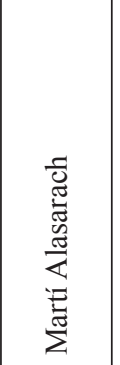 & 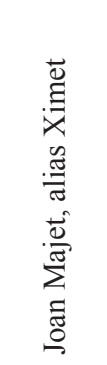 & 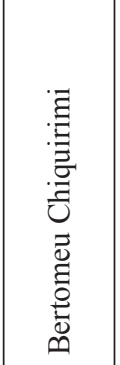 & 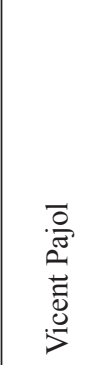 \\
\hline $\begin{array}{l}\frac{\pi}{60} \\
\frac{0}{0} \\
\frac{0}{0} \\
\frac{0}{0}\end{array}$ & $\begin{array}{l}2 \\
\vdots \\
n\end{array}$ & 各 & $\begin{array}{l}2 \\
\approx \\
2\end{array}$ & ڤิ & in & 命 & $\begin{array}{l}8 \\
8 \\
\frac{1}{2} \\
\text { 。े }\end{array}$ & $\begin{array}{l}\text { हे } \\
\stackrel{2}{2}\end{array}$ & ฉิ & ڤે & $\begin{array}{l}0 \\
0 \\
8 \\
0 \\
0\end{array}$ & 8 & ర్ & 8 & 8) \\
\hline
\end{tabular}




\begin{tabular}{|c|c|c|c|c|c|c|c|c|c|c|c|c|c|c|}
\hline ن⿺辶ّ & 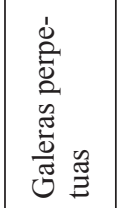 & 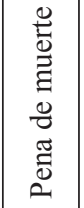 & 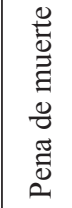 & 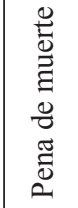 & $\frac{\tilde{E}}{\frac{\pi}{d}}$ & $\frac{\stackrel{\pi}{0}}{\frac{\pi}{\pi}}$ & & & & & 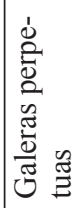 & 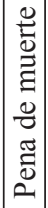 & & 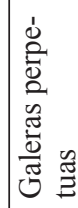 \\
\hline 苞 & 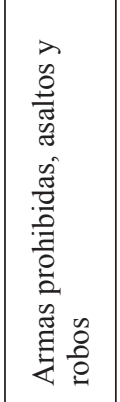 & 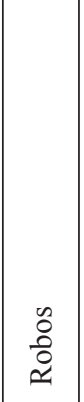 & $\begin{array}{l}0 \\
0 \\
0 \\
\approx\end{array}$ & 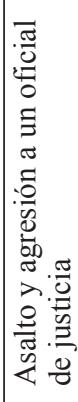 & 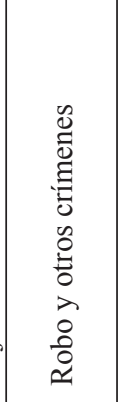 & 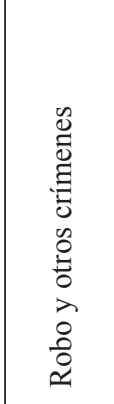 & 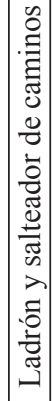 & 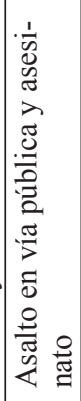 & 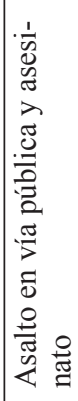 & 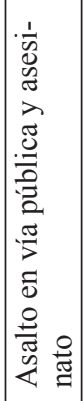 & 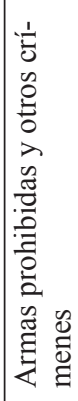 & 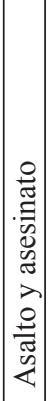 & 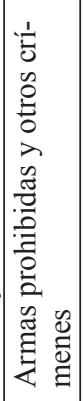 & 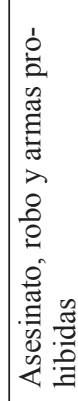 \\
\hline 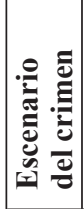 & 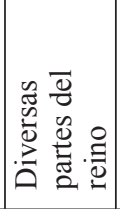 & & & 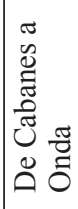 & 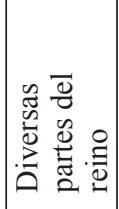 & 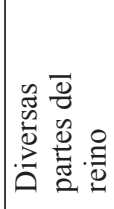 & & 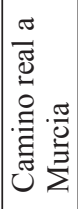 & 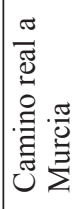 & 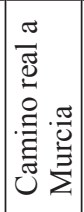 & & & & \\
\hline 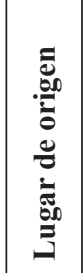 & 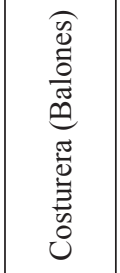 & $\begin{array}{l}\frac{\pi}{\tilde{J}} \\
\frac{\pi}{\tilde{J}} \\
\end{array}$ & 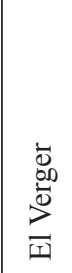 & 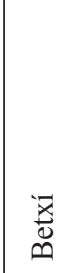 & $\begin{array}{l}0 \\
\stackrel{0}{0} \\
\infty \\
\infty \\
\infty\end{array}$ & 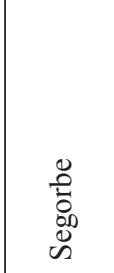 & 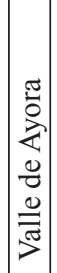 & $\begin{array}{l}\infty \\
0 \\
0 \\
0 \\
0\end{array}$ & $\begin{array}{l}0 \\
0 \\
0 \\
0 \\
0 \\
0\end{array}$ & $\begin{array}{l}n \\
0 \\
0 \\
0 \\
0 \\
0\end{array}$ & $\stackrel{\substack{0 \\
0}}{\ominus}$ & $\mid \begin{array}{l}0 \\
0 \\
0 \\
0 \\
0 \\
0 \\
0\end{array}$ & 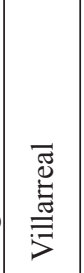 & $\begin{array}{l}\frac{0}{0} \\
\stackrel{0}{Z}\end{array}$ \\
\hline है & 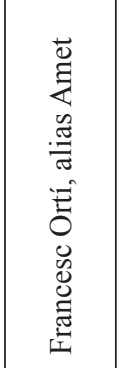 & 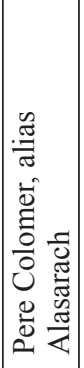 & 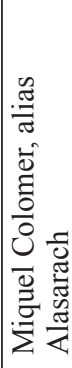 & $\begin{array}{l}\text { 目 } \\
\sum_{0}^{0} \\
0 \\
0 \\
0\end{array}$ & 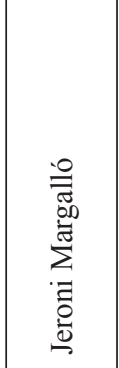 & 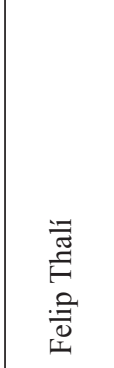 & 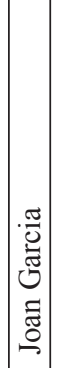 & 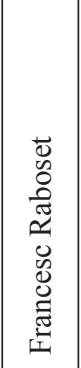 & 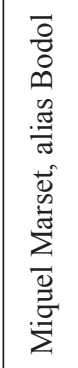 & 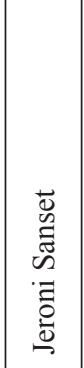 & 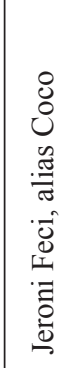 & 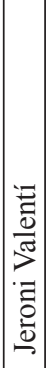 & 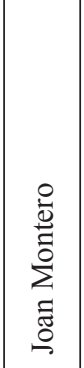 & $\begin{array}{l}\text { हैँ } \\
0 \\
0 \\
5 \\
0 \\
0 \\
0\end{array}$ \\
\hline 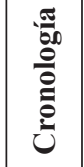 & 8 & రి & 8 & 8 & రి & 8 & $\begin{array}{l}0 \\
0 \\
1 \\
8 \\
8 \\
0 \\
-1\end{array}$ & $\overrightarrow{8}$ & 요 & $\stackrel{8}{-}$ & $\stackrel{8}{8}$ & $\overrightarrow{\overline{0}}$ & 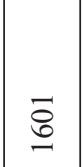 & 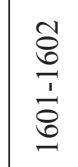 \\
\hline
\end{tabular}




\begin{tabular}{|c|c|c|c|c|c|c|c|c|c|c|c|c|c|c|c|c|c|}
\hline نَّ & 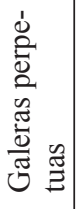 & 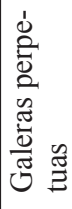 & 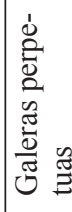 & 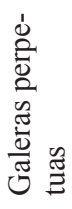 & 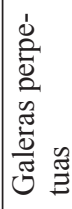 & & & 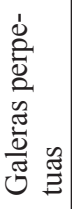 & & & 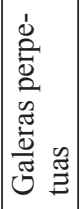 & 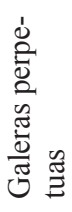 & 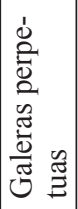 & 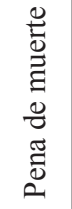 & & & \\
\hline 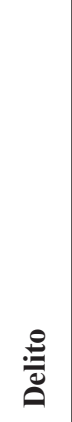 & 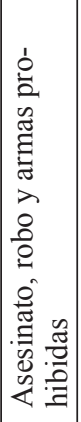 & 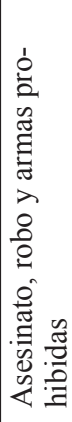 & 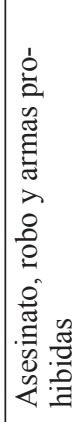 & 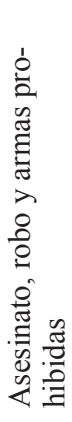 & 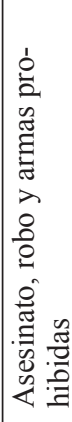 & 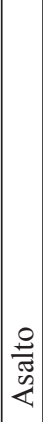 & 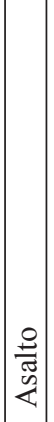 & 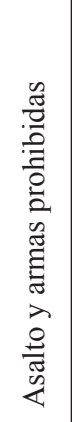 & 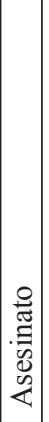 & 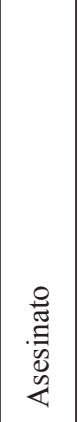 & 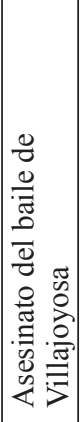 & 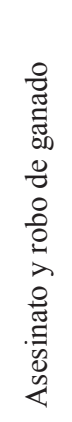 & 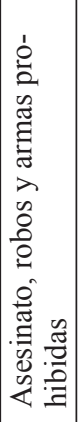 & 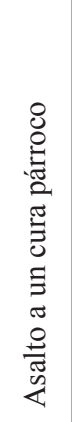 & 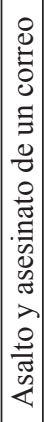 & 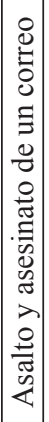 & 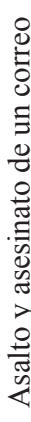 \\
\hline 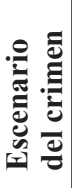 & & & & & & 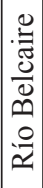 & 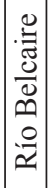 & & 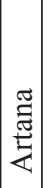 & 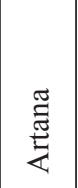 & 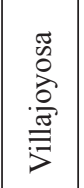 & & & 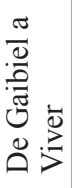 & 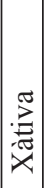 & 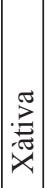 & 湑 \\
\hline 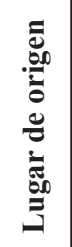 & $\begin{array}{l}\frac{\pi}{0} \\
\frac{0}{0} \\
0 \\
0\end{array}$ & $\stackrel{0}{0}$ & $\begin{array}{l}\tilde{D} \\
\stackrel{\Xi}{\Xi}\end{array}$ & 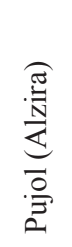 & 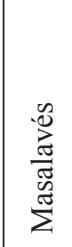 & 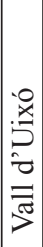 & 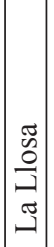 & 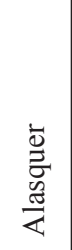 & & & $\begin{array}{l}\frac{\pi}{0} \\
0 \\
0 \\
0 \\
0\end{array}$ & 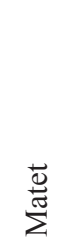 & 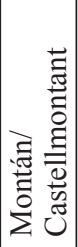 & $\begin{array}{l}\frac{8}{7} \\
\frac{0}{0} \\
\frac{\pi}{3} \\
\frac{0}{0} \\
\frac{0}{2}\end{array}$ & 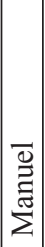 & 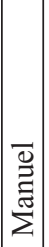 & 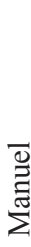 \\
\hline $\begin{array}{l}\text { ऐ. } \\
\text { है } \\
\text { Zे }\end{array}$ & 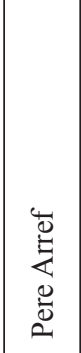 & 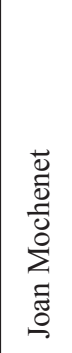 & 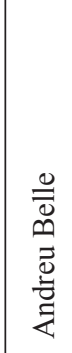 & 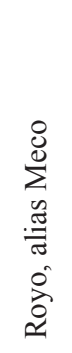 & 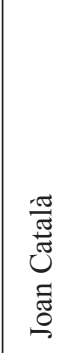 & 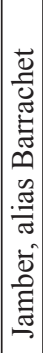 & 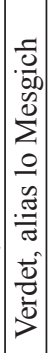 & 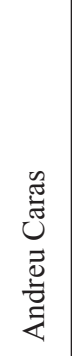 & 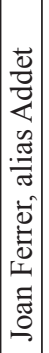 & 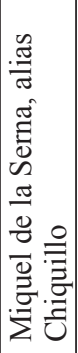 & 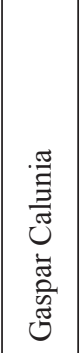 & 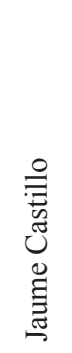 & 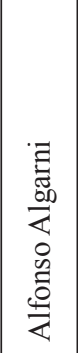 & 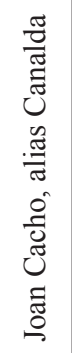 & 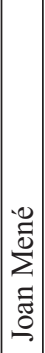 & 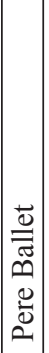 & 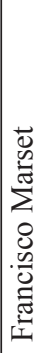 \\
\hline 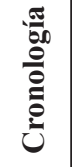 & $\begin{array}{l}\text { No } \\
0 \\
\frac{1}{1} \\
0 \\
0 \\
0\end{array}$ & $\begin{array}{l}2 \\
8 \\
0 \\
1 \\
0 \\
0 \\
0\end{array}$ & 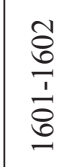 & 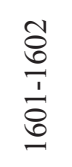 & 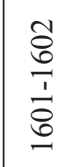 & 8 & $\mid \begin{array}{c}0 \\
0 \\
0 \\
-1\end{array}$ & రి & $\left(\begin{array}{c}\mathcal{1} \\
0 \\
- \\
-1\end{array}\right.$ & రి & రి & రి & ర్ & రి & $\begin{array}{l}0 \\
0 \\
0 \\
-1\end{array}$ & $\begin{array}{c}1 \\
\delta \\
- \\
-\end{array}$ & ర్ \\
\hline
\end{tabular}




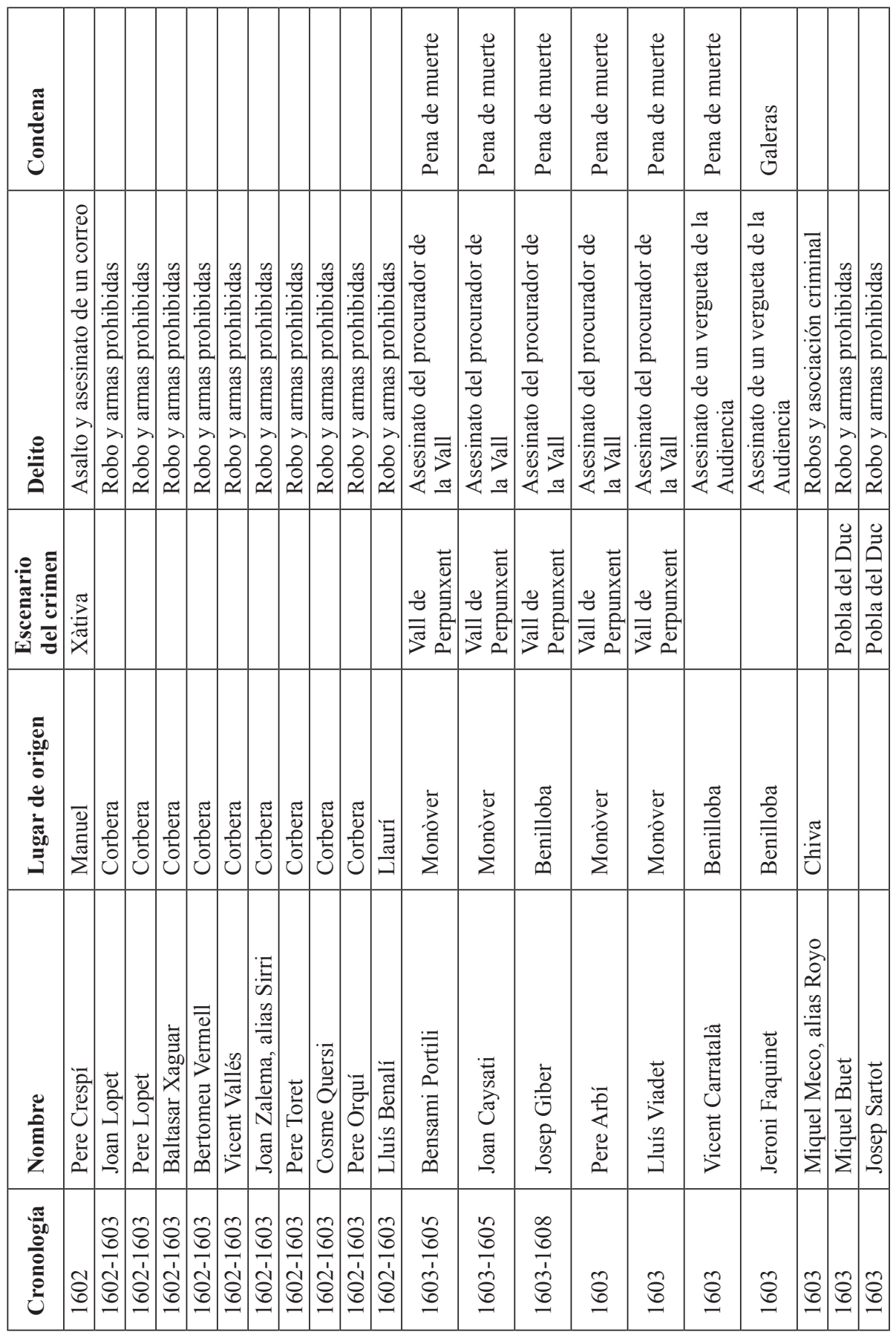




\begin{tabular}{|c|c|c|c|c|c|c|c|c|c|c|c|c|c|c|c|c|c|c|}
\hline نَّ & & & & & & 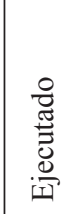 & 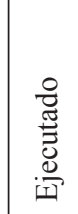 & & & & 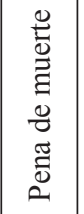 & 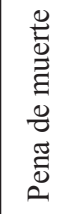 & & & 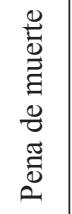 & 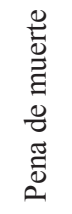 & & \\
\hline : & 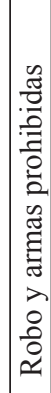 & 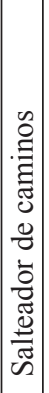 & 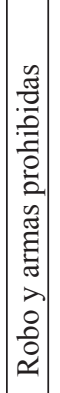 & 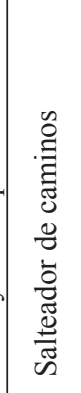 & 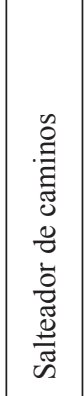 & 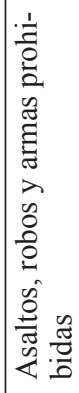 & 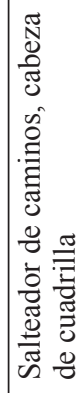 & 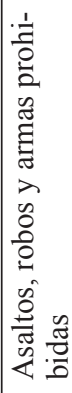 & 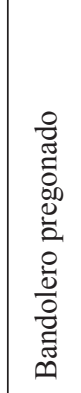 & 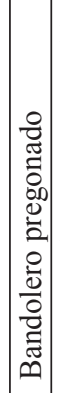 & 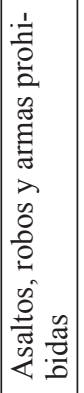 & 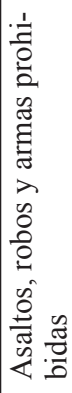 & 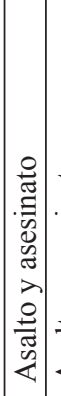 & 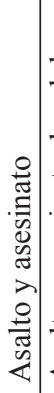 & 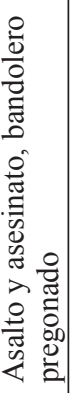 & 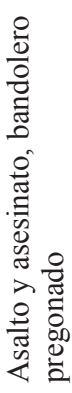 & 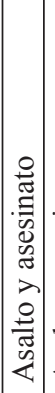 & 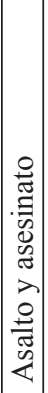 \\
\hline 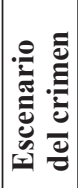 & $\begin{array}{c}0 \\
0 \\
0 \\
\frac{0}{0} \\
\frac{\pi}{0} \\
0 \\
0\end{array}$ & 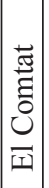 & & 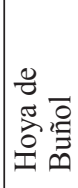 & 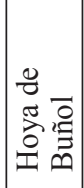 & 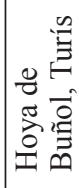 & 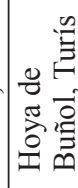 & 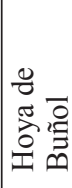 & & & 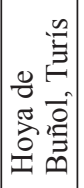 & 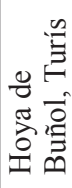 & $\mid \begin{array}{l}\pi \\
0 \\
0 \\
0\end{array}$ & 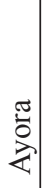 & $\begin{array}{l}\frac{\pi}{0} \\
\stackrel{2}{2}\end{array}$ & 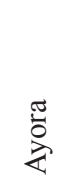 & \begin{tabular}{|l|}
$\mid$ \\
离 \\
妾
\end{tabular} & \begin{tabular}{|l|} 
\\
吾 \\
定
\end{tabular} \\
\hline 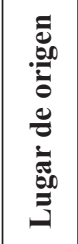 & & 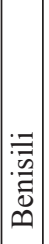 & $\mid \begin{array}{c}\frac{\pi}{\tilde{m}} \\
\frac{\tilde{v}}{2} \\
\sum \\
\Sigma\end{array}$ & $\stackrel{n}{\Xi}$ & $\stackrel{\mathscr{\Xi}}{\Xi}$ & 胥 & 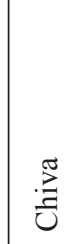 & 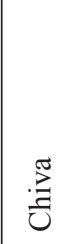 & & $\mid \begin{array}{l}\frac{\tilde{a}}{3} \\
\bar{\Xi} \\
0 \\
0\end{array}$ & & $\stackrel{n}{\Xi}$ & 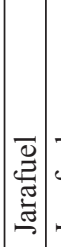 & 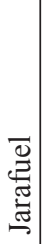 & 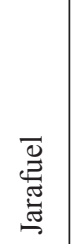 & 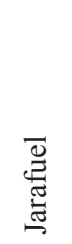 & 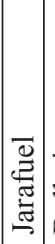 & 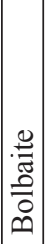 \\
\hline है & 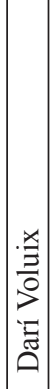 & 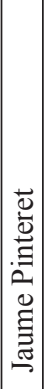 & 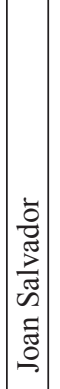 & 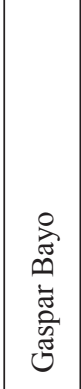 & 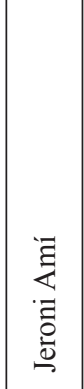 & 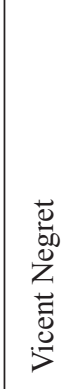 & $\begin{array}{l}\vec{\Xi} \\
\overline{0} \\
\mathbb{\Xi} \\
0\end{array}$ & $\begin{array}{l}\frac{\pi}{60} \\
0 \\
\approx\end{array}$ & 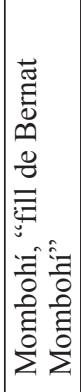 & 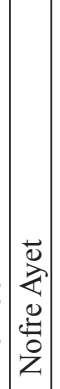 & 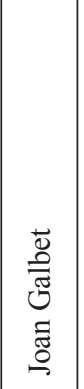 & 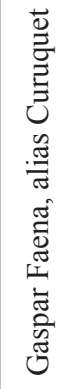 & 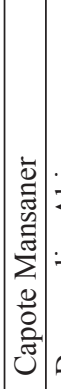 & 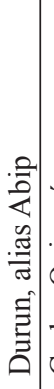 & 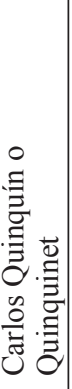 & 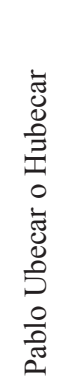 & 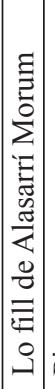 & $\begin{array}{l} \\
\\
. \\
.0 \\
. \\
0\end{array}$ \\
\hline $\begin{array}{l}\frac{\pi}{00} \\
\frac{0}{0} \\
\frac{0}{0} \\
\frac{0}{0}\end{array}$ & 登 & $\begin{array}{c}0 \\
0 \\
0 \\
-1\end{array}$ & 点 & 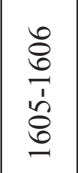 & $\begin{array}{l}0 \\
8 \\
0 \\
1 \\
\\
0 \\
0\end{array}$ & $\begin{array}{l}0 \\
8 \\
0 \\
1 \\
1 \\
0 \\
0 \\
-1\end{array}$ & $\begin{array}{l}0 \\
0 \\
1 \\
1 \\
0 \\
0\end{array}$ & $\begin{array}{l}8 \\
8 \\
0 \\
1 \\
1 \\
0 \\
0 \\
-1\end{array}$ & हి & $\mid \begin{array}{l}2 \\
\delta \\
0 \\
-1\end{array}$ & $\begin{array}{l}0 \\
8 \\
0 \\
1 \\
0 \\
0 \\
0\end{array}$ & $\begin{array}{l}0 \\
8 \\
0 \\
1 \\
1 \\
0 \\
0 \\
0\end{array}$ & 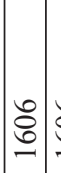 & 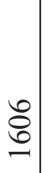 & 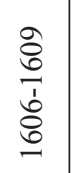 & $\begin{array}{l}8 \\
8 \\
1 \\
\text { bे } \\
0\end{array}$ & $\mid \begin{array}{l}0 \\
8 \\
0 \\
-1\end{array}$ & 总 \\
\hline
\end{tabular}




\begin{tabular}{|c|c|c|c|c|c|c|c|c|c|c|c|c|c|c|}
\hline $\begin{array}{l}\frac{\pi}{\tilde{\Xi}} \\
\overline{\tilde{E}} \\
\tilde{\Xi}\end{array}$ & & & & & & 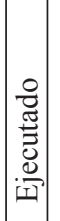 & & 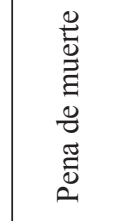 & 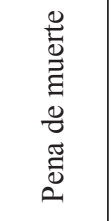 & 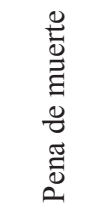 & 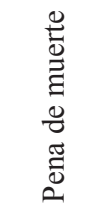 & 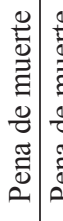 & 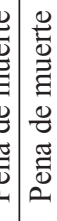 & 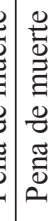 \\
\hline 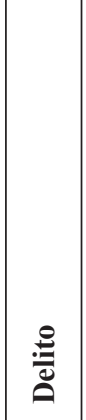 & 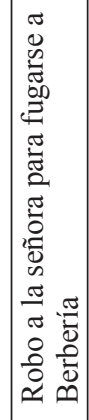 & 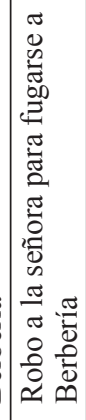 & 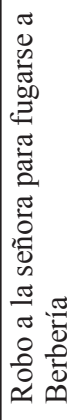 & 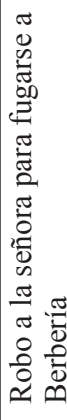 & 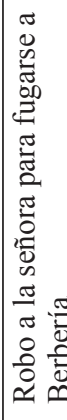 & 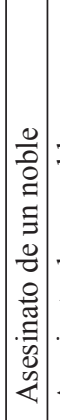 & 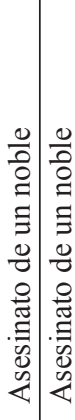 & 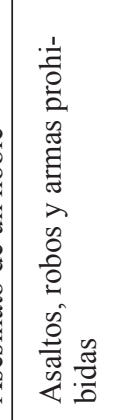 & 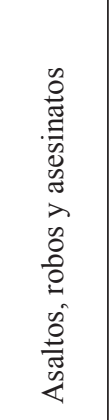 & 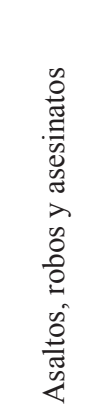 & 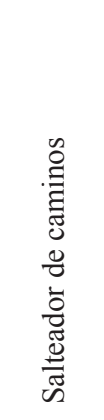 & 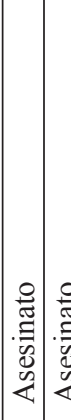 & & 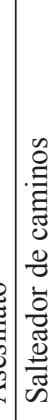 \\
\hline 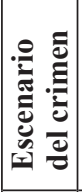 & 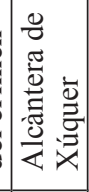 & 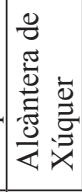 & 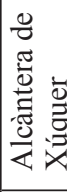 & 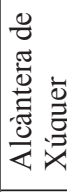 & 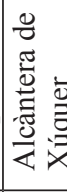 & & & 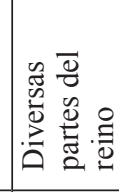 & 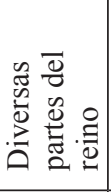 & 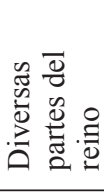 & 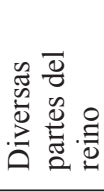 & & & \\
\hline 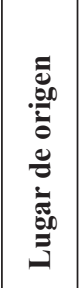 & 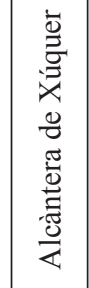 & 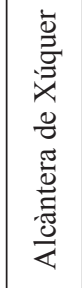 & 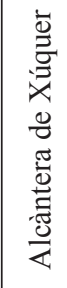 & 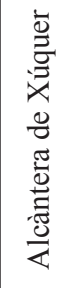 & 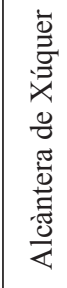 & 妾 & 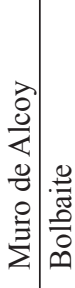 & $\begin{array}{l}\frac{\pi}{\tilde{\pi}} \\
\text { 吾 } \\
\text { م }\end{array}$ & 胥 & $\begin{array}{l}\frac{\pi}{2} \\
\frac{D}{U}\end{array}$ & 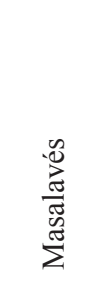 & 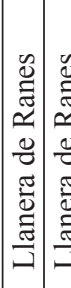 & 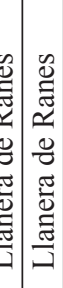 & 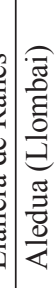 \\
\hline 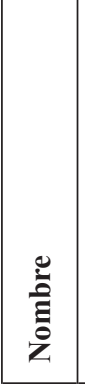 & 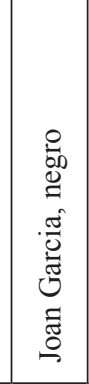 & 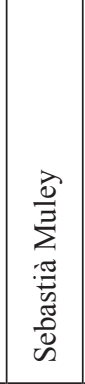 & 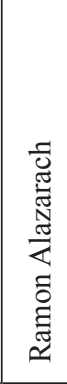 & $\begin{array}{l}\overrightarrow{0} \\
\overline{0} \\
\vdots \\
\mathscr{0} \\
\Xi \\
\exists\end{array}$ & 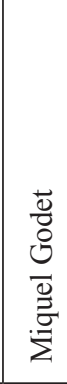 & 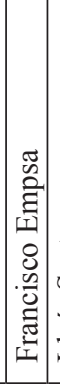 & 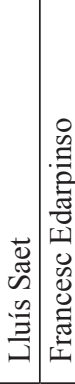 & 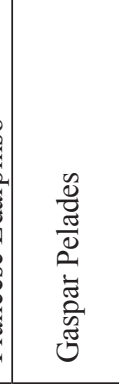 & 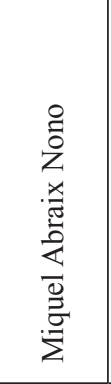 & 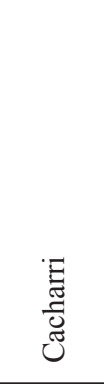 & 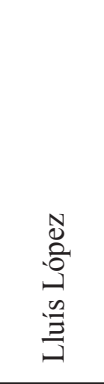 & 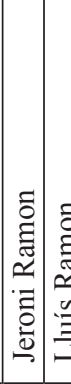 & 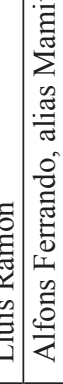 & 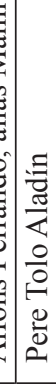 \\
\hline 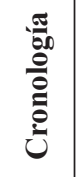 & : & : & - & $\stackrel{0}{0}$ & 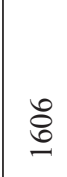 & 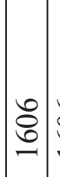 & : & : & $\begin{array}{l}0 \\
0 \\
0 \\
0 \\
0 \\
0\end{array}$ & $\begin{array}{l}8 \\
\frac{8}{0} \\
\stackrel{0}{0} \\
0\end{array}$ & 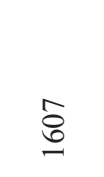 & a & $8: 0$ & 8 \\
\hline
\end{tabular}




\begin{tabular}{|c|c|c|c|c|c|c|c|c|c|c|c|c|c|c|c|c|c|}
\hline ن⿺ & 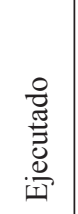 & 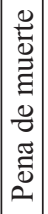 & 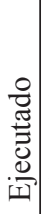 & 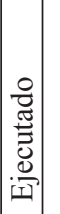 & 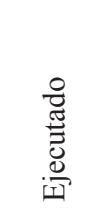 & 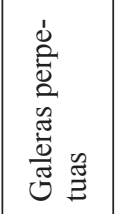 & 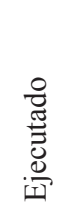 & & & 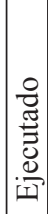 & 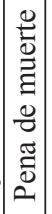 & 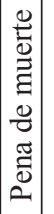 & 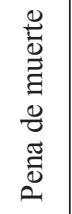 & & 응 & & 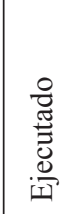 \\
\hline$\frac{\stackrel{\mathscr{E}}{0}}{\stackrel{0}{0}}$ & 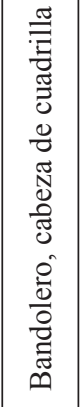 & 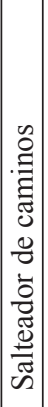 & 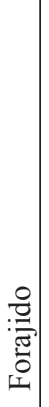 & 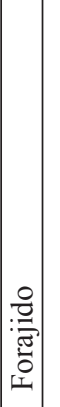 & 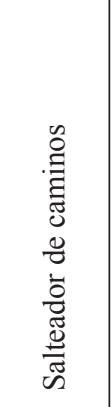 & 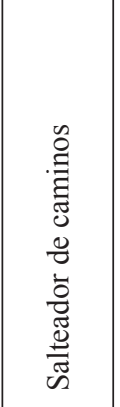 & 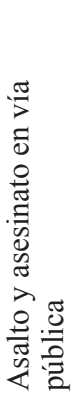 & 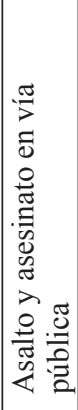 & 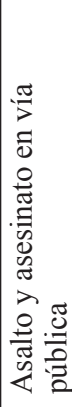 & 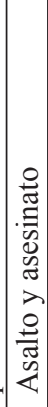 & 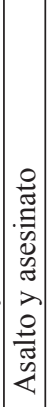 & 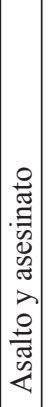 & 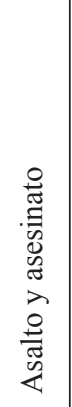 & 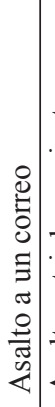 & 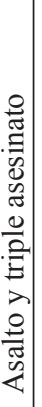 & 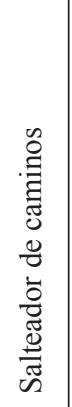 & 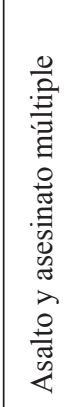 \\
\hline 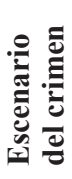 & 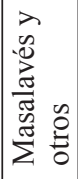 & 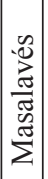 & & & 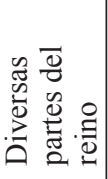 & 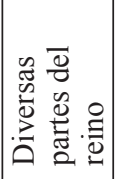 & 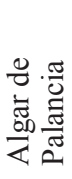 & 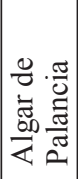 & 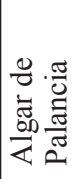 & 总 & 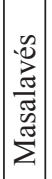 & 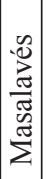 & 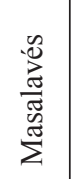 & . & : & 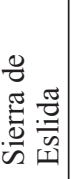 & 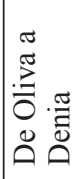 \\
\hline 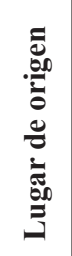 & 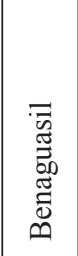 & $\mid \begin{array}{c}\bar{a} \\
i \mathfrak{\Xi} \\
\bar{n}\end{array}$ & 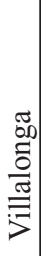 & 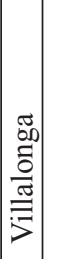 & 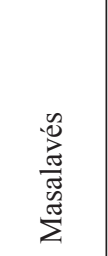 & 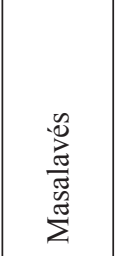 & 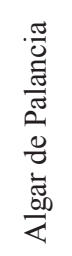 & 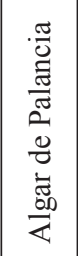 & $\begin{array}{l}\dot{0} \\
\stackrel{0}{0} \\
1 \\
0 \\
0 \\
0 \\
0 \\
\text { in }\end{array}$ & 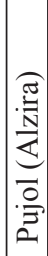 & 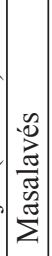 & 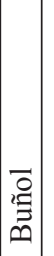 & $\begin{array}{l}\vec{\Xi} \\
\text { 品 }\end{array}$ & 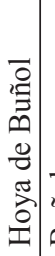 & 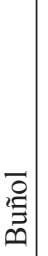 & & 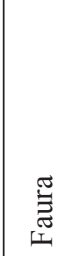 \\
\hline $\begin{array}{l}\text { : } \\
\text { है } \\
\text { Zे }\end{array}$ & 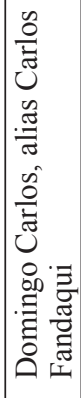 & 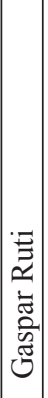 & 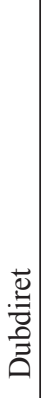 & 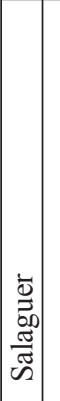 & 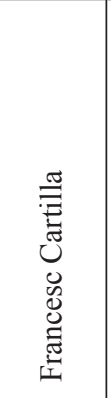 & 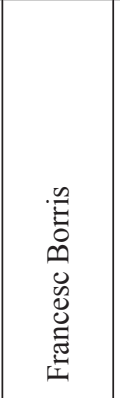 & 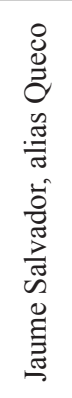 & 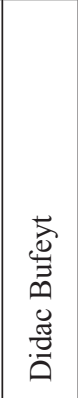 & 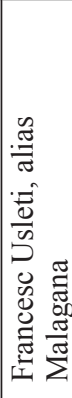 & 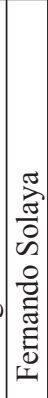 & 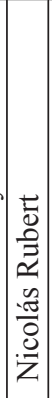 & 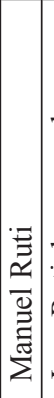 & 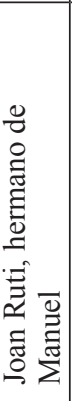 & 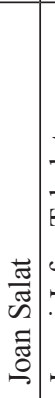 & 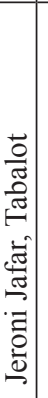 & 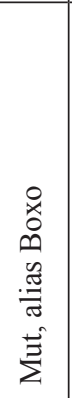 & 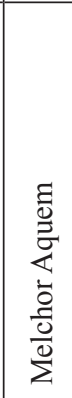 \\
\hline 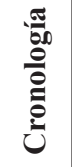 & $\widehat{8}$ & : & 움 & 0 & $\begin{array}{l}\infty \\
0 \\
0\end{array}$ & 0 & 8 & 5 & $\stackrel{8}{8}$ & $\begin{array}{l}\infty \\
0 \\
0 \\
0\end{array}$ & $\begin{array}{l}\infty \\
0 \\
0 \\
-1\end{array}$ & 웅 & $\stackrel{0}{0}$ & $\begin{array}{l}\infty \\
0 \\
0 \\
-1\end{array}$ & 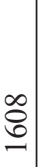 & $\stackrel{8}{8}$ & $\begin{array}{l}\infty \\
0 \\
0\end{array}$ \\
\hline
\end{tabular}




\begin{tabular}{|c|c|c|c|c|c|c|c|c|c|c|c|c|c|c|c|c|c|c|c|c|}
\hline نَّ & & 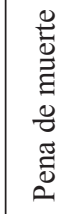 & 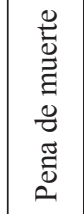 & & 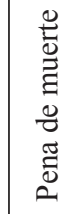 & 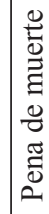 & 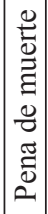 & 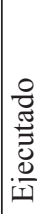 & $\begin{array}{l}\Xi \\
0 \\
0 \\
\tilde{J} \\
0 \\
0 \\
0\end{array}$ & 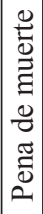 & 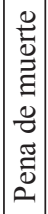 & & & & & & & & & \\
\hline$\stackrel{\stackrel{\Xi}{\bar{\Xi}}}{\stackrel{0}{0}}$ & 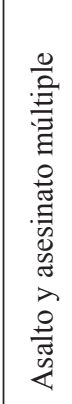 & 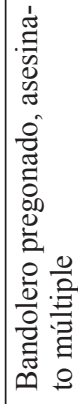 & 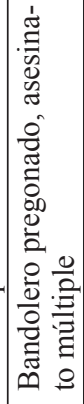 & 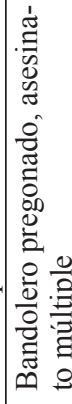 & 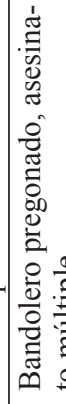 & 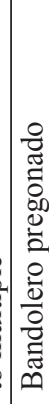 & 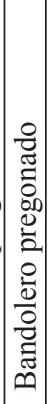 & 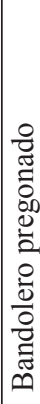 & 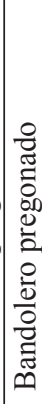 & 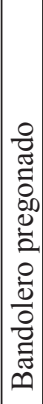 & 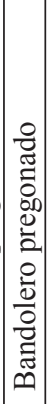 & 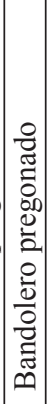 & 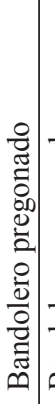 & 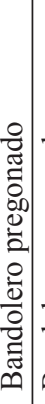 & 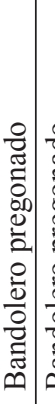 & 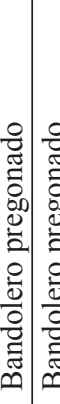 & 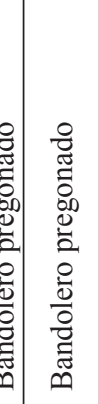 & 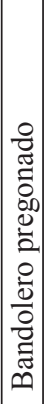 & $\begin{array}{c}0 \\
0 \\
0 \\
0 \\
0 \\
0 \\
0 \\
\vdots \\
0 \\
0 \\
0 \\
0 \\
0 \\
0 \\
\overline{0} \\
0 .\end{array}$ & $\begin{array}{l}0 \\
\overline{0} \\
\bar{\Xi} \\
\tilde{\Xi}\end{array}$ \\
\hline 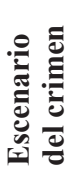 & 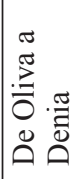 & 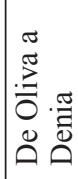 & 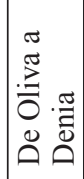 & 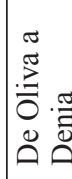 & 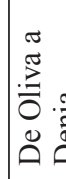 & & & & & & & & & & & & & & & \\
\hline 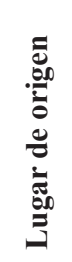 & & $\begin{array}{l}\dot{\bar{D}} \\
\frac{00}{0} \\
\overrightarrow{0} \\
\vec{د}\end{array}$ & 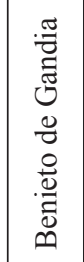 & 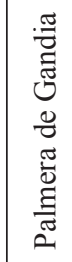 & $\begin{array}{l}\mathscr{E} \\
\stackrel{\Xi}{\Xi} \\
\stackrel{\Xi}{\varangle}\end{array}$ & $\begin{array}{l}. \frac{0}{\pi} \\
0 \\
0 \\
0 \\
0\end{array}$ & 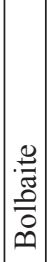 & 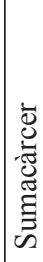 & 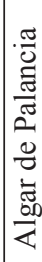 & $\begin{array}{l}\frac{\pi}{2} \\
\text { 矛 } \\
0\end{array}$ & 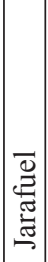 & 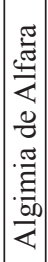 & 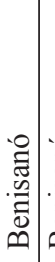 & 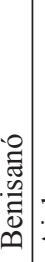 & $\frac{0}{2}$ & $\begin{array}{lll}\overrightarrow{0} & 0 \\
\Xi & \frac{0}{\pi}\end{array}$ & 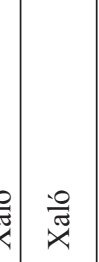 & $\mid$\begin{tabular}{|l}
$\frac{0}{\pi}$ \\
$\ddot{x}$ \\
\end{tabular} & $\mid \begin{array}{l}.00 \\
\frac{0}{0} \\
0 \\
.0 \\
0 \\
0 \\
0\end{array}$ & $\begin{array}{l}\text { E्] } \\
\frac{\vec{d}}{\pi} \\
\tilde{n}\end{array}$ \\
\hline $\begin{array}{l}\text { D. } \\
\text { है } \\
\text { है }\end{array}$ & 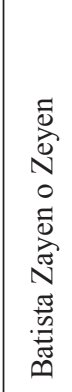 & 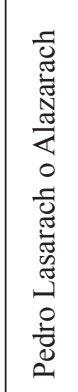 & 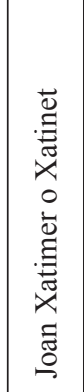 & 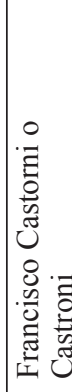 & $\begin{array}{l}\mathscr{E} \\
\mathscr{E} \\
\mathscr{\Xi} \\
\Xi\end{array}$ & 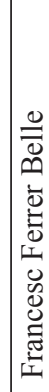 & 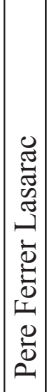 & 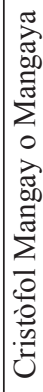 & 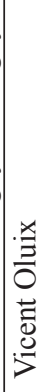 & 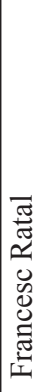 & 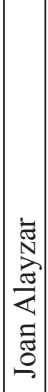 & 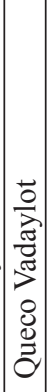 & 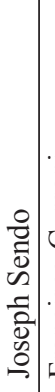 & 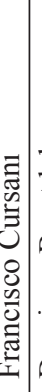 & 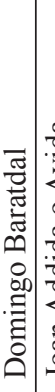 & 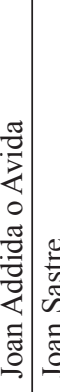 & 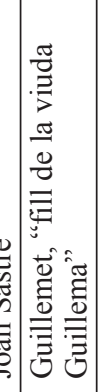 & 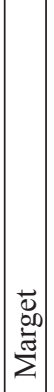 & 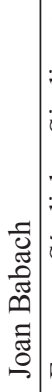 & 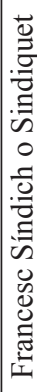 \\
\hline 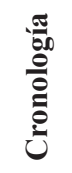 & $\begin{array}{l}\stackrel{8}{0} \\
\frac{1}{1} \\
0 \\
0\end{array}$ & $\begin{array}{l}8 \\
8 \\
1 \\
0 \\
0 \\
0\end{array}$ & $\begin{array}{l}8 \\
\stackrel{0}{0} \\
\frac{1}{\infty} \\
0 \\
0\end{array}$ & $\begin{array}{l}0 \\
0 \\
1 \\
0 \\
0 \\
0\end{array}$ & $\begin{array}{l}8 \\
0 \\
\frac{1}{1} \\
0 \\
0 \\
0\end{array}$ & \& & $\begin{array}{l}\infty \\
0 \\
0 \\
\end{array}$ & O & $\infty$ & $\begin{array}{l}0 \\
8 \\
0 \\
0\end{array}$ & $\mid \begin{array}{l}-1 \\
\dot{1} \\
0 \\
0 \\
0\end{array}$ & $\mid \begin{array}{l}\infty \\
0 \\
0 \\
-1 \\
\end{array}$ & $\begin{array}{l}\infty \\
0 \\
0 \\
-1\end{array}$ & - & \begin{tabular}{l|l}
$\infty$ \\
0 \\
0
\end{tabular} & 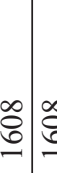 & $\stackrel{8}{-}$ & $\mid \begin{array}{l}\infty \\
0 \\
0 \\
-1\end{array}$ & $\begin{array}{l}\infty \\
0 \\
0 \\
-1\end{array}$ & 8 \\
\hline
\end{tabular}




\begin{tabular}{|c|c|c|c|c|c|c|c|c|c|c|c|c|c|c|c|c|c|c|c|c|}
\hline نَّ & & & & 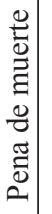 & & & & & & & & & & & 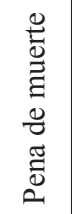 & $\begin{array}{l}0 \\
\frac{0}{0} \\
0 \\
\vec{\Xi} \\
0 \\
0 \\
\frac{0}{0} \\
0\end{array}$ & 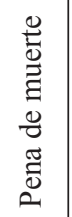 & 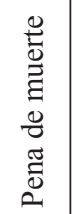 & 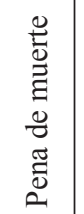 & \\
\hline 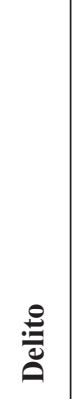 & 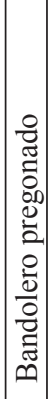 & 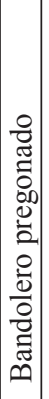 & 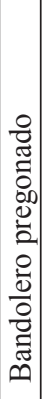 & \begin{tabular}{l|}
0 \\
0 \\
0 \\
0 \\
00 \\
0 \\
0 \\
0 \\
0 \\
0 \\
0 \\
0 \\
0 \\
0 \\
0
\end{tabular} & 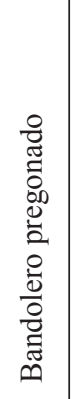 & $\begin{array}{l}0 \\
0 \\
0 \\
0 \\
0 \\
0 \\
\vdots \\
\vdots \\
0 \\
0 \\
0 \\
0 \\
0 \\
0 \\
0 \\
\overline{0} \\
0\end{array}$ & 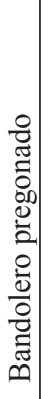 & 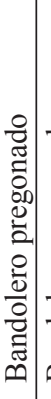 & 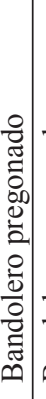 & 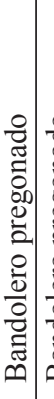 & 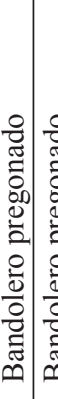 & 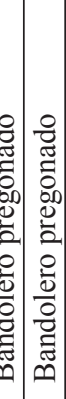 & 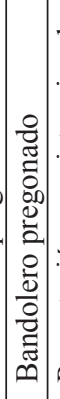 & 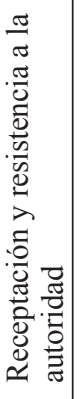 & 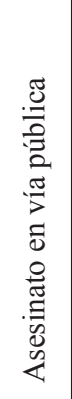 & 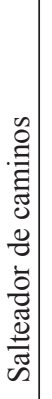 & 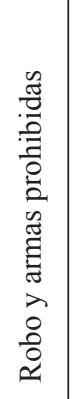 & 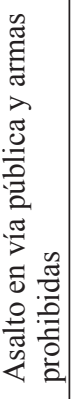 & 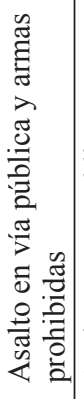 & 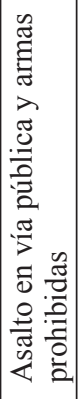 \\
\hline 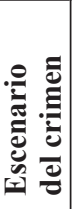 & & & & & & & & & & & & & & & 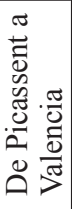 & & 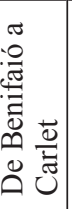 & & & \\
\hline 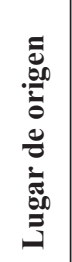 & 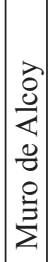 & 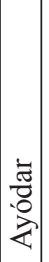 & 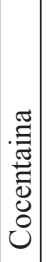 & 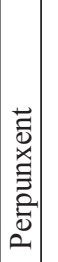 & 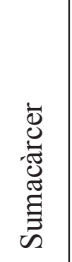 & 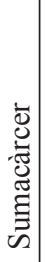 & 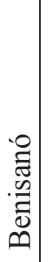 & 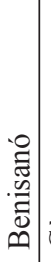 & . & 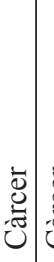 & 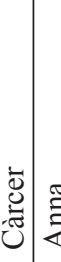 & 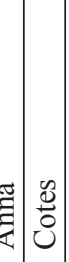 & 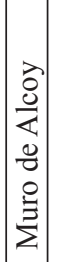 & 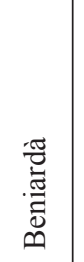 & 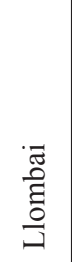 & 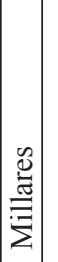 & $\frac{\vec{d}}{\bar{\Xi}}$ & 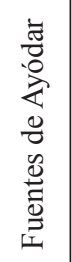 & 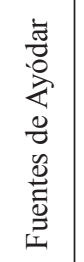 & 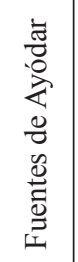 \\
\hline $\begin{array}{l}\text { है } \\
\text { है } \\
\text { है }\end{array}$ & 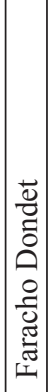 & 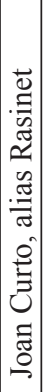 & 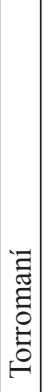 & 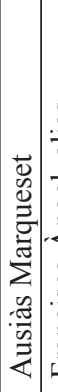 & 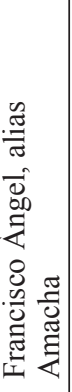 & 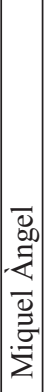 & 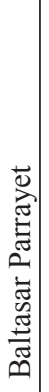 & 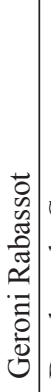 & 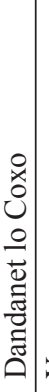 & 永 & 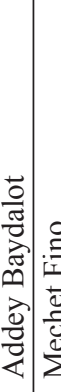 & 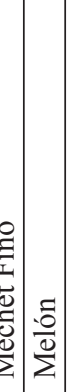 & 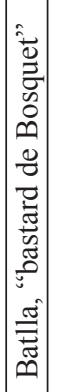 & 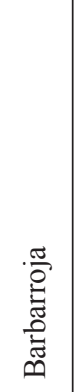 & 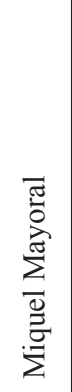 & 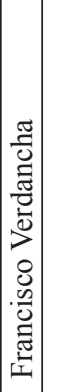 & 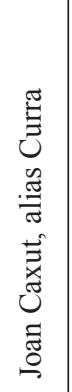 & 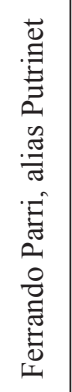 & 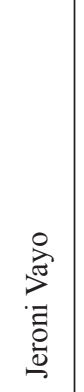 & 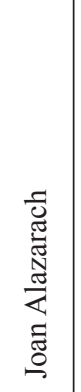 \\
\hline 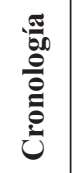 & $\begin{array}{l}\infty \\
0 \\
0 \\
-1\end{array}$ & $\left|\begin{array}{c}0 \\
0 \\
0 \\
-1\end{array}\right|$ & $\begin{array}{l}\infty \\
0 \\
0 \\
-1\end{array}$ & $\begin{array}{l}0 \\
0 \\
0 \\
0 \\
0 \\
0 \\
-1\end{array}$ & $\begin{array}{l}\infty \\
0 \\
0\end{array}$ & O & $\begin{array}{l}\infty \\
0 \\
0 \\
-1\end{array}$ & $\begin{array}{l}\infty \\
0 \\
-0 \\
-1\end{array}$ & $\stackrel{\circ}{\circ}$ & \begin{tabular}{l|l}
$\infty$ \\
$\vdots$ \\
$\vdots$
\end{tabular} & 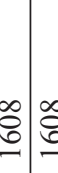 & $\begin{array}{c}0 \\
0 \\
0 \\
0\end{array}$ & $\begin{array}{l}\infty \\
0 \\
0 \\
-1\end{array}$ & $\begin{array}{l}9 \\
8 \\
\frac{1}{1} \\
1 \\
0 \\
0 \\
0\end{array}$ & oे & $\begin{array}{l}8 \\
0 \\
0\end{array}$ & \&े & : & : & : \\
\hline
\end{tabular}




\begin{tabular}{|c|c|c|c|c|c|c|c|c|c|}
\hline 苞 & 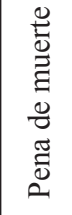 & 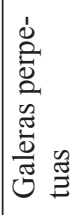 & 鞄 & 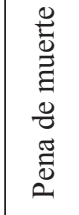 & 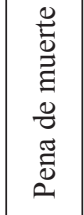 & 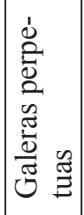 & $\begin{array}{l}0 \\
0 \\
0 \\
0 \\
0 \\
0 \\
0 \\
\tilde{0} \\
0 \\
0\end{array}$ & & 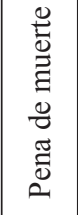 \\
\hline 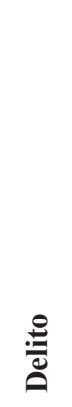 & 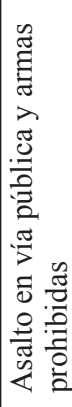 & 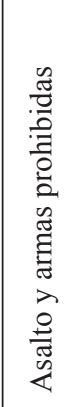 & 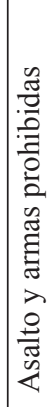 & 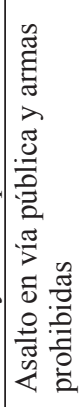 & 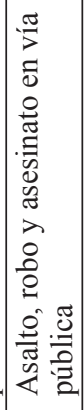 & 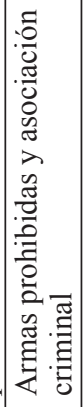 & 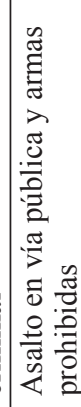 & 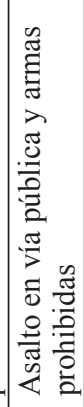 & 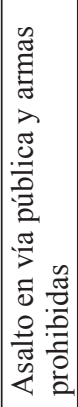 \\
\hline 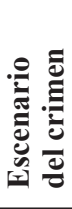 & & & & 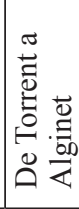 & 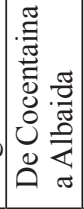 & & 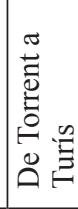 & 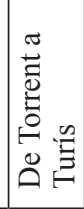 & \\
\hline 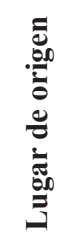 & $\stackrel{\mathbb{E}}{\tilde{U}}$ & 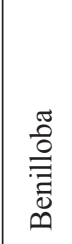 & 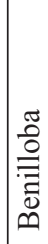 & & 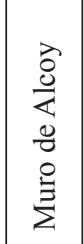 & 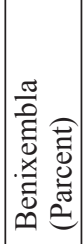 & 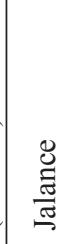 & $\begin{array}{l}\text { ]ٓ } \\
\text { हี } \\
\text { בี }\end{array}$ & ن \\
\hline है & 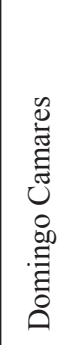 & 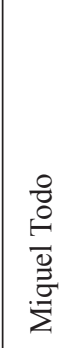 & 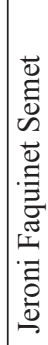 & 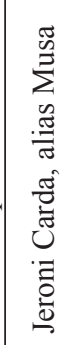 & 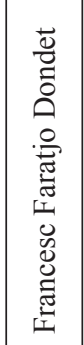 & 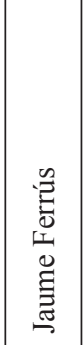 & 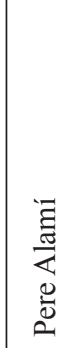 & 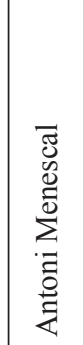 & $\begin{array}{l}\widetilde{\pi} \\
0 \\
0 \\
\tilde{0} \\
\simeq \\
0 \\
0 \\
0 \\
0 \\
0 \\
0 \\
0\end{array}$ \\
\hline 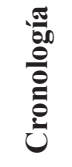 & : & : & ) & $\stackrel{0}{0}$ & $\stackrel{0}{0}$ & 8 & $\stackrel{0}{\circ}$ & $\stackrel{0}{-0}$ & : \\
\hline
\end{tabular}

